PAPERS IN PHYSICAL OCEANOGRAPHY AND METEOROLOGY

Published By

MASSACHUSETTS INSTITUTE OF TECHNOLOGY

AND

WOODS HOLE OCEANOGRAPHIC INSTITUTION

VOL. IX, NO. 4

\title{
A STUDY OF INTERDIURNAL PRESSURE AND TEMPERATURE VARIATIONS IN THE FREE ATMOSPHERE OVER NORTH AMERICA
}

BY

THOMAS F. MALONE

CAMBRIDGE AND WOODS HOLE, MASSACHUSETTS

August, 1946 
THE MURRAY PRINTING COMPANY CAMBRIDGE, MASSACHUSETTS 


\section{CONTENTS}

PAGE

INTRODUCTION

Chapter I. Observational Material and Methods of Analysis

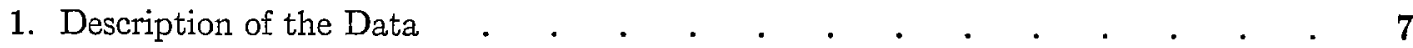

2. Mean Interdiurnal Variability of Pressure and Temperature . . . . . . $\quad 8$

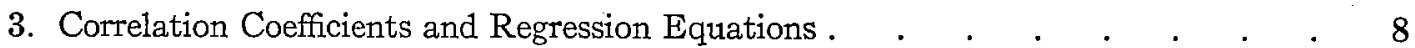

4. Density Variations and Advective Changes of Mass in the Different Layers . . 10

Chapter II. Mean Values of Interdiurnal Pressure and Temperature Variations

1. Seasonal Absolute Mean Values for all Data . . . . c . . . . . $\quad 11$

2. Seasonal Absolute and Algebraic Mean Values for $\Delta P_{0}>0$ and $\Delta P_{0}<0 \quad$. . . $\quad 12$

3. Seasonal Absolute and Algebraic Mean Values for the $\operatorname{sgn} \Delta P_{0}=\operatorname{sgn} \Delta T_{m o}$ and the $\operatorname{sgn} \Delta P_{0} \not \neq \operatorname{sgn} \Delta T_{m o}$ Groups . . . . . . . . . . . . . . . . . $\quad . \quad 14$

4. Seasonal Absolute and Algebraic Mean Values for $\Delta P_{0}=0$. . . . . . $\quad 20$

Chapter III. Correlation Coefficients and Regression Equations

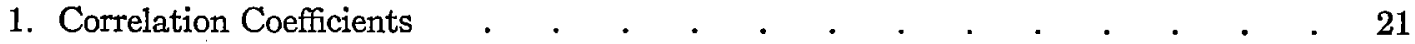

2. Regression Equations .

Chapter IV. Density Variations and the Advective Changes of Mass in the Different Layers

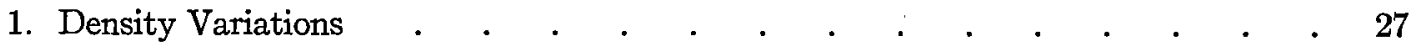

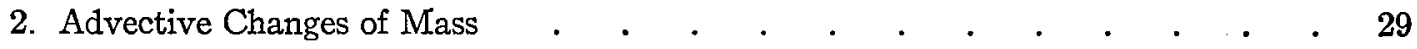

Chapter V. Interpretations and Conclusions

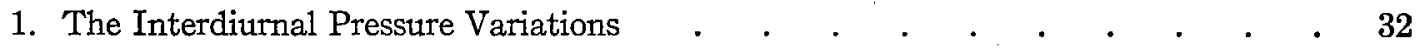

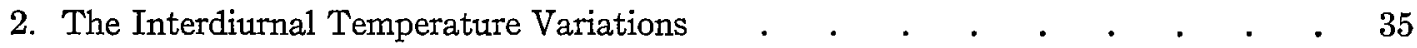

3. Some Implications of the Constancy of Density at Eight Kilometers . . . 36

4. The Significance of the Vertical Distribution of Density Variations for the $\operatorname{sgn} \Delta P_{0}=\operatorname{sgn} \Delta T_{m o}$ and the $\operatorname{sgn} \Delta P_{0} \neq \operatorname{sgn} \Delta T_{m o}$ Groups . . . . . . . 40

5. Summary of Results . . . . . . . . . . . . . . . . . . . . 41

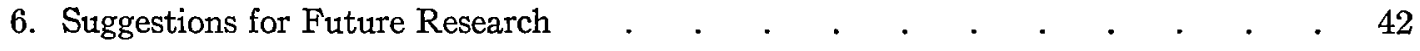

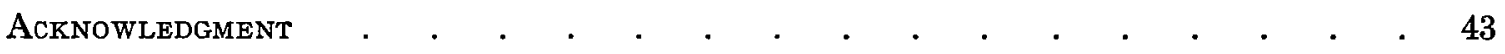

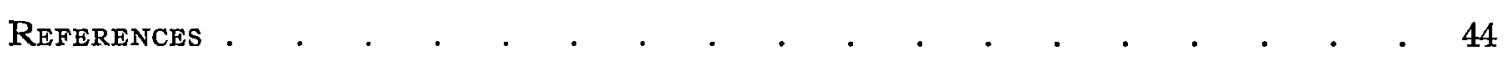

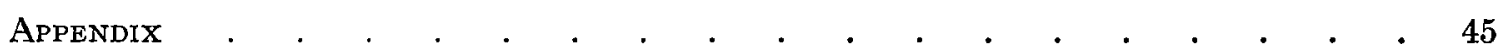




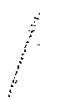




\section{INTRODUCTION}

The three-dimensional distribution of pressure and its variation with time are intimately associated with the principal weather phenomena. However, this association is indirect rather than direct and the link connecting the two is the horizontal and vertical field of motion. The relationship between the field of motion and the variation in time and space of pressure is one of interdependence. On the other hand, the field of motion seems causally related to most weather phenomena. Neither of these relationships is fully understood so it is not surprising that current attempts to utilize pressure distributions as tools for predicting weather phenomena do not meet with complete success. In this connection, the variation of pressure with time is of prime interest, inasmuch as it reflects physical processes currently in operation in the atmosphere and as it presages future developments. Study of these processes through an analysis of pressure variations is complicated by the compressibility of the atmosphere and by the observed fact that mass variations of either sign may be taking place within any layer in the atmosphere quite independently of variations of the mass within any other layer.

Since the instantaneous distribution of pressure and its variation with time are hydrostatically related to the temperature field and its changes, it is advantageous to study the two elements simultaneously. Any consideration of the temperature field in the atmosphere inevitably requires that some attention must be devoted to the tropopause as a major first order discontinuity of temperature. Moreover, the significance of this general region of the atmosphere as a location of processes important in determining tropospheric pressure variations has been stressed by the Austrian School of Meteorologists.

The problem of achieving a better understanding of the nature of pressure changes may be attacked in one or more of three different, though complementary ways - theoretically, descriptively, and/or, statistically. The theory has been discussed by Stūve [1], Defant [2], V. Bjerknes, J. Bjerknes, Solberg, and Bergeron [3], and more recently by Wulf and Obloy [4], J. Bjerknes and Holmboe [5], and Petterssen [6], as well as by others. The descriptive approach by means of detailed analyses of selected situations has been demonstrated in many investigations all over the world, among which are several particularly interesting studies in North America and Europe [7-11]. The statistical treatment was first attempted by Dines [12] and Schedler [13] and considerably extended and refined by Haurwitz and others [14-17] and by Penner [18].

The statistical studies mentioned above have been based upon an analysis of mean conditions and mean changes in vertical columns of air assumed to be in hydrostatic equilibrium. Since the problem is essentially dynamic, such analyses can never present the complete picture of the physical processes involved in pressure changes. However, in view of the present unsatisfactory state of knowledge concerning these processes, such statistical studies play an extremely valuable role in improving the general understanding of the complex systems of mass variations which are integrated into pressure changes by the atmosphere. They present mean conditions against which descriptive and theoretical studies may be evaluated with regard to representativeness and applicability, respectively. Furthermore, they are systematic summaries of actual conditions which may properly serve as a guide to the direction in which further theoretical and descriptive investigations may most profitably proceed.

The paucity of upper air data has restricted the scope of previous studies along these lines and so it is the aim of this investigation to utilize the information recently available as a result of the well organized network of radiosonde observation stations in North America to extend these 
studies. In particular, it is desired to investigate the geographical and seasonal differences in the mean values of pressure and temperature variation at all levels and the related upper air conditions. It is hoped that the greater number of observations in the stratosphere may throw some light on its true importance with respect to tropospheric pressure variations and that mean conditions throughout the lower atmosphere may be so defined that it will be possible to set up certain requirements which any proposed mechanism for pressure changes must satisfy in order to be thoroughly consistent with reality.

The observational material and the methods of analysis will be discussed in Chapter I. Chapters II, III, and IV will be devoted to a description of the results of the statistical analysis. Since the interpretations of one aspect of the study depend upon the results of some of the other aspects, most of the interpretations and conclusions will be discussed in Chapter V. 


\section{CHAPTER I \\ OBSERVATIONAL MATERIAL AND METHODS OF ANALYSIS}

\section{Description of the Data}

Complete upper air data from the following stations for the months indicated were used in this study.

RK - Bismarck, N. D.: February and August, 1940, 1941, and 1942.

OH - Omaha, Neb.: February and August, 1940, 1941, and 1942.

VC — S. Ste. Marie, Mich.: February and August, 1940, 1941, and 1942.

WA - Washington, D. C.: February and August, 1940, 1941, and 1942.

EO - Ei Paso, Texas: February and August, 1940, 1941, and 1942.

LS - St. Louis, Mo.: February 1940, 1941 and 1942; August, 1941 and 1942.

PW - Portland, Maine: February 1941 and 1942; August, 1941 and 1942.

HSJ — San Juan, P. R.: February, 1940, 1941, and 1942; August, 1941 and 1942.

MM - Miami, Fla.: February, 1940, 1941 and 1942; August, 1941 and 1942.

FX - Fairbanks, Alaska: February, 1940 and 1942; August, 1941 and 1942.

The data were obtained directly from the regularly transmitted radiosonde reports and the photostatic copies of the original station free-air summary forms, WB Form 1109 and Form No. 1109A-AER. These forms give the pressure and temperature at the station elevation and at each kilometer above sea level over the station (at each half kilometer up to three kilometers). The surface pressure was generally recorded to tenths of a millibar and the upper level pressures were always reported in whole millibars. The temperatures at all levels were reported to the nearest tenth of a degree Centigrade. The times of observation for these data were 010075 th Meridian Time during 1940 and 1941 and 2300 75th Meridian Time in 1942 for all stations except Washington, D. C., where the observations at the Naval Air Station during. February and August of 1940 and February of 1941 were made at 0400 75th Meridian Time. Occasionally the time of release of the radiosonde would be an hour late; however, no adjustment was made in the data since the values of the diurnal pressure and temperature variations at upper levels are not known and the error introduced is very likely well within the limits of instrumental accuracy.

Inasmuch as the terminal height of the radiosonde observations varied from day to day, it was not always possible to work with the same number of values at every level for each station. The consequences of this defect in the data will be discussed later and it will be seen that the results are not materially affected. The number of observations at each level for the various groupings of the data is given in Table $\mathrm{A}$ of the appendix. In general, mean values have not been computed when the number of observations was less than five. Exceptions to this are certain groupings of the San Juan data and a grouping of the data for the case of no interdiurnal pressure change at the surface.

The heights of the tropopause were determined from the transmitted radiosonde reports which give the pressure, temperature, and height in hundreds of meters for each significant point on the ascent. The exact location of the tropopause is not always obvious and in the treatment of a large amount of data, some criterion had to be decided upon which would permit it to be determined objectively. The height at which the lapse rate of temperature decreased to $4^{\circ} \mathrm{C}$ per $\mathrm{km}$ or less was selected as an appropriate line of demarcation between the moderate stability 
of the troposphere and the extreme stability of the stratosphere. It is somewhat more conservative than the $2^{\circ} \mathrm{C}$ per $\mathrm{km}$ criterion used by English meteorologists; however, use of the value which they suggest frequently gives tropopause heights which are inconsistent with the general definition of the tropopause. The mean values for the tropopause heights arrived at on the basis of the $4^{\circ} \mathrm{C}$ per $\mathrm{km}$ criterion are in substantial agreement with the heights of the transitional zone separating the troposphere from the stratosphere for North American stations as discussed by Willett [19].

The analysis of the data described above was divided into three parts:

a. The computation and graphical representation of the mean twenty-four-hour pressure and temperature changes at every level for all stations.

b. Computation and tabulation of correlation coefficients and regression equations involving the values of pressure at different levels, the mean temperature from the surface up to nine kilometers, and the height of the tropopause.

$c$. Computation and tabulation of the density variations and the advective changes of mass within each kilometer layer above every station for cases of rising pressure at the surface.

\section{Mean Interdiurnal Variability of Pressure and Temperature}

The interdiurnal pressure and temperature variations were first computed for all values of surface pressure change. Then they were divided according to the three groups:

$$
\begin{array}{lr}
\Delta P_{0}>0 & \Delta=24 \text {-hour change } \\
\Delta P_{0}<0 & P_{0}=\text { surface pressure } \\
\Delta P_{0}=0 &
\end{array}
$$

The data were then subdivided on the basis of whether or not the temperature change in the lowest kilometer layer contributed to the surface pressure change. This gave the groups:

$$
\begin{aligned}
& \Delta P_{0}>0>T_{m o} \\
& \Delta P_{0}>0<T_{m o} \\
& \Delta P_{0}<0<T_{m o} \\
& \Delta P_{0}<0>T_{m o}
\end{aligned} \quad T_{m o}=\text { mean temperature in the lowest kilometer layer }
$$

The mean values of the interdiurnal variability were first computed without regard for the algebraic sign and these were called absolute means. Then the sign of each variation was considered and the means thus obtained were called algebraic means. Both of these means were calculated at every station for each of the groups listed above and the results are presented in the six hundred curves of Figs. 1 to 16. All of the data were divided into a winter (February) and a summer (August) season. The mean heights of the tropopause for winter $\left(H_{w w}\right)$ and for summer $\left(H_{s}\right)$, based on all of the data for each season, have been indicated on each of the diagrams.

\section{Correlation Coefficients and Regression Equations}

The following variables were correlated:

$\begin{array}{ll}P_{0} T_{m 9} & P_{3} H \\ P_{3} T_{m 9} & P_{5} H \\ P_{5} T_{m 9} & P_{9} H \\ P_{9} T_{m 9} & T_{m 9} H \\ P_{0} P_{5}\end{array}$

$P_{0} P_{5}$ 
where $P_{0}, P_{3}, P_{5}$, and $P_{9}$ are the pressures at the surface, three, five, and nine kilometers respectively, $T_{m}$ is the mean temperature between the surface and nine kilometers, and $H$ is the height of the tropopause. These coefficients are presented in Tables II(a) and III(a). Regression coeffcients were computed for the pairs $P_{9} H, P_{9} T_{m 9}$, and $T_{m 9} H$ and the corresponding regression equations are given in Table $V$. Mean values and standard deviations for the variables involved have been tabulated in Table II(b) and III(b).

The correlation coefficients were calculated from the simple expression

$$
r=\frac{\Sigma X Y-n \bar{X} \bar{Y}}{\sqrt{\Sigma X^{2}-n \bar{X}^{2}} \sqrt{\Sigma Y^{2}-n \bar{Y}^{2}}}
$$

and the standard deviations from

$$
\sigma_{x}=\sqrt{\frac{\Sigma X^{2}}{n}-\bar{X}^{2}}
$$

with the probable error of the correlation coefficient

$$
\epsilon_{r}=0.67 \frac{1-r^{2}}{\sqrt{n}}
$$

and the probable error of the standard deviation

$$
\epsilon_{\sigma_{x}}=.477 \frac{\sigma_{x}}{\sqrt{n}}
$$

Linear regression equations have been assumed and calculated according to the form

$$
\begin{aligned}
& x=\frac{\sigma_{x}}{\sigma_{y}} r y \\
& y=\frac{\sigma_{x}}{\sigma_{y}} r x
\end{aligned}
$$

All of the symbols used here have the conventional meaning.

The data were divided seasonally and a subdivision was made on the basis of whether or not the temperature variation in the lowest kilometer layer contributed to the surface pressure variation. Thus the groups were:

$$
\begin{array}{cc}
\text { Winter } & \text { Summer } \\
\operatorname{sgn} \Delta P_{0} \neq \operatorname{sgn} \Delta T_{m o} & \operatorname{sgn} \Delta P_{0} \neq \operatorname{sgn} \Delta T_{m o} \\
\operatorname{sgn} \Delta P_{0}=\operatorname{sgn} \Delta T_{m o} & \operatorname{sgn} \Delta P_{0}=\operatorname{sgn} \Delta T_{m o}
\end{array}
$$

where "sgn" is an abbreviation for "the sign of."

Since the values studied here were instantaneous and not variations, it frequently happened that a single observation fell into both groups, that is, when paired with the preceding observation it fell into the $\operatorname{sgn} \Delta P_{0} \neq \operatorname{sgn} \Delta T_{m o}$ group, while if considered with the succeeding observation it fell into the $\operatorname{sgn} \Delta P_{0}=\operatorname{sgn} \Delta T_{m o}$ group. In such cases the observation was entered in both groups and this circumstance will tend to diminish the apparent differences between the characteristics of the two groups and make more significant any differences which may appear in the final results. However, observations which fall into the same group when considered either with the preceding or the succeeding observations have been used only once. It will be noted that only five stations have been studied in this phase of the investigation.

The different values of the variables used here are not strictly independent, as assumed in the statistical treatment, since many of the observations were taken on consecutive days. However, 
in their present form the correlation coefficients are directly comparable to the results of previous studies and the added rigor gained by using more observations has not been deemed necessary.

\section{Density Variations and Advective Changes of Mass in the Different Layers}

The algebraic differences between the mean values of interdiurnal pressure variation at successive kilometer levels have been computed in order to obtain the mean change in the weight $\Delta(\delta p)$ of each kilometer layer from the surface up to the height at which sufficient data are no longer available. This has been done only for the $\Delta P_{0}>0>\Delta T_{m o}$ and the $\Delta P_{0}>0<\Delta T_{m o}$ groups

during winter. These weight variations are close approximations to the mean density variations of the layers in question and have been considered as such. The values of $\Delta(\delta p)$ have been smoothed according to the formula

$$
\text { Smoothed } \Delta(\delta p)_{n}=\frac{\Delta(\delta p)_{n+1}+2 \Delta(\delta p)_{n}+\Delta(\delta p)_{n-1}}{4}
$$

in which $\Delta(\delta p)_{n}$ is the density variation within a layer bounded by two successive standard kilometer heights, and $\Delta(\delta p)_{n+1}$ and $\Delta(\delta p)_{n-1}$ are the density variations of the next higher and next lower unit kilometer layers respectively.

The advective contribution of mass within any layer has been taken as the difference between the total mass variation above the top of that layer and the total mass variation above the bottom of the layer. It obtains its name from the nature of the simplifying assumptions upon which Rossby [20] and later Ertel and Sjansi Li [22] developed an expression for the total mass variation per unit horizontal cross section above a fixed height in terms of the observed pressure variation at that height. This relation is

$$
\delta \pi=\frac{\delta p}{1-\frac{g \rho}{\kappa} \int_{0}^{z} \frac{d z}{p}}
$$

in which $\delta \pi=$ the total mass variation per unit horizontal cross section above the fixed level

$\delta p=$ the pressure change at the fixed level

$g=$ the acceleration of gravity

$\rho=$ density

$\kappa=$ ratio of the specific heat of air at constant pressure to that at constant volume

$p=$ pressure

The factor $1-\frac{g \rho}{\kappa} \int_{0}^{z} \frac{d z}{p}$ for the various levels has been taken from the tabulated values computed by Haurwitz and Haurwitz [17] which were based on the mean pressure and temperature distribution over the United States. Values for this factor at each kilometer level are given in Table B in the Appendix. Since the formula given above is very sensitive to pressure variations, particularly at high elevations, the mean interdiurnal variations of pressure were smoothed by the same method employed in adjusting the mean density variations and these smoothed values were used for computing the total mass variations. The advective contribution of mass within each layer is

$$
\delta^{2} \pi=\delta \pi_{z_{1}}-\delta \pi_{z_{2}}
$$

Values of $\delta^{2} \pi$ were obtained for the groups $\Delta P_{0}>0>\Delta T_{m o}$ and $\Delta P_{0}>0<\Delta T_{m o}$ during winter and represented along with the density variations by the curves in Fig. 19. 


\section{CHAPTER II \\ MEAN VALUES OF INTERDIURNAL PRESSURE AND TEMPERATURE VARIATIONS}

\section{Seasonal Absolute Mean Values for All Data}

The absolute mean values of interdiurnal pressure variation $|\Delta p|$ for all data are presented in Fig. 1 and the corresponding absolute temperature changes $|\Delta T|$ are given in Fig. 2.

The $|\Delta p|$ curves for the winter at every station except San Juan show two maxima, one at the surface and the other in the vicinity of seven or eight kilometers. The surface maximum is the primary one, except at E1 Paso. The variability of pressure changes most rapidly with elevation in the layers near the ground, generally reaching a minimum between two and four kilometers. The increase to the upper level maximum is rather gradual and the rate of change above this maximum is only slightly greater. The upper level maximum definitely seems to occur in the troposphere and not in the stratosphere, usually lying a kilometer or so below the mean height of the tropopause in winter. In general the day to day pressure changes in the stratosphere gradually decrease with increasing elevation to a value of about one millibar at sixteen or eighteen kilometers. At San Juan there is a gradual increase in the interdiurnal variation up to eight kilometers and then an irregular decrease up to the termination of adequate data at fourteen kilometers.

The data for summer indicate characteristics similar to those of winter except at Miami where the conditions seem to agree more closely with San Juan than with the other stations. In general the magnitude of the variations has decreased in the troposphere and this decrease is more pronounced at the two maxima than at the minimum with the result that in summer the variability does not change as rapidly with elevation as it does in winter throughout that portion of the atmosphere studied. The upper level maximum is less pronounced and is now found at a higher elevation - the change in height corresponding well in most cases with the seasonal change in the height of the tropopause. At Bismarck the upper level maximum and minimum seem to shift toward lower elevations in summer than in winter; however, both are poorly defined and the evidence of such an anomalous seasonal change is not conclusive. The conditions at Omaha, S. Ste. Marie, Portland and Miami combine to give larger mean interdiurnal variations in some parts of the stratosphere during summer than during winter.

The most striking feature of the variation of $|\Delta p|$ curve characteristics with latitude is the difference between the shape of the profile and magnitude of the variability at Miami and San Juan during both seasons and at El Paso in summer as representative of warm latitude stations, and the remaining stations as representative of colder, higher latitudes. Actually, the other characteristics of the curves appear to depend more upon general geographical location than merely upon latitude. Thus, for example, the continental stations, Bismarck, Omaha, S. Ste. Marie and St. Louis are all essentially similar with regard to pressure variation profile and magnitude, while Fairbanks, Portland and Washington seem to have certain characteristics which may be taken as typical of stations alternately exposed to maritime and continental influences. The principal differences between the two types, continental and continental-maritime, are that the variations are smaller in the case of the former and show a more marked decrease with elevation in the lower layers, with a more pronounced minimum around three kilometers.

Previous studies of composite data from selected North American stations [16] showed a very pronounced primary maximum of $|\Delta p|$ in the upper troposphere during summer. The same held 
true at Boston [17]. This is not in agreement with the data presented here which suggest that the largest changes occur in the lower troposphere. This difference between the results of previous studies and those indicated here may arise either from the difference in the amount of data employed or from the fact that different months have been taken as characteristic of summer. In winter the general features of the absolute pressure change curve at Boston agree with those discussed here, but the corresponding curves for the North American stations show a very slight tendency toward larger changes aloft than at the surface.

The curves in Fig. 2 representing the absolute mean values of the interdiurnal temperature variation $|\Delta T|$ during the winter show three maxima - a primary at or near the surface, a secondary in the lower part of the stratosphere approximately a kilometer above the tropopause, and a tertiary at a height of about six or seven kilometers. The low latitude stations, Miami, San Juan, and E1 Paso do not conform to this general characteristic, and at Fairbanks and S. Ste. Marie the primary maximum is in the stratosphere instead of at the surface. The effect of this general distribution of maxima is to give minima near two and eight kilometers - the latter occurring in the immediate vicinity of the tropopatuse. These profiles are more irregular than the corresponding pressure variation profiles, as might be expected, and only the major features lend themselves to interpretation.

In summer all of the stations show a decrease in the magnitude of the temperature variations throughout most of the tropopause, and all stations except Bismarck now show the largest variation aloft instead of at the surface. Fairbanks, S. Ste Marie, and Washington have a primary maximum in the upper troposphere well below the tropopause and a secondary maximum about a kilometer above the surface. Omaha, St. Louis, and Portland have a primary maximum just about at the tropopause with a secondary maximum between one and two kilometers. However, at Omaha and Portland the upper level maximum could be considered as occurring well below the tropopause and at St. Louis it is just barely below the tropopause. At Bismarck the primary is at a height of one half a kilometer and the secondary is just above the tropopause. The last four stations mentioned show only faint evidence of the tropospheric tertiary maximum which was present in winter. E1 Paso, Miami, and San Juan show a primary maximum well up in the stratosphere, then a secondary maximum near the tropopause, and at E1 Paso there is a tertiary maximum just above the surface. Bismarck, Omaha, El Paso and San Juan show greater absolute . mean interdiurnal temperature variations in the stratosphere in summer than in winter.

In general, the stations with continental characteristics show a decrease in temperature variability with elevation while the continental-maritime stations show little change - if anything somewhat of an increase of variability - with increasing elevation. It is interesting to note that at El Paso a single primary maximum of $|\Delta T|$ is found at about the same elevation at which the principal maximum of $|\Delta p|$ was located.

The study at Boston referred to above had indicated rather extreme maxima at nine kilometers in summer and at ten kilometers in winter. There was no evidence of the triple maxima noted in the present study. The composite curves for the North American stations were similar to those presented here with definite indications of a surface and a stratospheric maximum and a faint suggestion of an upper tropospheric maximum.

\section{Seasonal Absolute and Algebraic Mean Values for $\Delta P_{0}>0$ and $\Delta P_{0}<0$}

Comparison between the interdiurnal pressure and temperature variation curves for cases of $\Delta P_{0}>0$ (Figs. 3 and 4 ) and $\Delta P_{0}<0$ (Figs. 5 and 6 ) reveals a basic symmetry for corresponding curves. The $|\Delta p|$ curves for both cases show a maximum at the surface and another just below the tropopause with a minimum located at a height between two and four kilometers. The triple maxima which characterized the $|\Delta T|$ curves for all cases can be detected in both sets of $|\Delta T|$ 

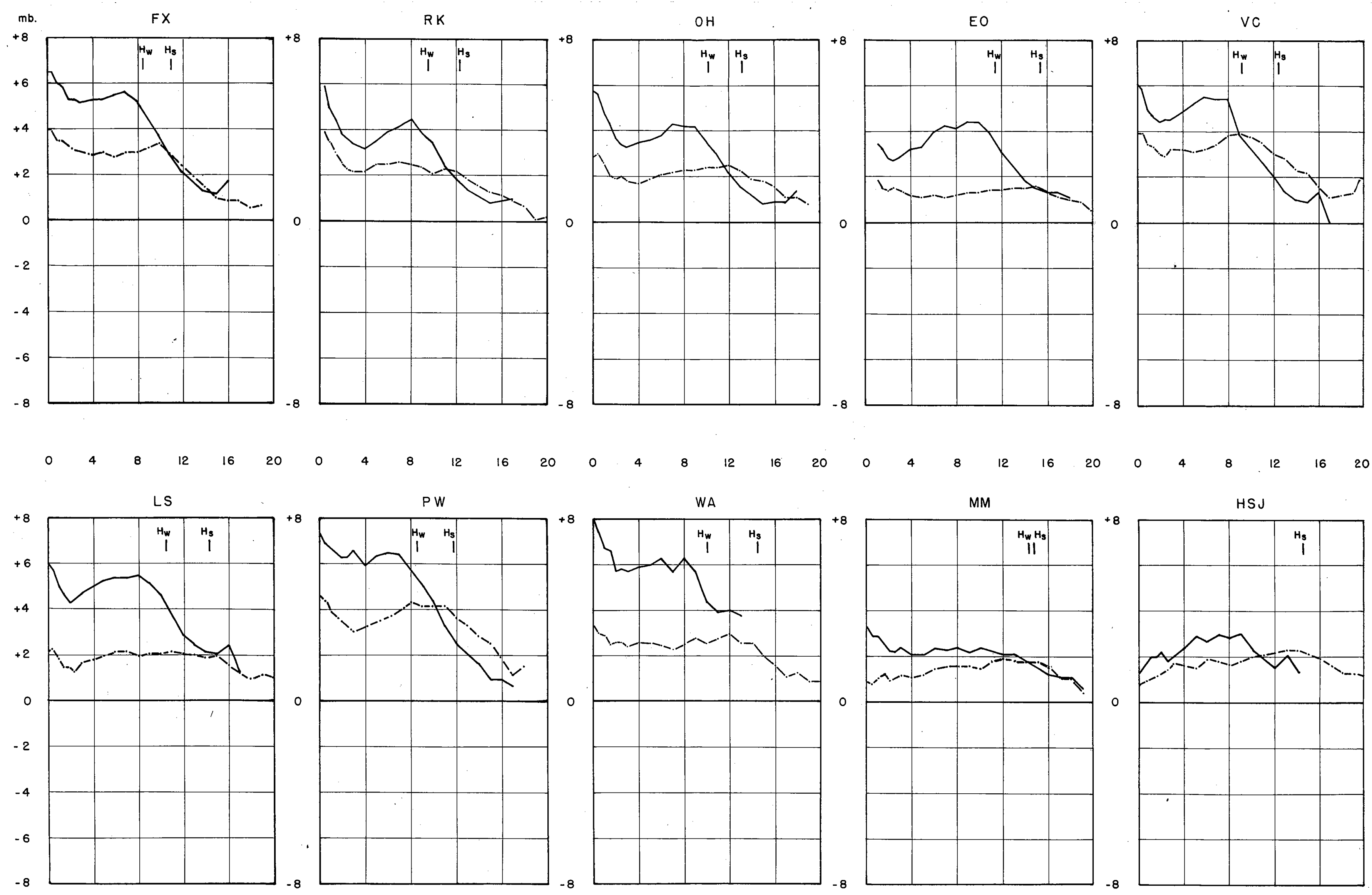

FIG. I

MEANS OF THE INTERDIURNAL PRESSURE VARIATION - ALL CASES 

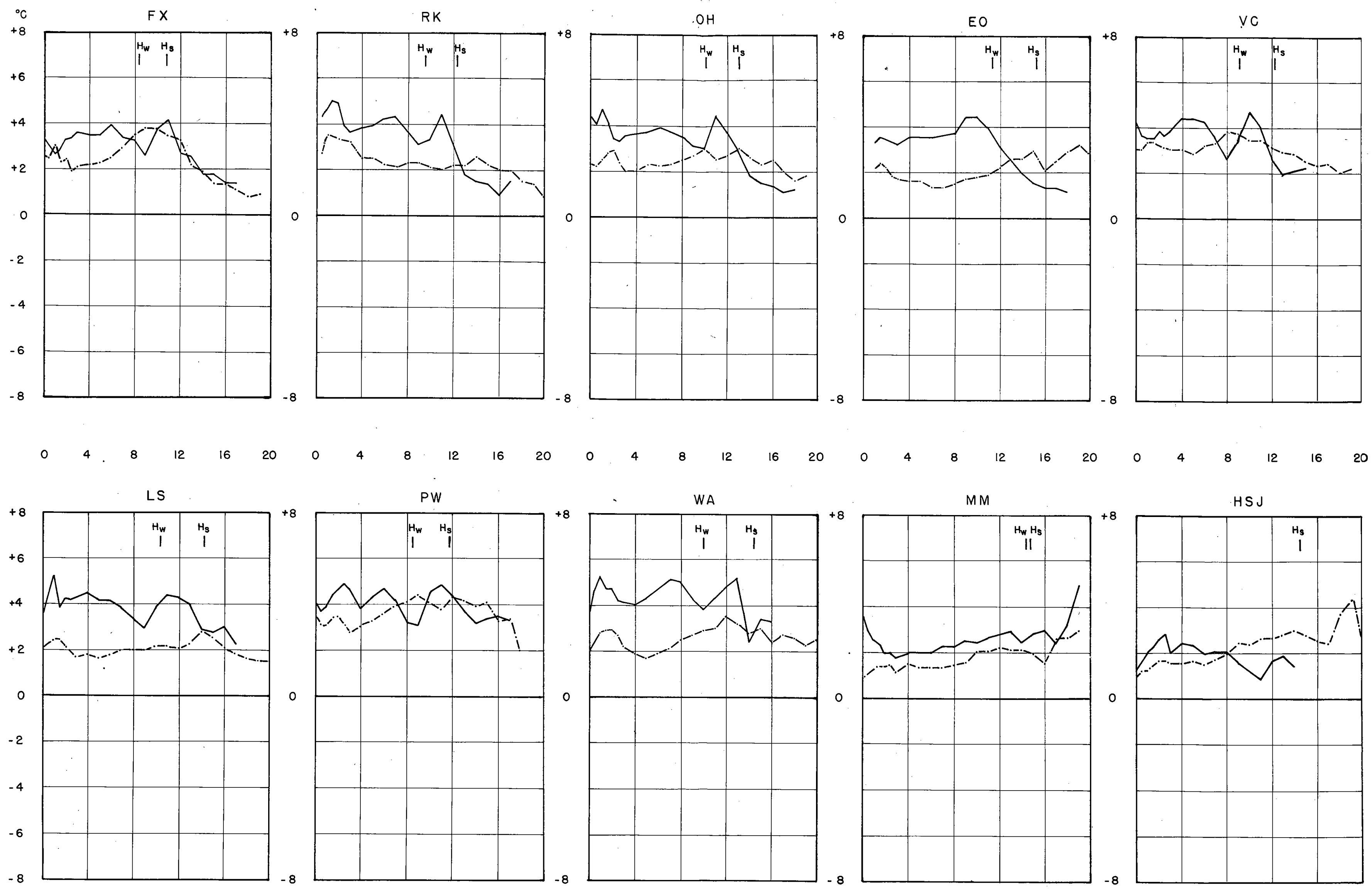

FIG. 2

MEANS OF THE INTERDIURNAL TEMPERATURE VARIATION - ALL CASES 

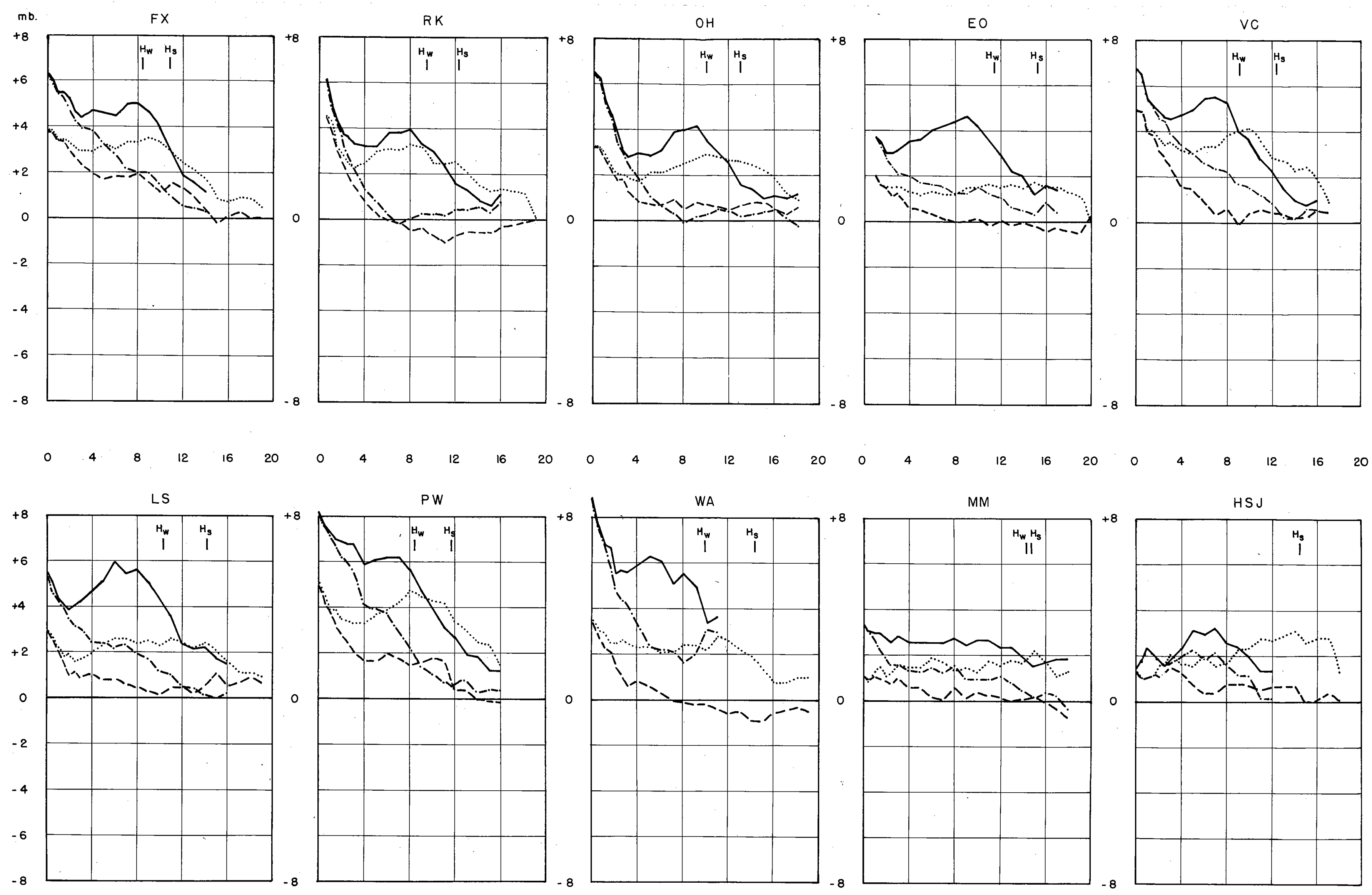

FIG. 3

MEANS OF THE INTERDIURNAL PRESSURE VARIATION $\triangle P_{0}>0$

$$
\begin{aligned}
& |\triangle P| \quad \text { WINTER }-\quad|\triangle P| \text { SUMMER } \quad \cdots \ldots . . . . . . \\
& \triangle P \quad \text { WINTER -.-.-.- } \triangle P \text { SUMMER }
\end{aligned}
$$



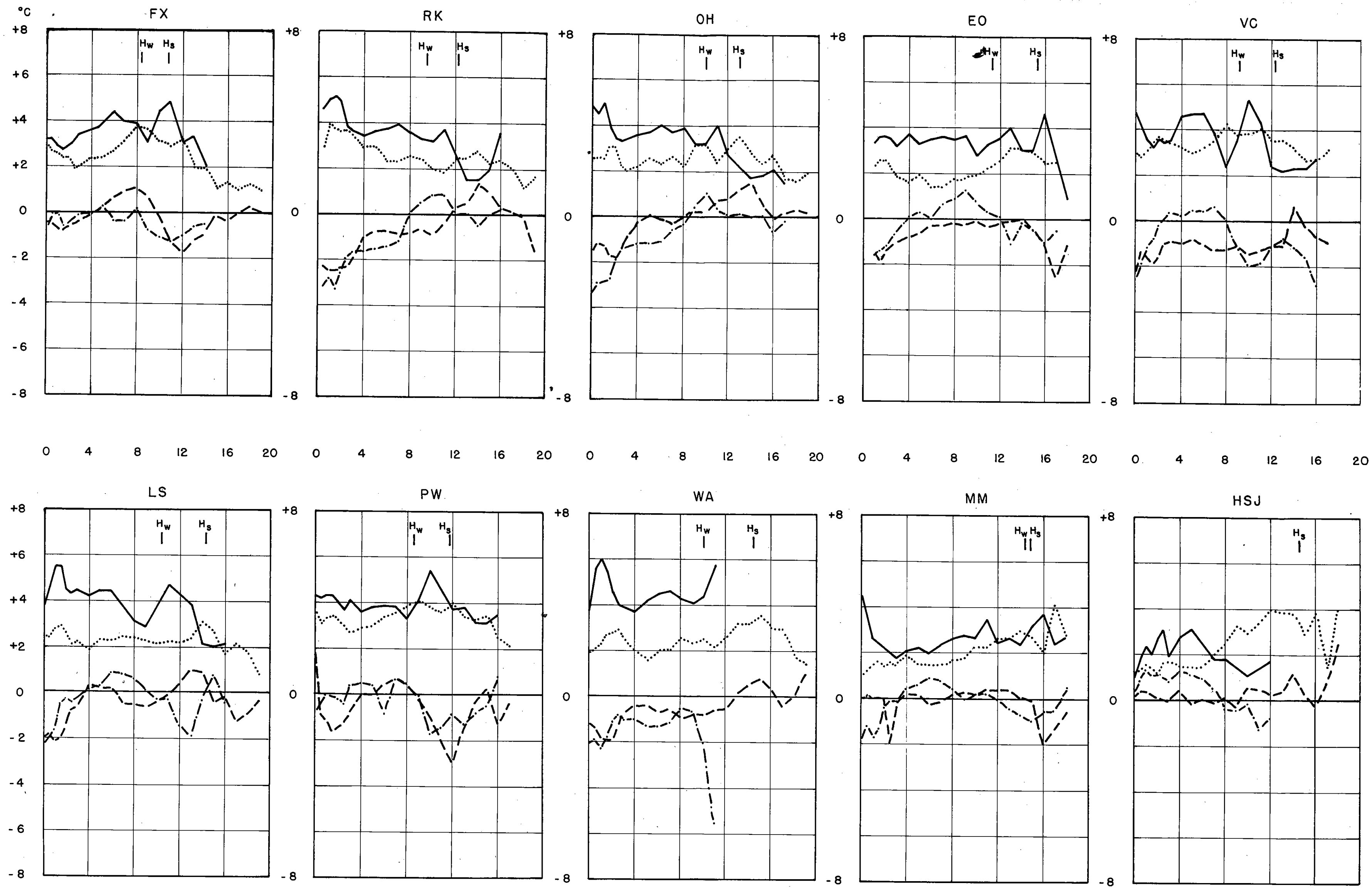

FIG. 4

MEANS OF THE INTERDIURNAL TEMPERATURE VARIATION $\Delta P_{0}>0$

$|\Delta T| \quad$ WINTER $-\quad|\Delta T|$ SUMMER $\ldots . . . . . . . . .$.

$\Delta T \quad$ WINTER -...- $\quad \Delta T$ SUMMER - - - 

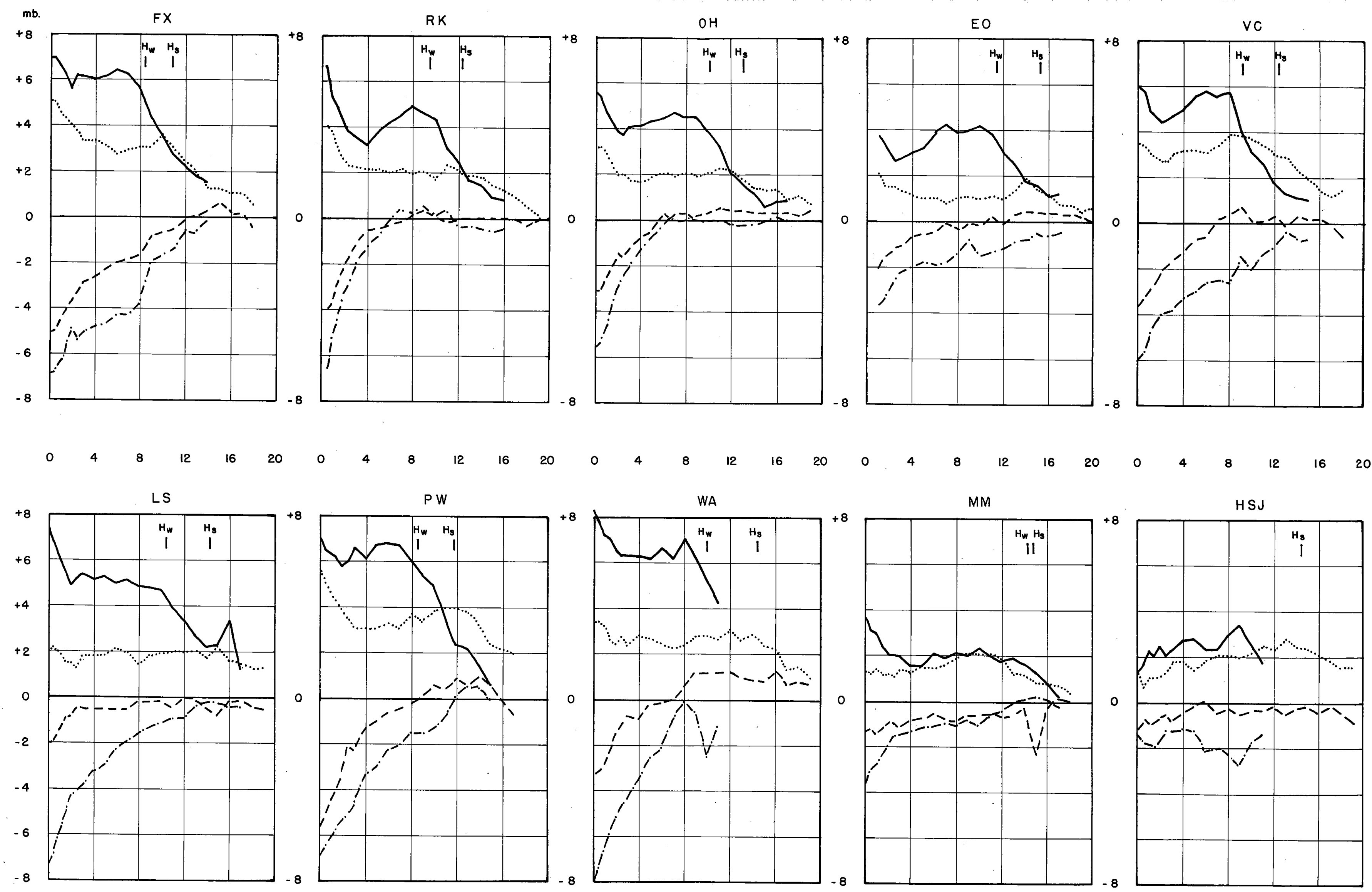

FIG. 5

MEANS OF THE INTERDIURNAL PRESSURE VARIATION $\triangle P_{0}<0$

$|\triangle P| \quad$ WINTER - $\quad|\triangle P|$ SUMMER.............

$\triangle P \quad$ WINTER - - - . $\triangle P$ SUMMER - - - 

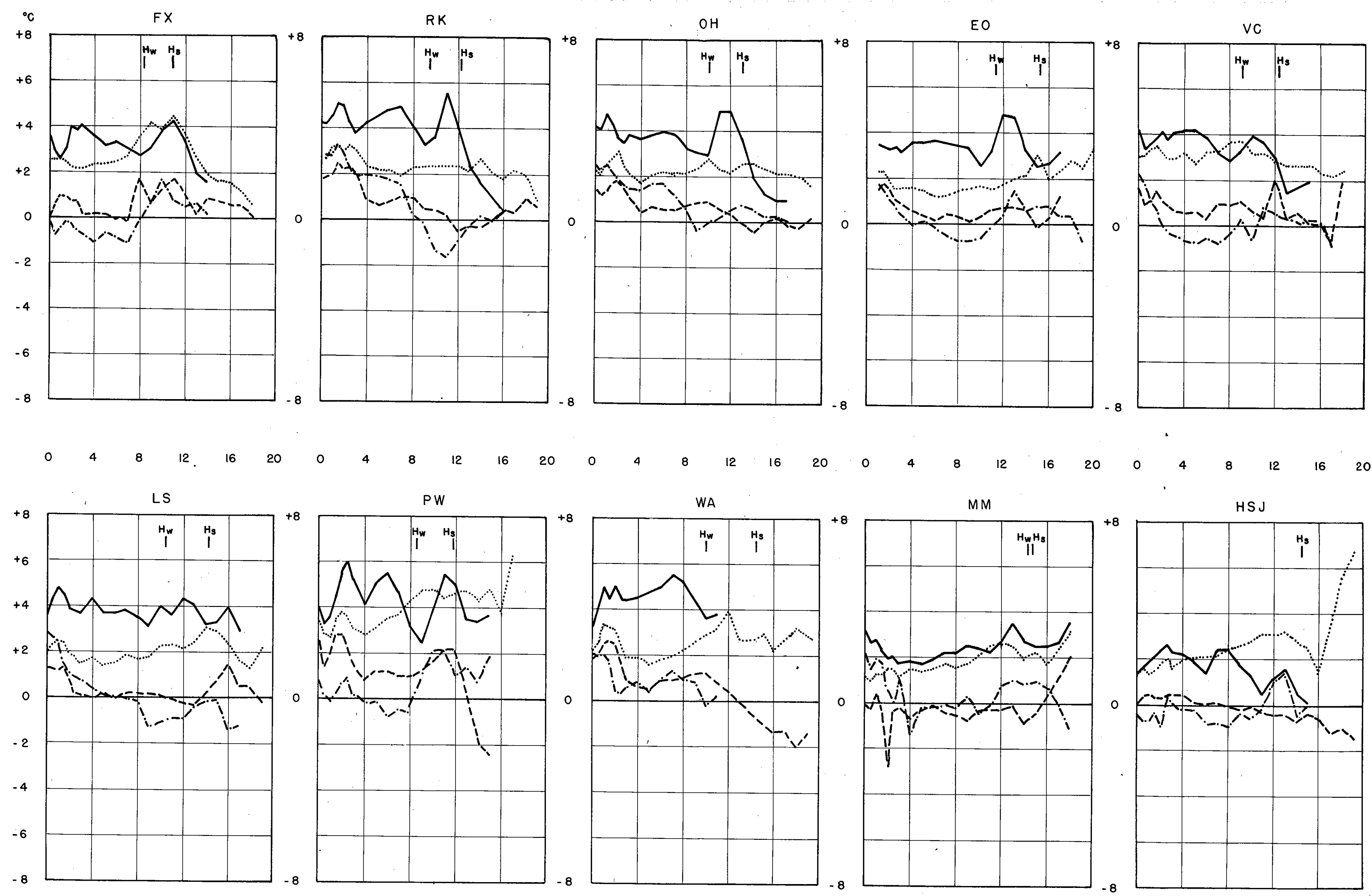

FIG. 6

MEANS OF THE INTERDIURNAL TEMPERATURE VARIATION $\triangle P_{0}<0$

IDT| WINTER — IAT| SUMMER ............

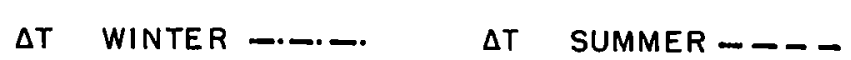


curves. Inasmuch as the number of times that $\Delta P_{0}>0$ occurs is nearly the same as the occurrences of $\Delta P_{0}<0$, and these two groups comprise by far the greater portion of the data, it is not surprising that the absolute variation curves show profiles similar to each other and similar to the profiles for all data. Since there is only a negligible change in the mean values of pressure and temperature during that portion of each season studied here, any appreciable difference between the mean variability of the same element at a given level for $\Delta P_{0}>0$ and for $\Delta P_{0}<0$ must be explained by reference to the relatively infrequent cases of $\Delta P_{0}=0$, or as the result of incomplete data. Such a conclusion is based on the assumption that $\Delta P_{0}>0$ occurs as frequently as $\Delta P_{0}<0$. Since the mean variations under discussion are all mean changes per unit of time (twenty-four hours) it would be possible to encounter an appreciably larger mean variation at a given level for $\Delta P_{0}>0$ than for $\Delta P_{0}<0$, or vice versa, provided that the number of data for $\Delta P_{0}>0$ was different from the number for $\Delta P_{0}<0$. In the case of St. Louis the surface pressure change is 28 per cent larger for $\Delta P_{0}<0$ than for $\Delta P_{0}>0$ during winter; however, there are 31 per cent more cases of rising surface pressure than of falling surface pressure. Since the summer data show just the opposite conditions, it is not safe to conclude that the rate of change of pressure is greater for $\Delta P_{0}<0$ than for $\Delta P_{0}>0$. The indications for all of the other stations suggest that the rates of change of pressure are the same in both cases and this implies that there is a certain symmetry in the mechanisms associated with pressure rises and pressure falls, i.e. the physical processes which produce a large fall at the surface, a small change at about three kilometers, and a large change at eight kilometers must have their counterpart in the processes which produce a large rise at the surface and symmetrical changes at the other two significant levels.

The magnitude of the algebraic mean pressure variations, $\Delta P$ diminishes in fairly regular fashion for $\Delta P_{0}>0$ and for $\Delta P_{0}<0$. In quite a few cases this decrease proceeds until a reversal of sign occurs, although for the majority of the curves there is simply a gradual decrease to a magnitude of a millibar or less. When the sign does change, there is nearly always a maximum or minimum shortly thereafter, above which the variation again approaches zero. There is a slightly greater tendency for this change of sign to occur in summer than in winter and for $\Delta P_{0}<0$ rather than for $\Delta P_{0}>0$. It is pronounced at Washington for both cases. The surface pressure variations are less in summer than in winter and this is usually associated with a less rapid decrease in the variability with elevation in summer than in winter.

The general pattern for the variation of $|\Delta T|$ with elevation is to have a temperature change in the lower troposphere which has a sign opposite to the surface pressure change, i.e. falling temperature with rising pressure and vice versa. The magnitude of this variation generally decreases rather rapidly with elevation and changes sign at a somewhat different height for each station. This is nearly always followed by another reversal which takes the variation back to its original algebraic sign. Sometimes still another reversal takes place so that at the termination of the curve the sign is opposite to that at the surface, and the magnitude is comparatively small. On the average, the data indicate that rising pressure at the surface is accompanied by falling temperature in the lower troposphere, rising temperature in some portion of the middle or upper troposphere - or even the lower stratosphere - and falling temperature again in the upper stratosphere. However, the degree to which this pattern is followed varies considerably from station to station and there are several exceptions. At E1 Paso and S. Ste. Marie there is no indication of a change in the sign of the temperature variation from the surface until well up into the stratosphere and at San Juan rising pressure at the surface is accompanied by rising temperature in the lower troposphere and falling surface pressure is associated with falling temperature in that same region. In summer at San Juan there is very little change of temperature in the lower levels for either $\Delta P_{0}>0$ or $\Delta P_{0}<0$ but in the stratosphere warming is indicated in the first case and cooling in the second. 
A similar generalization may be made concerning the distribution of temperature variation with altitude in the case of $\Delta P_{0}<0$. However, it is obvious from a comparison of the absolute and the algebraic mean values that the magnitude and sign of the temperature variations are often just the opposite of the average conditions described here. Hence it is necessary to subdivide the cases of $\Delta P_{0}>0$ and $\Delta P_{0}<0$ into more homogeneous groups. This has been done in the fashion described in Chapter I and the results are presented in Figs. 7 to 14.

\section{Seasonal Absolute and Algebraic Mean Values for the $\operatorname{sgn} \Delta P_{0}=\operatorname{sgn} \Delta T_{m o}$ AND THE SGN $\Delta P_{0} \not \neq \mathrm{SGN} \Delta T_{m o}$ GROUPS}

Considering first the $|\Delta P|$ curves for the $\Delta P_{0}>0>\Delta T_{m o}$ group (Fig. 7), it is evident that the general profile of these curves resembles that of the $|\Delta P|$ curves for $\Delta P_{0}>0$. However, there are certain significant differences in the profile details of the two groups. For the $\Delta P_{0}>0>\Delta T_{m o}$ group the surface pressure variations are larger, the decrease of variability with elevation is more rapid in the first two or three kilometers, the tropospheric minima are more clearly defined, and the upper tropospheric maxima are sharper than in the $\Delta P_{0}>0$ group. The difference in the magnitudes of the surface pressure changes indicates the significant role played by the low level advection of more dense air in influencing surface pressure changes. The more rapid decrease of variability in the lower layers for the $\Delta P_{0}>0>\Delta T_{m o}$ group is consistent with hydrostatic principles which require a considerably smaller pressure change aloft to accompany a given pressure change at the surface if there is advection of colder air in the intervening layers. This may be seen mathematically by applying the barometric formula to $n$ successive layer of equal height $h$ and differentiating logarithmically with respect to time, giving

$$
\frac{\partial P_{n}}{\partial t}=\frac{P_{n}}{P_{0}} \frac{\partial P_{0}}{\partial t}+\frac{g}{R} h P_{0} \sum_{k=1}^{n} \frac{1}{T_{k}^{2}} \frac{\partial T_{k}}{\partial t}
$$

in which $P_{0}=$ surface pressure

$$
\begin{aligned}
P_{n} & =\text { pressure at height } n h \\
T_{k} & =\text { temperature in the layer } k \text { from }(k-1) h \text { to } k h \\
t & =\text { time } \\
R & =\text { gas constant for air } \\
g & =\text { acceleration of gravity }
\end{aligned}
$$

The second term on the right hand side will be negative for temperature falls, and it is apparent that in the case under consideration the variability of pressure should decrease more rapidly with elevation than in the general case of $\Delta P_{0}>0$ which includes many instances of interdiurnal temperature rises in the surface layers.

The mean algebraic pressure variations for this group show a very rapid decrease with elevation, so that in most cases the mean pressure changes become negative, or in a few instances only negligible, at relatively low elevations. These curves which show an actual reversal of sign frequently indicate a maximum of negative pressure variations at about the same height at which the absolute variation curve displays its upper level maximum.

The $\Delta T$ curves for this group (Fig. 8) show large falls at the surface, decreasing rather rapidly between one and three kilometers and then gradually approaching a positive maximum in the lower stratosphere. At Fairbanks and Portland in both seasons and at S. Ste. Marie in summer there are pronounced negative maxima in the upper troposphere - definitely just below the tropopause. S. Ste Marie shows a strong negative maximum at high levels in winter, but it is quite clearly in the stratosphere. It is interesting to note that at Miami and San Juan during both seasons and at E1 Paso during the summer, the mean temperature changes are negative at almost every level in the troposphere and up into the stratosphere as far as the curves are extended. 

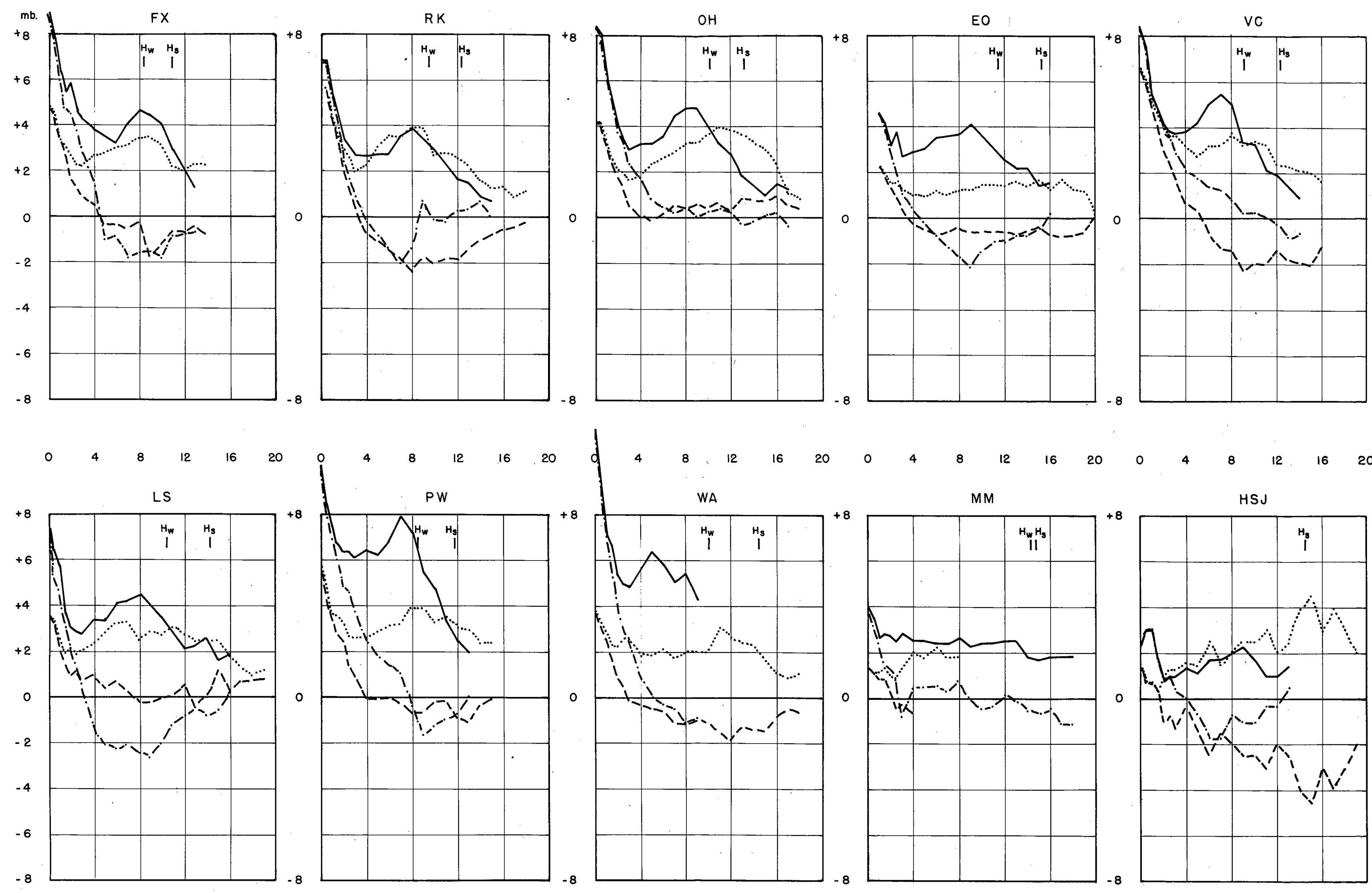

MEANS OF. THE INTERDIURNAL PRESSURE VARIATION $\triangle P_{0}>0>T m_{0}$

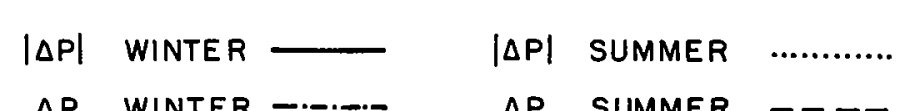

$\triangle P$ WINTER - -...- $\triangle P$ SUMMER - - - 

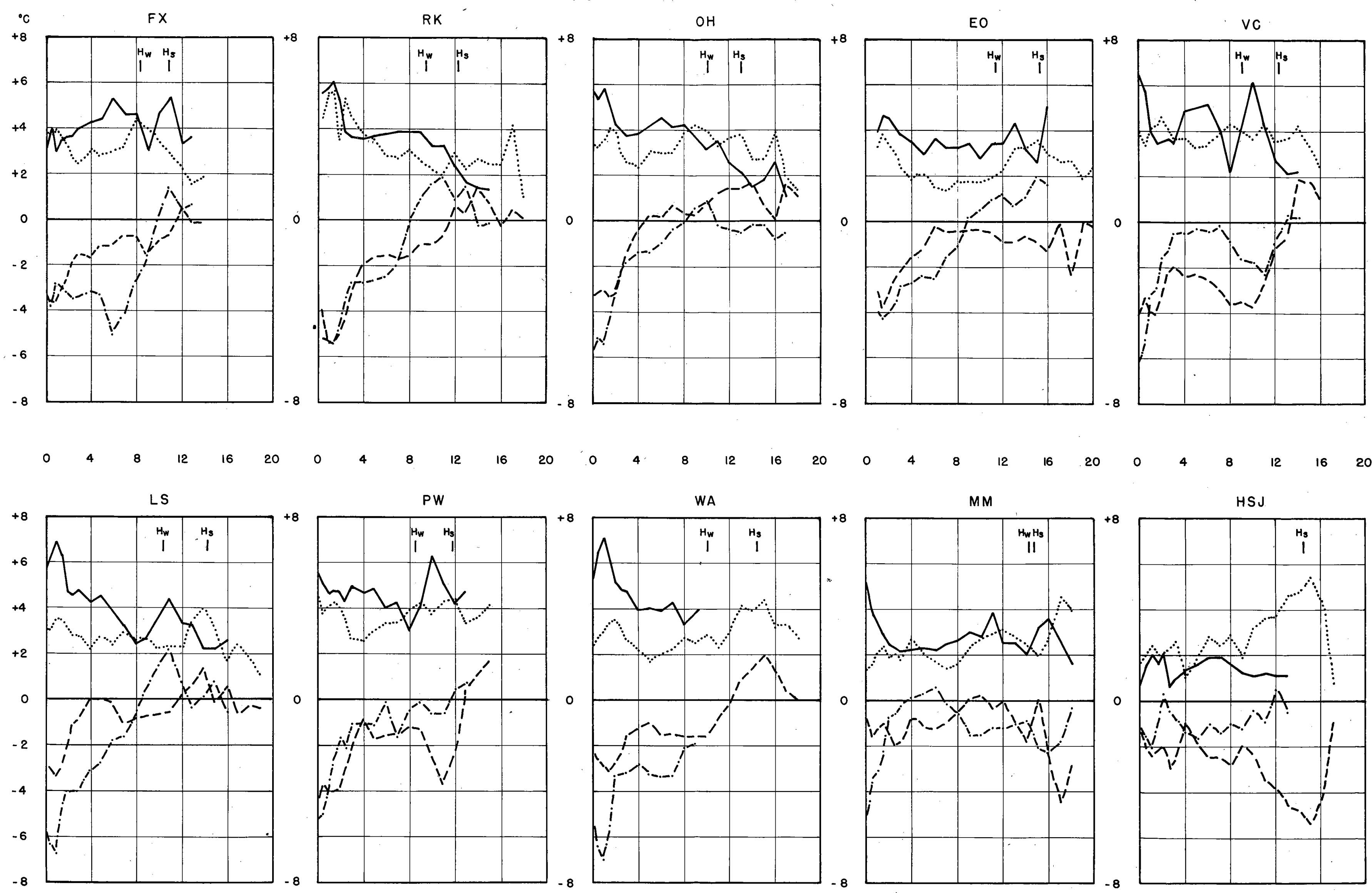

FIG. 8

MEANS OF THE INTERDIURNAL TEMPERATURE VARIATION $\Delta P_{0}>0>\Delta T m_{0}$

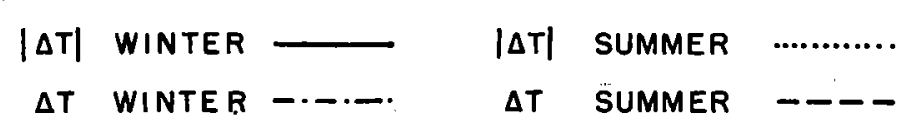



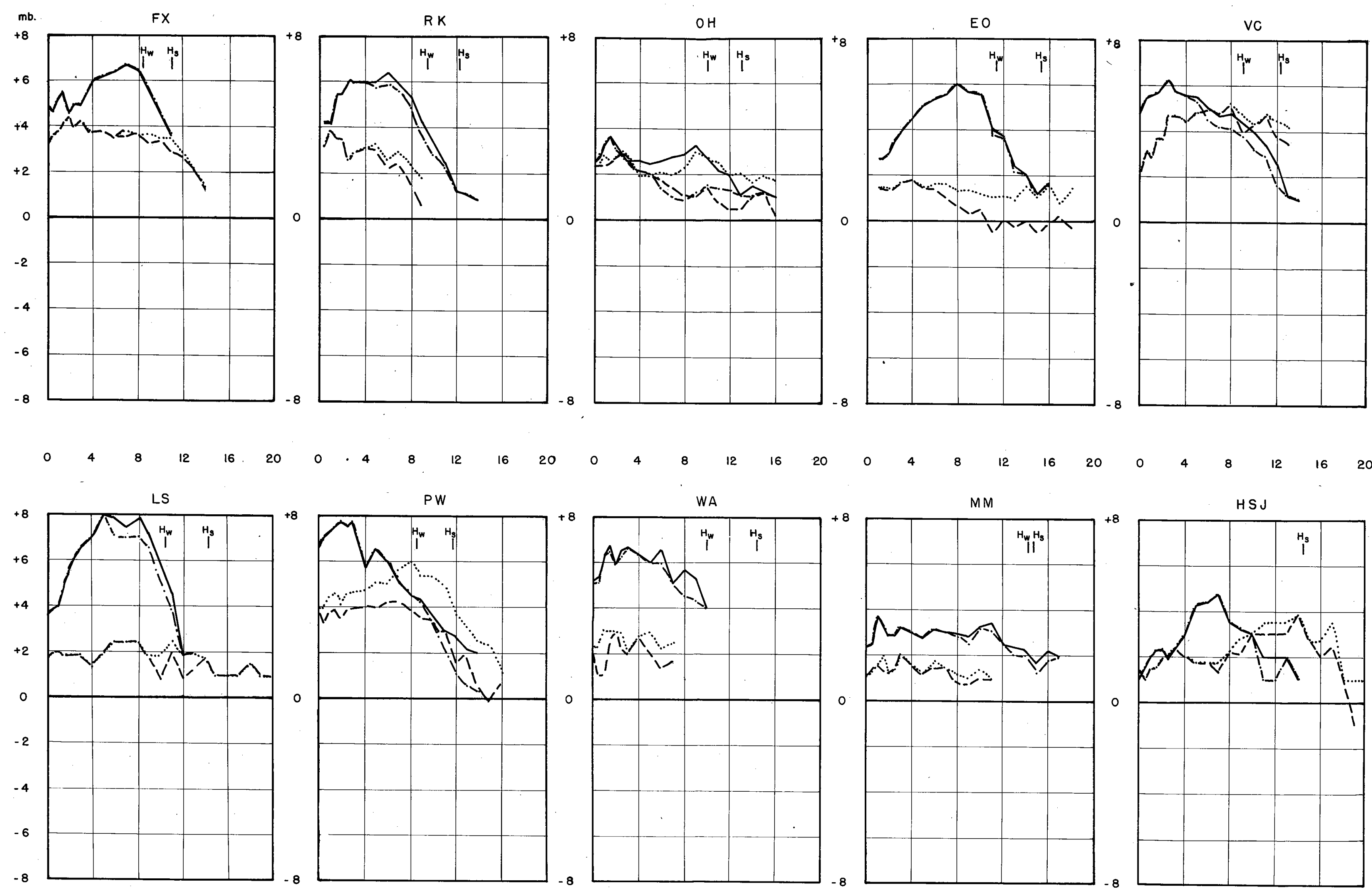

MEANS OF THE INTERDIURNAL PRESSURE VARIATION $\triangle P_{0}>0<\Delta T m_{0}$

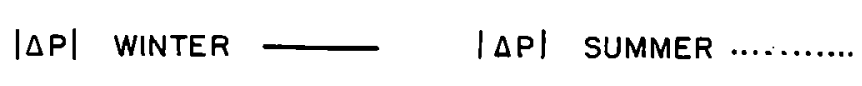



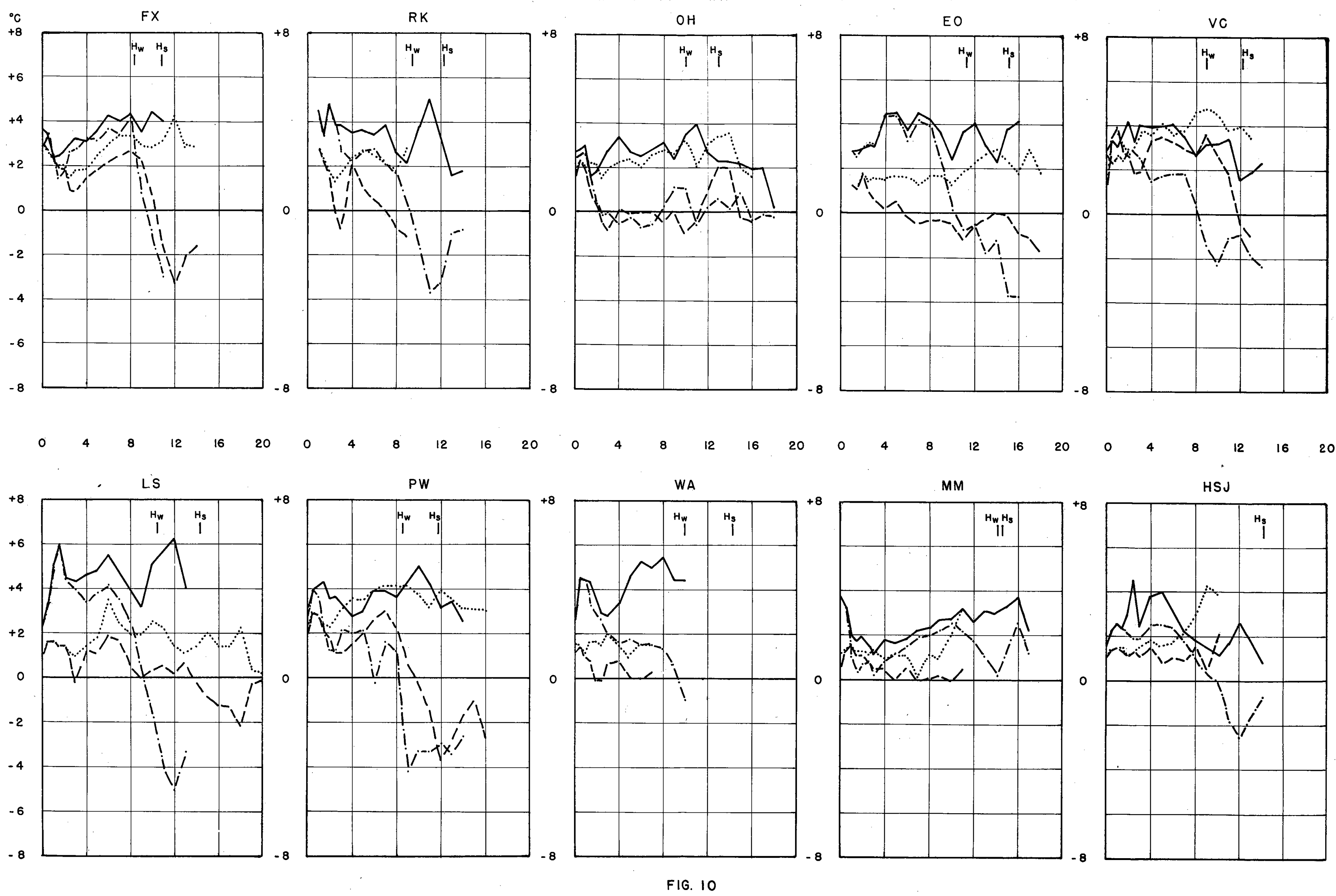

MEANS OF THE INTERDIURNAL. TEMPERATURE VARIATION $\Delta P_{0}>0<\Delta T m_{0}$

|DT| WINTER

|DT| SUMMER ….......... 

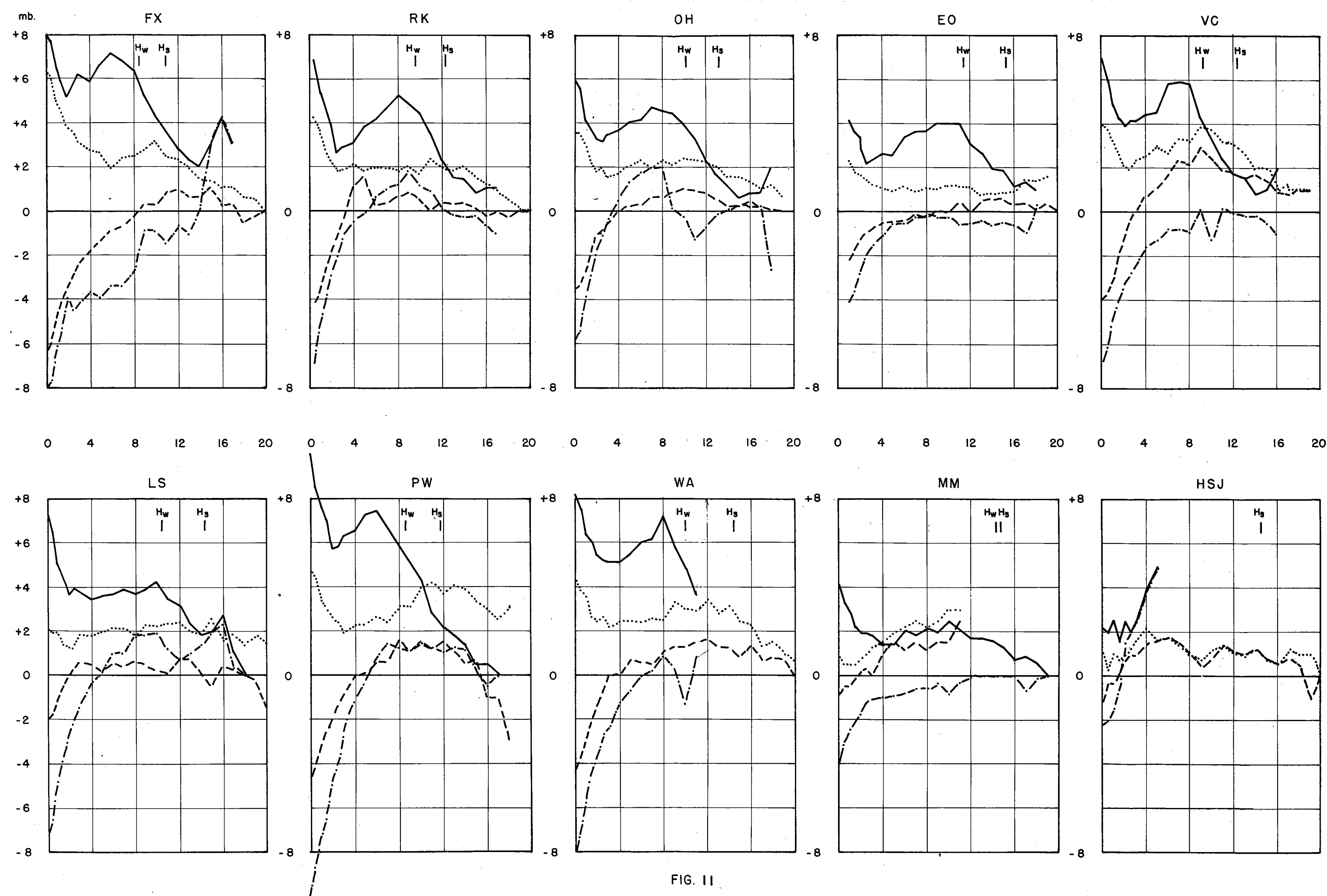

MEANS OF THE INTERDIURNAL PRESSURE VARIATION $\triangle P_{0}<0<T m_{0}$

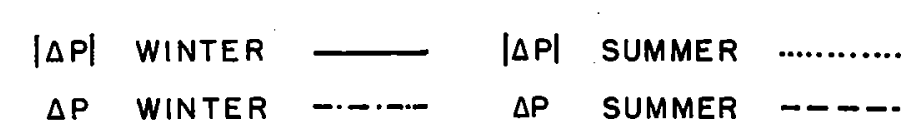



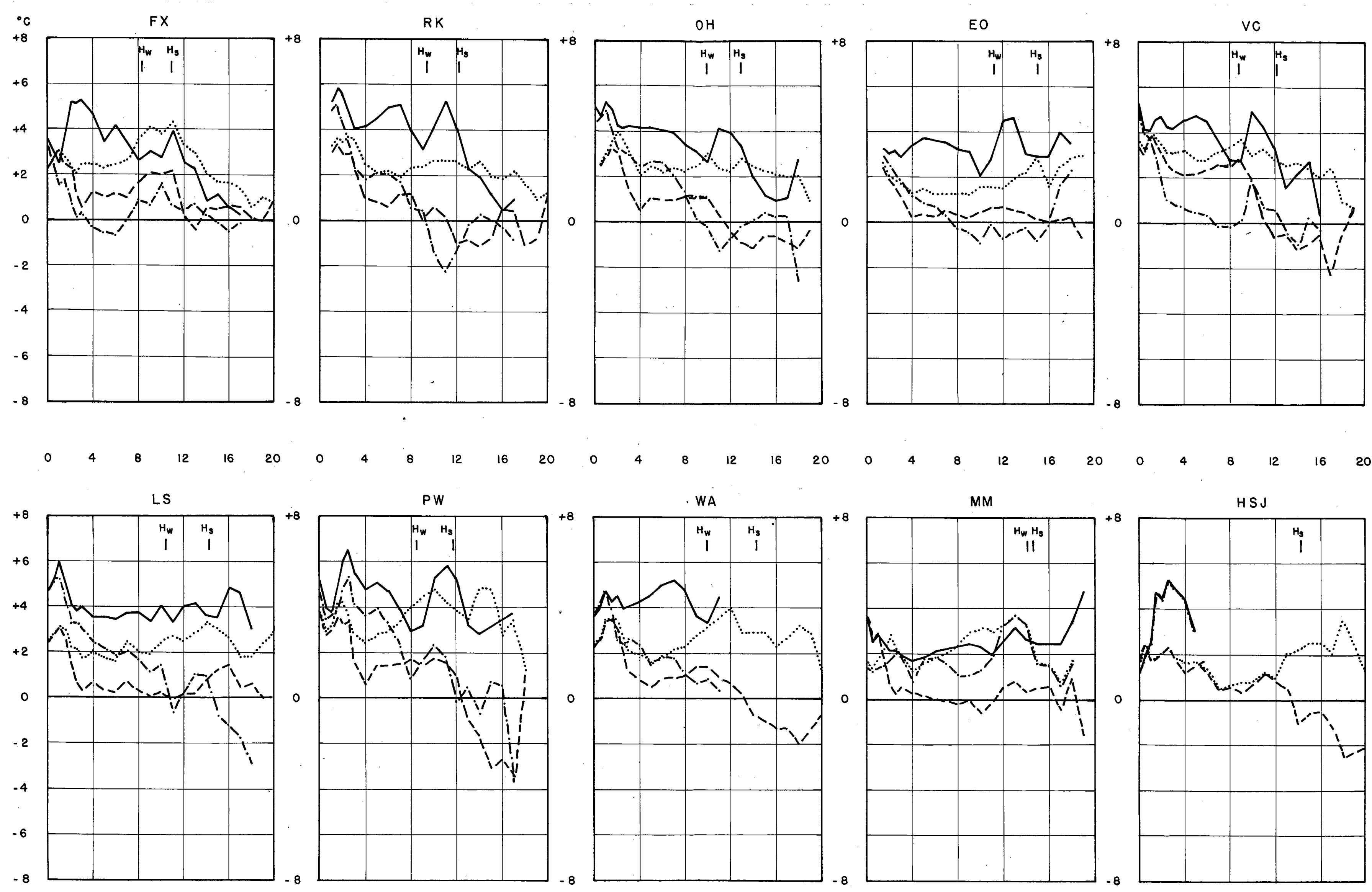

FIG. 12

MEANS OF THE INTERDIURNAL TEMPERATURE VARIATION $\Delta P_{0}<0<\Delta T m_{0}$

$|\triangle T|$ WINTER - $\quad|\triangle T|$ SUMMER $\cdots \cdots . . . . . . .$.

$\triangle T$ WINTER - .... $\quad \Delta$ T SUMMER - - 

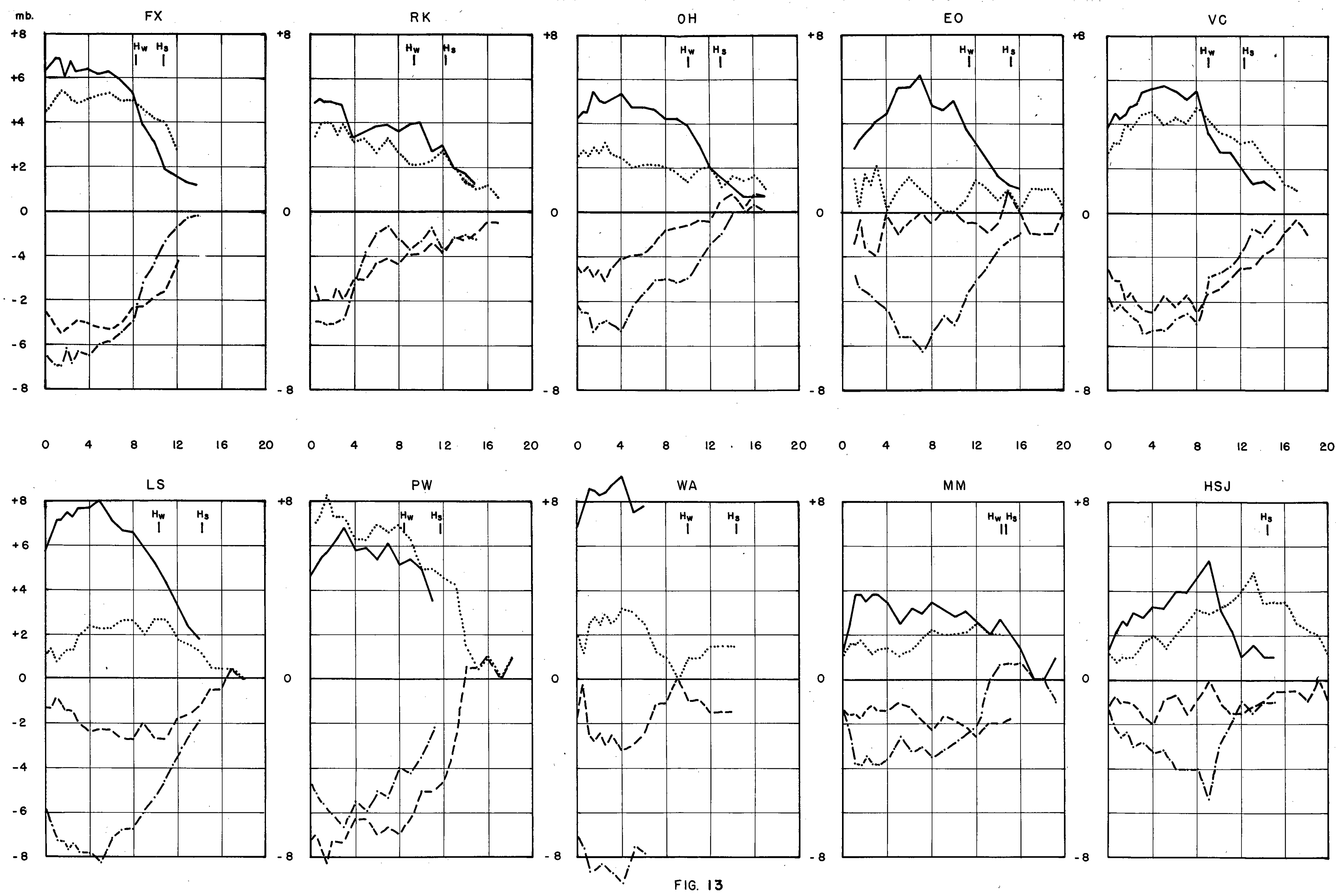

MEANS OF THE INTERDIURNAL PRESSURE VARIATION $\Delta P_{0}\langle 0\rangle \Delta T m_{0}$

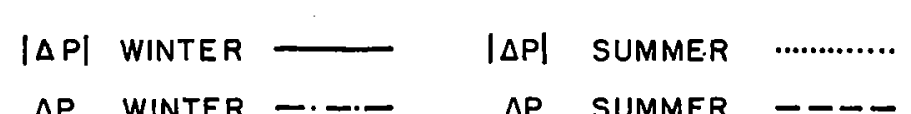



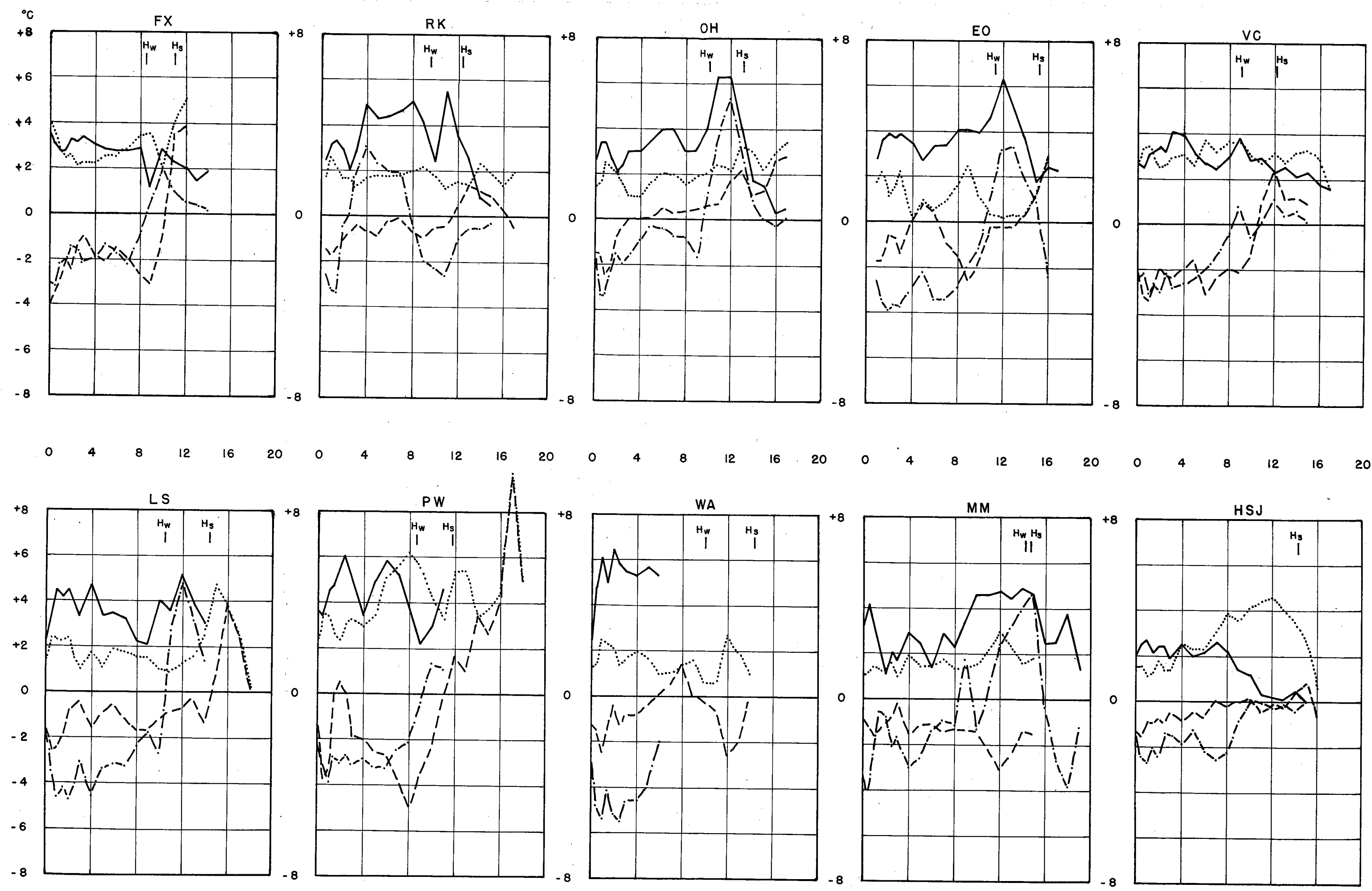

FIG. 14

MEANS OF THE INTERDIURNAL TEMPERATURE VARIATION

$\Delta P_{0}\langle 0\rangle \Delta T m_{0}$

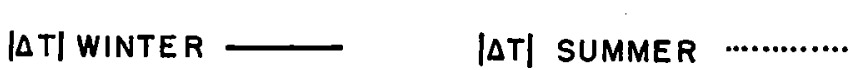

$\Delta T$ WINTER -

$\triangle T$ SUMMFR 


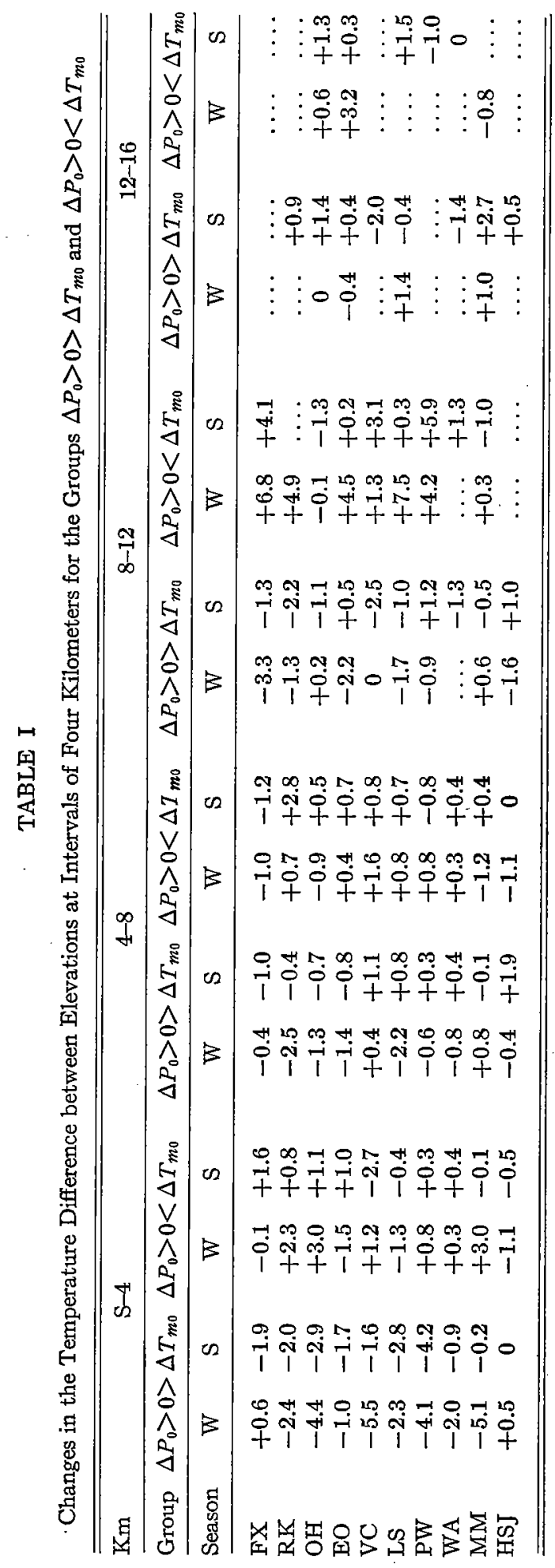


Applying the mean interdiurnal temperature variation curves to a consideration of stability changes, it is apparent that, except for the cases just mentioned, there is a pronounced increase in the stability of the entire troposphere and a slight decrease in the stability of the first few kilometers of the stratosphere for the group $\Delta P_{0}>0>\Delta T_{m o}$. Changes in the temperature difference between elevations at intervals of four kilometers have been tabulated in Table I. These values were obtained directly from the observed algebraic temperature changes so that positive signs indicate a de-stabilizing effect and negative sign a stabilizing effect. At those stations which are characterized by maximum negative temperature changes in the upper levels there is an appreciable trend toward de-stabilization in the middle and upper troposphere with an associated strong trend toward greater stability at about the level of the mean height of the tropopause. This seems to be more characteristic of the coastal stations than of the continental stations.

A glance at the temperature variation curves for cases of falling surface pressure reveals that the stability changes at corresponding levels are of opposite sense and symmetrical to those just described for rising surface pressure.

A comparison between the algebraic and the absolute means suggests that there must be quite a few cases where the sign of the interdiurnal temperature variation in the middle and upper troposphere is opposite to that of the lowest layers. This follows directly from equation (9) cited above and the difference between the magnitude of the mean algebraic pressure change and the absolute pressure change at the level of the upper tropospheric maximum in the latter. For example, at Omaha the value of $|\Delta P|$ at eight kilometers in winter is nearly five millibars while the value of $\Delta P$ is only a fraction of a millibar. Obviously then, at this height for the $\Delta P_{0}>0>\Delta T_{m o}$ group, there are combined cases of large rises and large falls which nearly cancel when the algebraic mean is taken. Since the same general conditions hold true to a greater or lesser extent at most of the other stations, the Omaha data for this group have been subdivided into two categories, one with $\Delta P_{8}>0$ and the other with $\Delta P_{8}<0$. The absolute and algebraic mean variations at each level for these two categories have been computed and are presented in Figs. 17 and 18. It is worth noting that the $|\Delta P|$ and the $\Delta P$ curves are coincident for the case of $\Delta P_{8}>0$. They show a very rapid decrease in the first two kilometers, a minimum at three kilometers and then a rise to a maximum at seven kilometers after which the variability gradually decreases to about one millibar at sixteen kilometers. The corresponding algebraic temperature variation curve shows marked cooling at the surface and rapidly diminishing variability with elevation so that at two kilometers it is nearly zero. Above two kilometers it shows a rapid increase with a definite maximum of positive changes at seven or eight kilometers. Above this maximum the variability rapidly decreases again, passing through zero at ten kilometers and showing a maximum of negative falls at eleven kilometers. The magnitude of the changes decreases somewhat above eleven kilometers but remains definitely negative up to the termination of the data at sixteen kilometers. Thus there is a marked trend toward greater stability in the layer from the surface up to eight kilometers - the temperature difference between the top and the bottom of this layer showing a decrease in the mean of nearly $10^{\circ} \mathrm{C}$. Above eight kilometers there has been a definite trend toward less stability with the temperature difference between eight and ten kilometers undergoing an increase of $7^{\circ} \mathrm{C}$. Above twelve kilometers there is a slight trend again toward greater stability.

In the case of $\Delta P_{8}<0$ there is almost a linear decrease in the algebraic value of pressure variability from the surface up to eight kilometers. The curve passes through zero at four kilometers. Above eight kilometers the magnitude of the interdiurnal pressure variation gradually decreases again to one millibar at sixteen kilometers. Comparison with the $|\Delta P|$ curve for the same data shows that the layer between three and six kilometers is the only region where the algebraic magnitude is appreciably less than the magnitude of the absolute variations. This is the zone within which the change of the algebraic sign of $\Delta P$ occurs for the individual ascents and while there is 

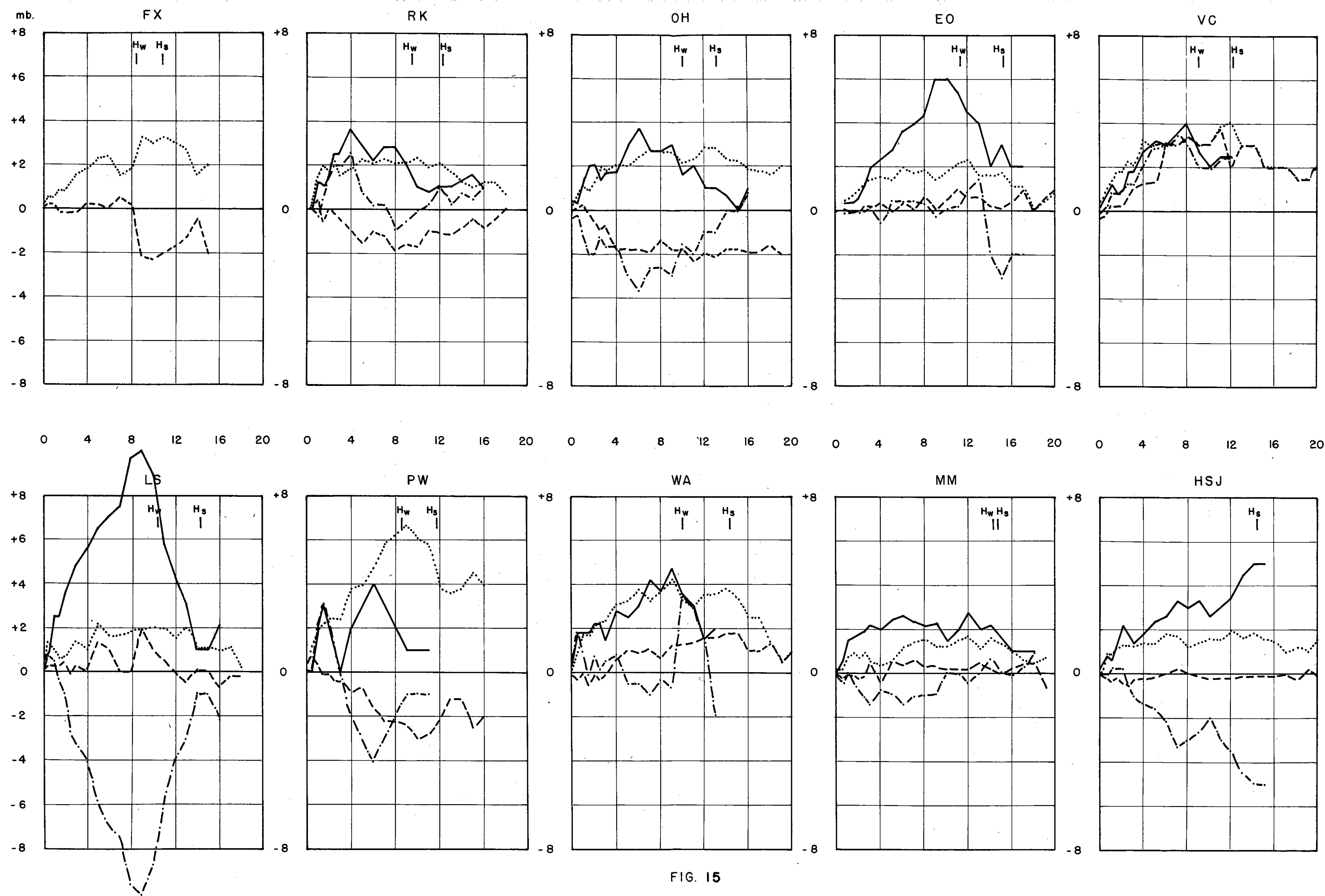

MEANS OF THE INTERDIURNAL PRESSURE VARIATION $\Delta P_{0}=0$

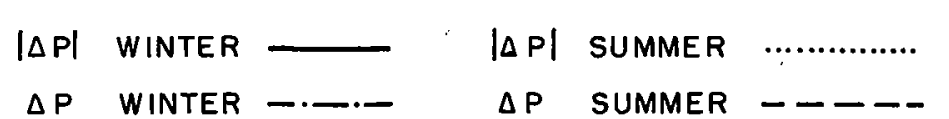



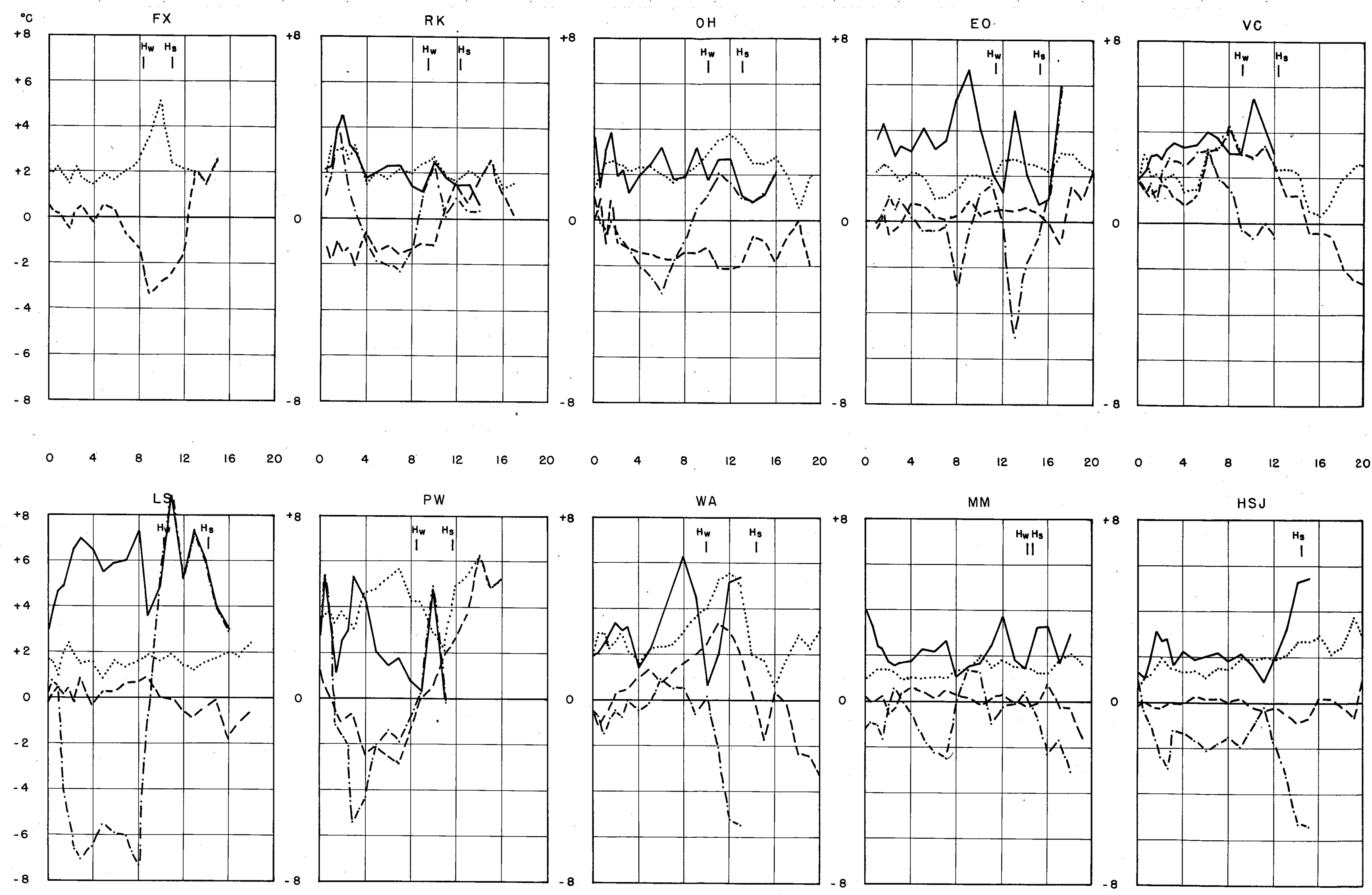

FIG. 16

MEANS OF THE INTERDIURNAL TEMPERATURE VARIATION $\Delta B_{0}=0$

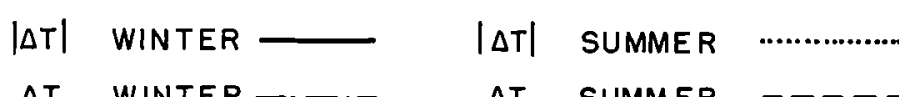

$$
\begin{aligned}
& \triangle T \text { WINTER - - - }- \text { DT SUMMER --- }
\end{aligned}
$$




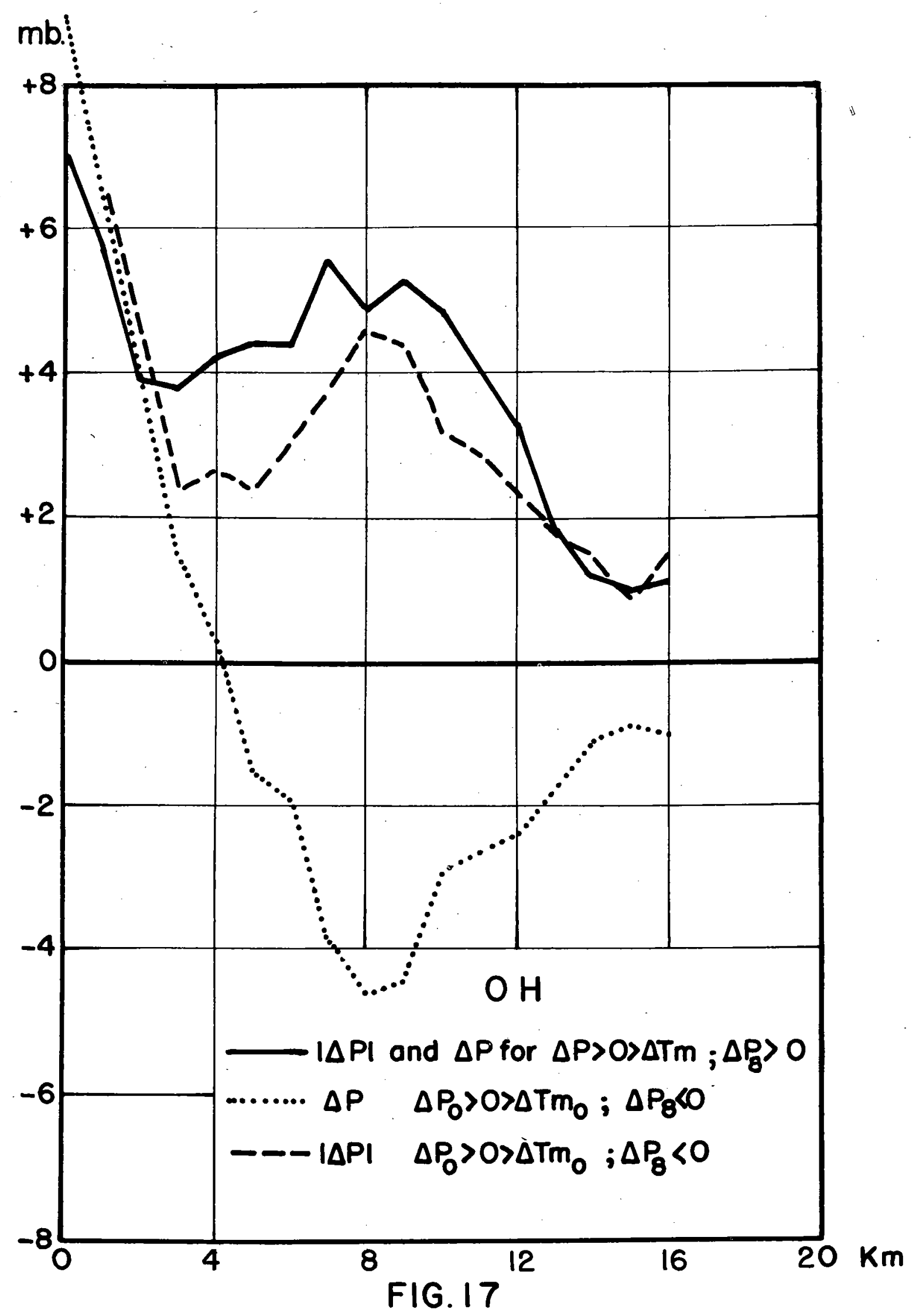




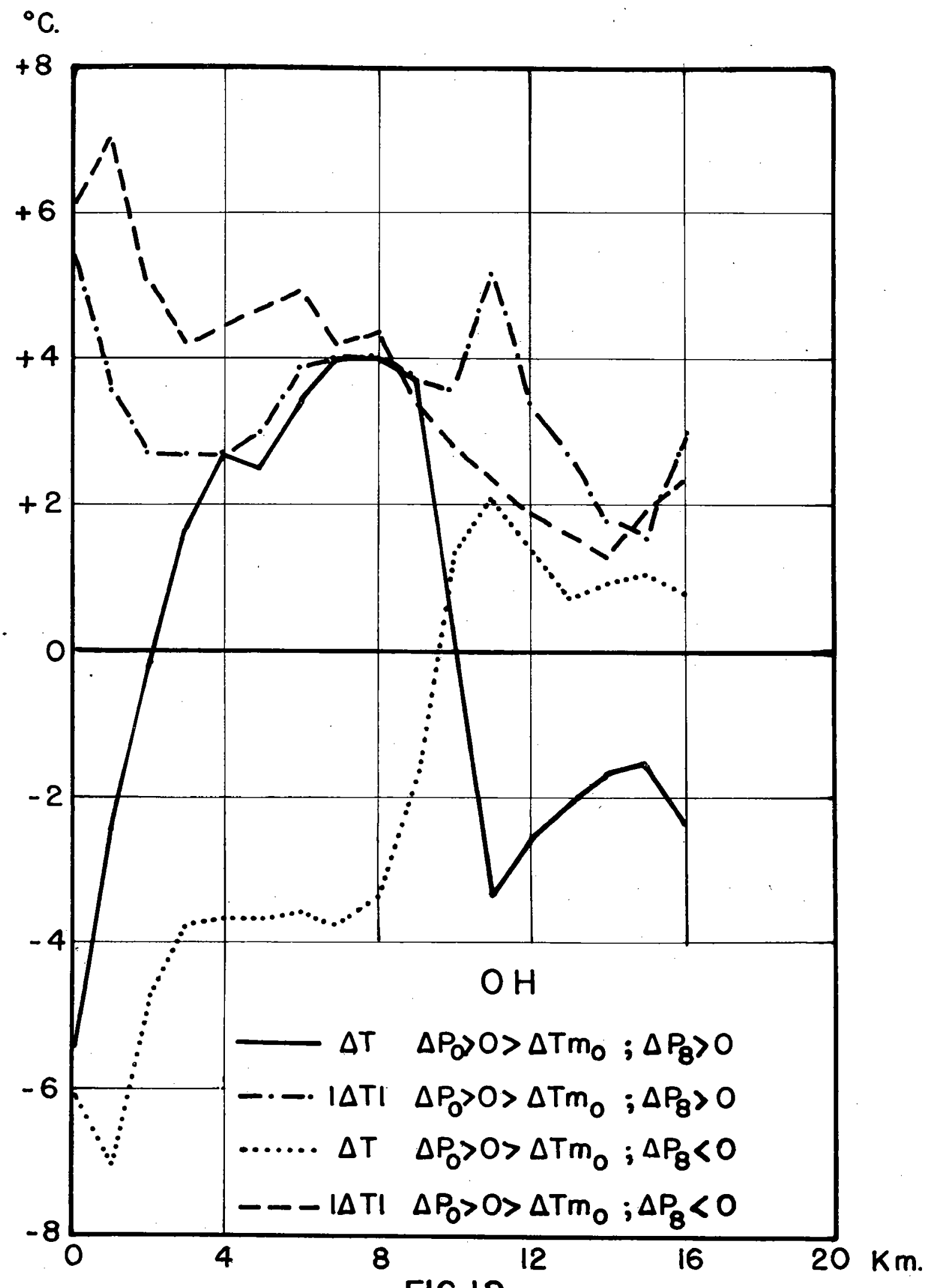

FIG. 18 
considerable difference in the elevation at which this takes place for each ascent, the mean height is four kilometers. The $\Delta T$ curve for this case shows strong temperature falls at the surface with the largest changes at one kilometer. Above one kilometer the magnitude decreases sharply up to three kilometers and then remains almost constant at $-3.5^{\circ} \mathrm{C}$ up to seven kilometers. Above seven kilometers it again decreases rapidly, passing through zero and attaining a definite positive maximum of about $2^{\circ} \mathrm{C}$ at eleven kilometers. Above this maximum it decreases again to about $1^{\circ} \mathrm{C}$ at thirteen kilometers and changes very little in the next three kilometers.

This breakdown of the $\Delta P_{0}>0>\Delta T_{m o}$ group data for Omaha has been discussed in some detail since it appears to be fairly typical of a condition existing at most of the other stations for this group and the description of these curves, with minor modifications, may be taken as applying almost equally well to most of the other stations.

Turning now to the group $\Delta P_{0}>0<\Delta T_{m o}$ curves (Figs. 9 and 10), the most conspicuous feature of the interdiurnal pressure variation is the approximate congruence of the $|\Delta P|$ and $\Delta P$ curves. The winter curves at Fairbanks, Bismarck, El Paso and St. Louis and the summer curves at $\mathrm{S}$. Ste. Marie, St. Louis and Portland show values which increase from the surface to a maximum in the upper troposphere and then decrease again farther up into the stratosphere. This type of pressure variability profile is associated with moderate temperature rises in the lower and middle troposphere and generally large temperature falls in the upper troposphere and lower stratosphere. At S. Ste. Marie, Portland, and Washington in the winter and at Fairbanks and Bismarck in the summer, the maximum is found in the lower troposphere and only a very gradual decrease with increasing elevation exists above this maximum. In these cases the temperature variation differential between the troposphere and the stratosphere is neither as sharp nor as large as for the cases of the maximum pressure variation at higher elevations. At Omaha there is a primary maximum near the surface and a secondary maximum at nine or ten kilometers during both seasons, but the profiles are relatively flat. The corresponding temperature variation curves show negative changes in the middle troposphere which simply suggest that the variations of the mean temperature in the lowest kilometer are frequently of a different sign than the temperature changes higher in the troposphere. The pressure variation profiles at Miami are notably flat in both seasons but the temperature variations show appreciably greater warming at high elevation. This is consistent with the pressure variation equation discussed earlier since if there were no temperature changes in a column of air, the pressure change at each successively higher level would diminish as the ratio of the pressure at that level to the pressure at the surface. Thus, in order for the pressure variation to remain constant with elevation, the temperature term in that equation must be operative.

Fundamentally, the pattern for the pressure and temperature variation profiles for this group fall into the same general pattern - pressure rises increasing from the surface to a tropospheric maximum and then diminishing slowly and without changing sign at the heights reached by this data - temperature rises in the troposphere and falls in the stratosphere. It is only in the matter of detail that the higher latitude stations show much difference.

The typical stability change for the group $\Delta P_{0}>0<\Delta T_{m o}$ gives a slightly greater stability in the lower layers and considerably less stability in the layer from eight to twelve kilometers as may be seen directly from an examination of the $\Delta T$ curves or by reference to Table $I$.

The curves for the groups $\Delta P_{0}<0<\Delta T_{m o}$ and $\Delta P_{0}<0>\Delta T_{m o}$ will not be discussed in detail because they are mirror images, in their major features, of the curves for the $\Delta P_{0}>0>\Delta T_{m o}$ and the $\Delta P_{0}>0<\Delta T_{m o}$ groups respectively. There is no theoretical reason why this should be so - it is simply a matter of observation - and offers further evidence for the idea expressed earlier that there is a definite similarity between the physical processes which produce pressure falls and those which produce pressure rises and that this similarity carries right down through various groupings of the two sets of data. 
There is one difference in detail which should be mentioned and that is the tendency of the pressure variation curves for $\Delta P_{0}>0<\Delta T_{m o}$ to show a more distinct increase of variability in the lower layers and a more pronounced tropospheric maximum than the corresponding curves for $\Delta P_{0}<0>\Delta T_{m o}$. This simply means that the association between large rises at the surface and large rises aloft is better than the association between falls at the surface and larger falls aloft for cases in which the change of mean temperature in the lowest layers has the same sign as the surface pressure change.

\section{Seasonal Absolute and Algebraic Mean Values for $\Delta P_{0}=0$}

The limited amount of data available for these curves (Figs. 15 and 16) precludes any detailed description and interpretation. They are presented merely for the sake of completeness and to illustrate the type of changes which can take place aloft even though there is no change in the surface pressure. The pressure variation curves tend to show a maximum in the middle or upper troposphere and this may be positive or negative depending on the variation of temperature in the lower and middle troposphere. 


\section{CHAPTER III}

\section{CORRELATION COEFFICIENTS AND REGRESSION EQUATIONS}

\section{Correlation Coefficients}

The correlation coefficients involving the height of the tropopause are presented in Table II(a). The coefficients determined by Haurwitz and Haurwitz [17] for Boston have been included as a reference. The correlations between the height of the tropopause and the pressure at three, five and nine kilometers, respectively, are best at S. Ste. Marie during both seasons and at El Paso in winter. A somewhat orderly relationship is suggested by these coefficients. The same variables correlate very poorly at Miami during both seasons and at El Paso in summer, showing almost

TABLE II (a)

The Correlation Coefficients and Probable Errors of the Correlation Coefficients for the Pairs $P_{8} H, P_{5} H, P_{0} H$, and $T_{m a} H$

( $n=$ number of cases)

\begin{tabular}{|c|c|c|c|c|c|c|c|c|c|c|c|}
\hline & \multirow[b]{2}{*}{ Feb } & \multirow[b]{2}{*}{$\operatorname{sgn} \Delta P_{0} \neq \operatorname{sgn} \Delta T_{m 0}$} & \multicolumn{2}{|c|}{$P_{3} H$} & \multicolumn{2}{|c|}{$P_{5} H$} & \multicolumn{2}{|c|}{$P_{9} H$} & \multicolumn{2}{|c|}{$T_{m 9} H$} & \multirow{2}{*}{$\begin{array}{c}n \\
42\end{array}$} \\
\hline & & & +.68 & \pm .06 & +.82 & \pm .03 & +.83 & \pm .03 & +.70 & \pm .05 & \\
\hline & Feb & $\operatorname{sgn} \Delta P_{0}=\operatorname{sgn} \Delta T_{m 0}$ & +.76 & \pm .05 & +.88 & \pm .03 & +.82 & \pm .04 & +.70 & \pm .06 & 34 \\
\hline \multicolumn{12}{|c|}{ 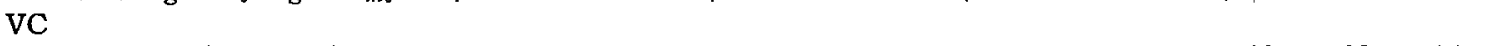 } \\
\hline & Aug & $\operatorname{sgn} \Delta P_{0} \not \operatorname{sgn} \Delta T_{m 0}$ & +.65 & \pm .05 & +.73 & \pm .04 & +.83 & \pm .03 & +.82 & $\neq .03$ & 51 \\
\hline & Aug & $\operatorname{sgn} \Delta P_{0}=\operatorname{sgn} \Delta T_{m 0}$ & +.61 & \pm .07 & +.65 & $\neq .07$ & +.74 & \pm .05 & +.75 & \pm .05 & 33 \\
\hline & $\mathrm{Feb}$ & $\operatorname{sgn} \Delta P_{0} \neq \operatorname{sgn} \Delta T_{m 0}$ & +.08 & \pm .10 & +.22 & \pm .09 & +.30 & \pm .09 & +.38 & \pm .08 & 47 \\
\hline & $\mathrm{Feb}$ & $\operatorname{sgn} \Delta P_{0}=\operatorname{sgn} \Delta T_{m 0}$ & -.15 & \pm .16 & +.06 & \pm .16 & +.29 & \pm .15 & +.39 & \pm .14 & 17 \\
\hline \multicolumn{12}{|c|}{ MM } \\
\hline & Aug & $\operatorname{sgn} \Delta P_{0} \neq \operatorname{sgn} \Delta T_{m 0}$ & +.14 & \pm .14 & +.19 & \pm .14 & +.17 & \pm .14 & +.31 & \pm .13 & 22 \\
\hline & Aug & $\operatorname{sgn} \Delta P_{0}=\operatorname{sgn} \Delta T_{m 0}$ & +.40 & \pm .11 & +.41 & \pm .11 & +.33 & \pm .12 & +.43 & \pm .11 & 25 \\
\hline & Feb & $\operatorname{sgn} \Delta P_{0} \not \operatorname{sgn} \Delta T_{m 0}$ & +.52 & \pm .06 & +.66 & \pm .05 & +.72 & \pm .04 & +.71 & \pm .04 & 61 \\
\hline & Feb & $\operatorname{sgn} \Delta P_{0}=\operatorname{sgn} \Delta T_{m 0}$ & +.42 & \pm .12 & +.66 & \pm .08 & +.74 & \pm .06 & +.82 & \pm .05 & 22 \\
\hline \multicolumn{12}{|c|}{ 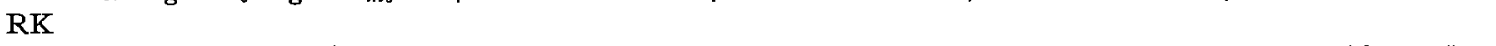 } \\
\hline & Aug & $\operatorname{sgn} \Delta P_{0} \neq \operatorname{sgn} \Delta T_{m_{0}}$ & +.25 & \pm .03 & +.46 & \pm .07 & +.64 & \pm .05 & +.61 & \pm .06 & 57 \\
\hline & Aug & $\operatorname{sgn} \Delta P_{0}=\operatorname{sgn} \Delta T_{m_{0}}$ & +.42 & \pm .14 & +.65 & \pm .10 & +.76 & \pm .07 & +.70 & \pm .09 & 16 \\
\hline & $\mathrm{Feb}$ & $\operatorname{sgn} \Delta P_{0} \neq \operatorname{sgn} \Delta T_{m 0}$ & +.51 & \pm .06 & +.68 & \pm .05 & +.76 & \pm .04 & +.69 & \pm .04 & 61 \\
\hline & $\mathrm{Feb}$ & $\operatorname{sgn} \Delta P_{0}=\operatorname{sgn} \Delta T_{m 0}$ & +.17 & \pm .08 & +.46 & \pm .09 & +.59 & \pm .08 & +.55 & \pm .08 & 32 \\
\hline \multicolumn{12}{|l|}{$\mathrm{OH}$} \\
\hline & Aug & $\operatorname{sgn} \Delta P_{0} \not=\operatorname{sgn} \Delta T_{m 0}$ & +.46 & \pm .08 & +.66 & \pm .05 & +.74 & \pm .04 & +.79 & \pm .04 & 50 \\
\hline & Aug & $\operatorname{sgn} \Delta P_{0}=\operatorname{sgn} \Delta T_{m 0}$ & +.61 & \pm .08 & +.79 & \pm .05 & +.84 & \pm .04 & +.84 & \pm .04 & 25 \\
\hline & Feb & $\operatorname{sgn} \Delta P_{0} \neq \operatorname{sgn} \Delta T_{m 0}$ & +.61 & \pm .06 & +.64 & \pm .06 & +.67 & \pm .05 & +.58 & \pm .06 & 51 \\
\hline & Feb & $\operatorname{sgn} \Delta P_{0}=\operatorname{sgn} \Delta T_{m 0}$ & +.70 & \pm .06 & +.68 & \pm .06 & +.67 & \pm .06 & +.60 & \pm .07 & 33 \\
\hline & \multicolumn{9}{|c|}{ 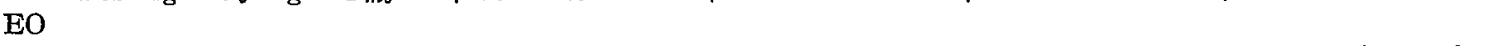 } & & \\
\hline & Aug & $\begin{array}{l}\operatorname{sgn} \Delta P_{0}=\operatorname{sgnt} \Delta P_{0}=\operatorname{sgn} \Delta T_{m 0}\end{array}$ & $\begin{array}{l}-.12 \\
+.07\end{array}$ & $\begin{array}{l} \pm .08 \\
\pm .13\end{array}$ & $\begin{array}{l}-.14 \\
+.24\end{array}$ & $\begin{array}{l} \pm .08 \\
\pm .12\end{array}$ & $\begin{array}{l}+.11 \\
+.45\end{array}$ & $\begin{array}{l} \pm .08 \\
\pm .10\end{array}$ & $\begin{array}{r}-.01 \\
+.39\end{array}$ & $\begin{array}{l} \pm .09 \\
\pm .11\end{array}$ & $\begin{array}{l}62 \\
28\end{array}$ \\
\hline \multirow{2}{*}{\multicolumn{2}{|c|}{ Boston }} & $\operatorname{sgn} \Delta P_{0} \neq \operatorname{sgn} \Delta T_{m 0}$ & +.61 & \pm .06 & +.70 & \pm .05 & +.72 & \pm .04 & +.78 & \pm .04 & $51+$ \\
\hline & & $\operatorname{sgn} \Delta P_{0}=\operatorname{sgn} \Delta T_{m 0}$ & +.66 & \pm .08 & +.73 & \pm .07 & +.77 & \pm .06 & +.81 & \pm .05 & $51+$ \\
\hline
\end{tabular}




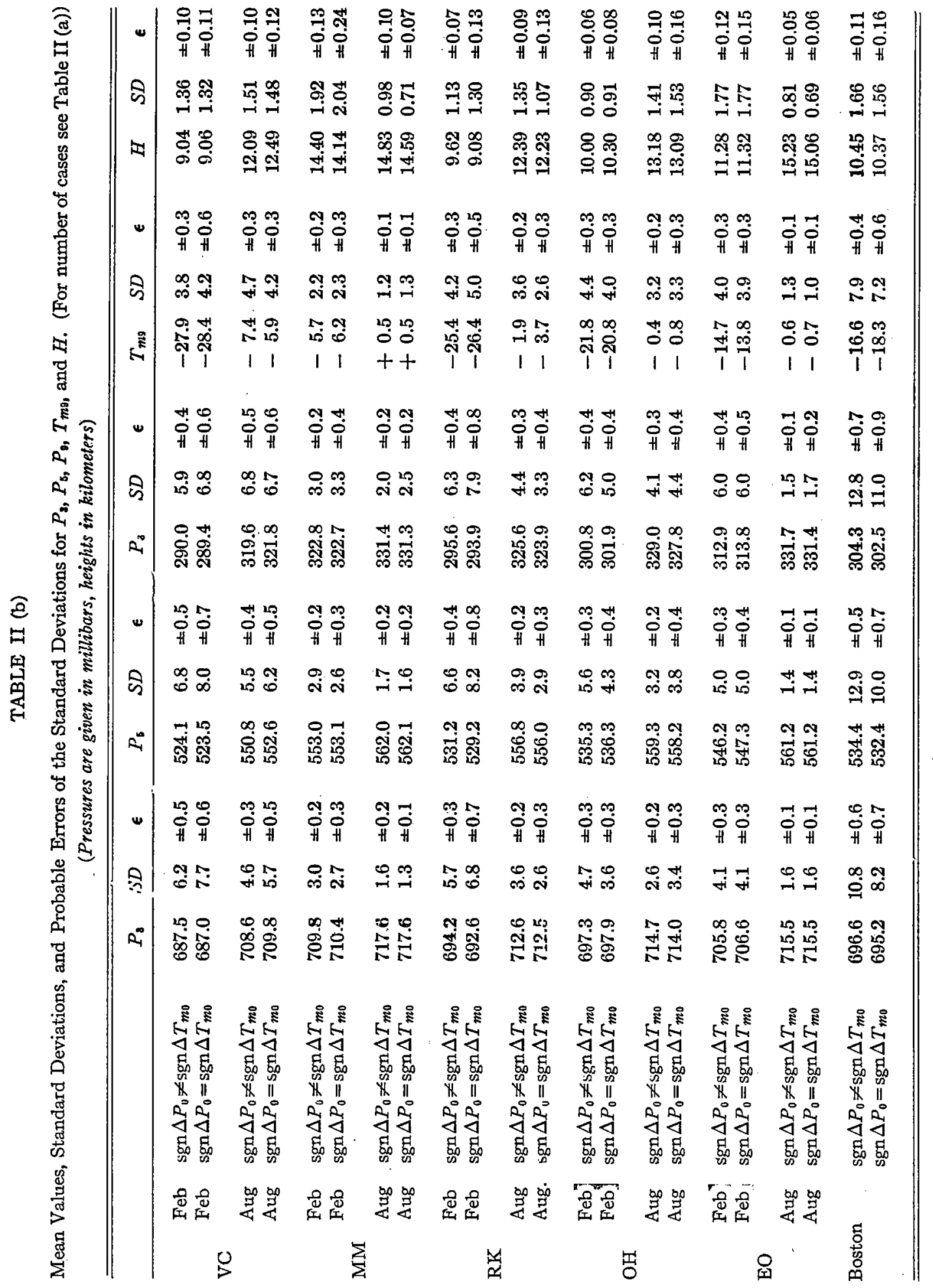


no relationship. The coefficients at Bismarck and Omaha are midway between those at S. Ste. Marie and those at Miami. In general the correlation between the height of the tropopause and the pressures at constant elevations becomes higher with increasing elevation. Exceptions to this generalization are found at Miami in summer and at El Paso. The correlations are higher for the $\operatorname{sgn} \Delta P_{0}=\operatorname{sgn} \Delta T_{m o}$ groups than for the $\operatorname{sgn} \Delta P_{0} \neq \operatorname{sgn} \Delta T_{m o}$ groups at all stations during the summer except S. Ste. Marie. In winter there is no significant difference between the two groups except at Omaha where slightly higher correlations are found for the $\operatorname{sgn} \Delta P_{0} \neq \operatorname{sgn} \Delta T_{m o}$ group than for the $\operatorname{sgn} \Delta P_{0}=\operatorname{sgn} \Delta T_{m o}$ group.

The mean temperature from the surface up to nine kilometers correlates reasonably well with the height of the tropopause everywhere except at El Paso in the summer and at Miami. There is no systematic difference between the two groups $\operatorname{sgn} \Delta P_{0}=\operatorname{sgn} \Delta T_{m o}$ and $\operatorname{sgn} \Delta P_{0} \neq \operatorname{sgn} \Delta T_{m o}$.

All of the correlations at $\mathrm{El}$ Paso for the $\operatorname{sgn} \Delta P_{0} \neq \operatorname{sgn} \Delta T_{m o}$ group are negligible. The standard deviations for the variables in this group (Table II $(b)$ ) indicate that the interdiurnal variations

\section{TABLE III (a)}

The Correlation Coefficients and Probable Errors of the Correlation Coefficients for the pairs $P_{0} T_{m 9}, P_{3} T_{m 9}, P_{5} T_{m 9}$, $P_{9} T_{m 9}$, and $P_{0} P_{5} \quad(n=$ number of cases)

\begin{tabular}{|c|c|c|c|c|c|c|c|c|}
\hline & & & $P_{0} T_{m 9}$ & $P_{3} T_{m 9}$ & $P_{5} T_{m 9}$ & $P_{9} T_{m 9}$ & $P_{0} P_{\mathrm{s}}$ & $n$ \\
\hline \multirow{4}{*}{$\mathrm{VC}$} & Feb. & $\operatorname{sgn} \Delta P_{0} \not \operatorname{sgn} \Delta T_{m 0}$ & $-.07 \pm .09$ & $+.49 \pm .07$ & $+.51 \pm .07$ & $+.87 \pm .02$ & $+.57 \pm .06$ & 53 \\
\hline & Feb. & $\operatorname{sgn} \Delta P_{0}=\operatorname{sgn} \Delta T_{m 0}$ & $+.06 \pm .11$ & $+.50 \pm .08$ & $+.72 \pm .05$ & $+.81 \pm .04$ & $+.70 \pm .06$ & 37 \\
\hline & Aug. & $\operatorname{sgn} \Delta P_{0} \not \operatorname{sgn} \Delta T_{m 0}$ & $-.11 \pm .08$ & $+.72 \pm .04$ & $+.88 \pm .02$ & $+.97 \pm .01$ & $+.34 \pm .08$ & 62 \\
\hline & Aug. & $\operatorname{sgn} \Delta P_{0}=\operatorname{sgn} \Delta T_{m 0}$ & $+.21 \pm .11$ & $+.81=.04$ & $+.90=.02$ & $+.97 \pm .01$ & $+.58 \pm .07$ & 36 \\
\hline \multirow{4}{*}{ MM } & Feb. & $\operatorname{sgn} \Delta P_{0} \not \operatorname{sgn} \Delta T_{m 0}$ & $-.32 \pm .07$ & $.+.39=.07$ & $+.59 \pm .05$ & $+.85 \pm .02$ & $+.46 \pm .06$ & 70 \\
\hline & Feb. & $\operatorname{sgn} \Delta P_{0}=\operatorname{sgn} \Delta T_{m 0}$ & $-.07 \pm .12$ & $+.66 \pm .07$ & $+.57 \pm .08$ & $+.94 \neq .01$ & $+.26 \pm .11$ & 32 \\
\hline & Aug. & $\operatorname{sgn} \Delta P_{0} \not=\operatorname{sgn} \Delta T_{m 0}$ & $+.16=.11$ & $+.39 \pm .10$ & $+.41 \pm .10$ & $+.75 \pm .05$ & $+.48=.09$ & 31 \\
\hline & Aug. & $\operatorname{sgn} \Delta P_{0}=\operatorname{sgn} \Delta T_{m 0}$ & $+.11=.11$ & $+.41 \pm .09$ & $+.59 \pm .07$ & $+.83 \pm .03$ & $+.42 \pm .06$ & 37 \\
\hline \multirow{4}{*}{ RK } & Feb. & $\operatorname{sgn} \Delta P_{0} \not=\operatorname{sgn} \Delta T_{m 0}$ & $-.35 \pm .07$ & $+.56 \pm .06$ & $+.77 \pm .03$ & $+.88 \pm .02$ & $+.27 \pm .02$ & 69 \\
\hline & Feb. & $\operatorname{sgn} \Delta P_{0}=\operatorname{sgn} \Delta T_{m 0}$ & $-.24 \pm .12$ & $+.60 \pm .08$ & $+.83 \pm .04$ & $+.90 \pm .02$ & $+.29 \pm .12$ & 28 \\
\hline & Aug. & $\operatorname{sgn} \Delta P_{0} \not 1 \operatorname{sgn} \Delta T_{m 0}$ & $-.37 \pm .07$ & $+.48 \pm .06$ & $+.77 \pm .03$ & $+.89 \pm .02$ & $+.21 \pm .08$ & 66 \\
\hline & Aug. & $\operatorname{sgn} \Delta P_{0}=\operatorname{sgn} \Delta T_{m 0}$ & $-.39 \pm .12$ & $+.38 \pm .13$ & $+.73 \pm .07$ & $+.94 \pm .02$ & $+.23 \pm .06$ & 22 \\
\hline \multirow{4}{*}{$\mathrm{OH}$} & Feb. & $\operatorname{sgn} \Delta P_{0} \neq \operatorname{sgn} \Delta T_{m 0}$ & $-.41 \pm .07$ & $+.36 \pm .07$ & $+.70 \pm .04$ & $+.84 \pm .02$ & $+.23 \pm .08$ & 72 \\
\hline & Feb. & $\operatorname{sgn} \Delta P_{0}=\operatorname{sgn} \Delta T_{m 0}$ & $-.60=.07$ & $+.13 \pm .11$ & $+.60 \pm .07$ & $+.85 \pm .03$ & $+.21 \pm .11$ & 37 \\
\hline & Aug. & $\operatorname{sgn} \Delta P_{0} \not=\operatorname{sgn} \Delta T_{m 0}$ & $-.41 \neq .07$ & $+.58 \pm .06$ & $+.82 \pm .03$ & $+.94 \pm .01$ & $+.06 \pm .09$ & 58 \\
\hline & Aug. & $\operatorname{sgn} \Delta P_{0}=\operatorname{sgn} \Delta T_{m 0}$ & $-.26 \pm .11$ & $+.62 \pm .08$ & $+.83 \pm .04$ & $+.91 \pm .02$ & $+.23 \pm .12$ & 30 \\
\hline \multirow{4}{*}{ EO } & Feb. & $\operatorname{sgn} \Delta P_{0} \not \operatorname{sgn} \Delta T_{m 0}$ & $+.15 \pm .08$ & $+.65 \pm .05$ & $+.84 \pm .02$ & $+.95 \pm .01$ & $+.57 \pm .06$ & 67 \\
\hline & Feb. & $\operatorname{sgn} \Delta P_{0}=\operatorname{sgn} \Delta 1_{m 0}$ & $+.18 \pm .10$ & $+.70 \pm .05$ & $+.86 \pm .03$ & $+.96 \pm .01$ & $+.58 \pm .07$ & 43 \\
\hline & Aug. & $\operatorname{sgn} \Delta P_{0} \neq \operatorname{sgn} \Delta T_{m 0}$ & $-.36 \pm .07$ & $-.14 \pm .08$ & $+.19 \pm .08$ & $+.40 \pm .07$ & $+.50 \pm .06$ & 70 \\
\hline & Aug. & $\operatorname{sgn} \Delta P_{0}=\operatorname{sgn} \Delta I_{m 0}$ & $-.35 \pm .10$ & $-.17 \pm .12$ & $+.11 \pm .12$ & $+.45 \pm .10$ & $+.58 \pm .08$ & 32 \\
\hline \multirow{2}{*}{\multicolumn{2}{|c|}{ Boston }} & $\operatorname{sgn} \Delta P_{0} \not=\operatorname{sgn} \Delta T_{m 0}$ & $-.14 \pm .07$ & $+.72 \pm .04$ & $+.77 \pm .03$ & $+.89 \pm .01$ & $+.24 \pm .05$ & $79+$ \\
\hline & & $\operatorname{sgn} \Delta P_{0}=\operatorname{sgn} \Delta T_{m 0}$ & $-.05=.11$ & $+.89 \pm .02$ & $+.88 \pm .02$ & $+.95 \pm .01$ & $+.17 \pm .09$ & $79+$ \\
\hline
\end{tabular}




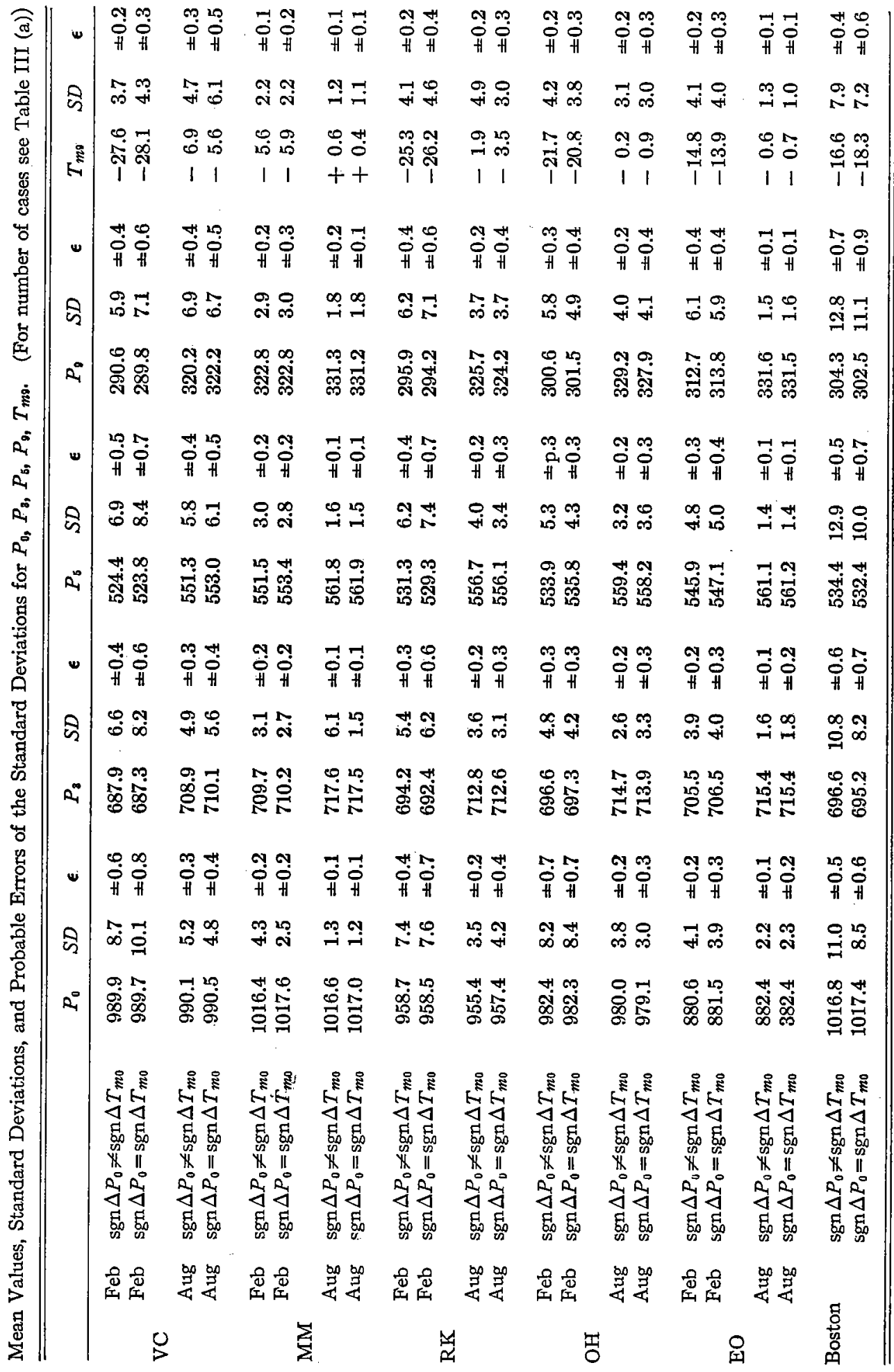


are extremely small and are very likely exceeded by the intrumental errors of the original observations.

The correlations between the pressures at various levels and the mean temperature between the surface and nine kilometers are presented in Table III(a). It is apparent that better correlations are obtained with increasing elevations until at nine kilometers the correlations between $P_{9}$ and $T_{m 9}$ indicate a very close relation between these two quantities everywhere except at E1 Paso in the summer. It is only above three kilometers, however, that the association becomes appreciable. The correlations between $P_{0}$ and $T_{m 9}$ are negligible everywhere except at El Paso in the summer and at Bismarck and Omaha. In the case of these exceptions the correlations are significantly negative. Comparison with the +0.45 correlations between these two variables found by Dines [12] over Europe suggests an appreciable difference between the conditions at these stations and those prevailing over Europe. There is no tendency for cases of $\operatorname{sgn} \Delta P_{0}=\operatorname{sgn} \Delta T_{m o}$ to show higher correlations than cases of $\operatorname{sgn} \Delta P_{0} \neq \operatorname{sgn} \Delta T_{m o}$ as was noted in the study at Boston referred to above.

The correlations between the pressure at five kilometers and the pressure at the surface are very small at Bismarck and Omaha, are somewhat better at Miami, and indicate some real association at El Paso and S. Ste. Marie. At the last three stations they are significantly larger than the value of +0.24 for $\operatorname{sgn} \Delta P_{0} \neq \operatorname{sign} \Delta T_{m o}$ and +0.17 for $\operatorname{sgn} \Delta P_{0}=\operatorname{sgn} \Delta T_{m o}$ found previously at Boston.

The ratio of the frequency of cases where $\operatorname{sign} \Delta P_{0} \neq \operatorname{sgn} \Delta T_{m 0}$ to the frequency of cases where $\operatorname{sgn} \Delta P_{0}=\operatorname{sgn} \Delta T_{m o}$ has been computed for each station and is given in Table IV. San Juan is the only station where cases of $\operatorname{sgn} \Delta P_{0}=\operatorname{sgn} \Delta T_{m o}$ occur more frequently than cases of $\operatorname{sgn} \Delta P_{0} \neq \operatorname{sgn} \Delta T_{m o}$ in both summer and winter. This is true also at Miami during the summer. Taking into account both seasons, advection in the lowest layer contributes to the surface pressure change most frequently at Bismarck where the continental influences are the greatest. The next highest frequency occurs at Washington, and E1 Paso ranks third by virtue of the favorable conditions prevailing there during the summer. At Fairbanks and Portland the ratio is nearly unity. The corresponding ratio was 3.0 at Boston, 1.7 in Europe, and the average for selected North American stations was 2.0. The influence of adjacent bodies of water seems to be important and at Fairbanks the orographic shielding and radiative effects also may be important.

\section{TABLE IV}

Seasonal and Total Frequency of Cases in which $\Delta P_{0}>0>\Delta T_{m 0}$ (columns headed by $N_{1}$ ) and in which $\Delta P_{0}>0<\Delta T_{m 0}$ (columns headed by $N_{2}$ ) and the Ratio of the two Frequencies $\left(R=N_{1} / N_{2}\right)$

\begin{tabular}{lrllrrrrrrr}
\hline & & \multicolumn{3}{l}{ Winter } & \multicolumn{3}{c}{ Summer } & \multicolumn{3}{c}{ Total } \\
\hline & $N_{1}$ & $N_{2}$ & $R$ & \multicolumn{1}{l}{$N_{1}$} & \multicolumn{1}{l}{$N_{2}$} & $R$ & $N_{1}$ & $N_{2}$ & $R$ \\
\hline RK & $\mathbf{5 5}$ & 17 & 3.2 & 53 & 15 & 3.5 & 108 & 32 & 3.4 \\
FX & 23 & 24 & 1.0 & 26 & 19 & 1.4 & 49 & 43 & 1.1 \\
EO & $\mathbf{4 7}$ & $\mathbf{2 2}$ & 2.1 & 42 & 11 & 3.8 & 89 & 33 & 2.7 \\
HSJ & 5 & 12 & 0.4 & 9 & 15 & 0.6 & 14 & 27 & 0.5 \\
MM & 51 & 16 & 3.2 & 10 & 16 & 0.6 & 61 & 32 & 1.9 \\
OH & 53 & 21 & 2.5 & 46 & 18 & 2.6 & 99 & 39 & 2.5 \\
PW & 23 & 24 & 1.0 & 32 & 14 & 2.3 & 55 & 38 & 1.4 \\
LS & 44 & 22 & 2.0 & 33 & 9 & 3.7 & 77 & 31 & 2.5 \\
VC & 44 & 25 & 1.8 & 52 & 22 & 2.4 & 96 & 47 & 2.0 \\
WA & 42 & 20 & 2.1 & 45 & 11 & 4.1 & 87 & 31 & 2.8 \\
\hline \hline
\end{tabular}




\section{REgRESSION EQUATIONS}

Only three pairs of variables showed fairly good correlations and the computation of regression coefficients was restricted to these three pairs. They are $P_{9} T_{m 9}, \dot{P}_{9} H$, and $T_{m 9} H$. Since there was no significant difference between the values of the correlation coefficients or of the standard deviations in the $\operatorname{sgn} \Delta P_{0}=\operatorname{sgn} \Delta T_{m o}$ group and those in the $\operatorname{sgn} \Delta P_{0} \neq \operatorname{sgn} \Delta T_{m o}$ group, only the values for the latter group were used for the regression coefficients. Regression equations for summer and winter are given in Table V.

\section{TABLE V}

Regression Equations for the Pairs $P_{9} T m_{9}, P_{9} H$, and $T m_{9} H$

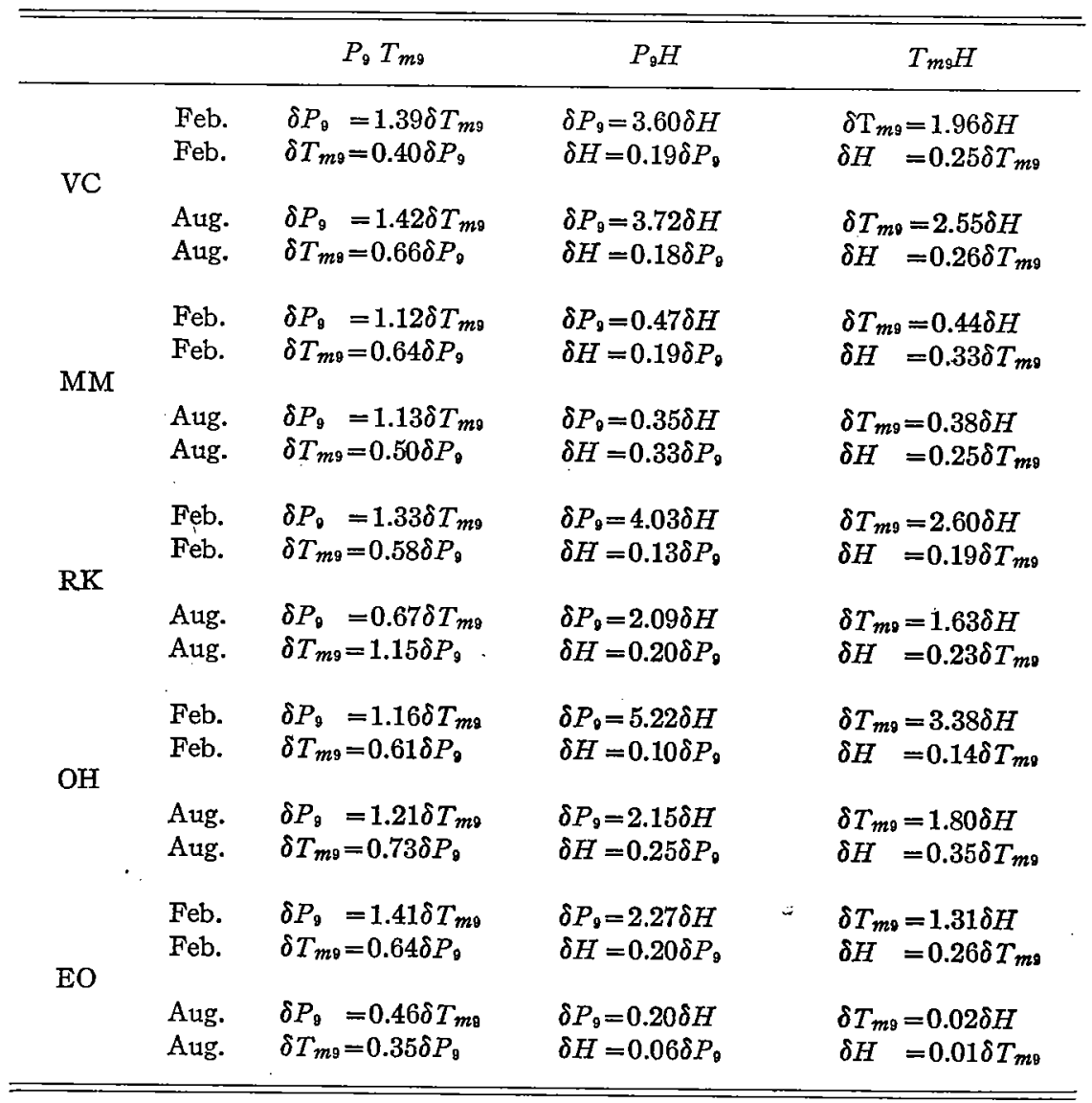




\section{CHAPTER IV}

\section{DENSITY VARIATIONS AND THE ADVECTIVE CHANGES OF MASS IN THE DIFFERENT LAYERS}

\section{Density Variations}

The surface pressure change represents the integral of the density variations from the surface to the top of the atmosphere, according to the relation

$$
\frac{\partial P_{0}}{\partial t}=\int_{0}^{\infty} g \frac{\partial \rho}{\partial t} d z
$$

which may also be written

$$
\frac{\partial P_{0}}{\partial t}=\int_{o}^{1 k m} g \frac{\partial \rho}{\partial t} d z+\int_{1 k m}^{2 k m} g \frac{\partial \rho}{\partial t} d z+\cdots+\int_{n k m}^{(n+1) k m} g \frac{\partial \rho}{\partial t} d z+\int_{(n+1) k m}^{\infty} g \frac{\partial \rho}{\partial t} d z
$$

which reduces to the identity

Since

$$
\frac{\partial P_{0}}{\partial t}=\left(\frac{\partial P_{0}}{\partial t}-\frac{\partial P_{1}}{\partial t}\right)+\left(\frac{\partial P_{1}}{\partial t}-\frac{\partial P_{2}}{\partial t}\right)+\left(\frac{\partial P_{2}}{\partial t}-\frac{\partial P_{3}}{\partial t}\right)+\cdots
$$

$$
\begin{aligned}
& \frac{\partial}{\partial t}\left(\frac{\partial P}{\partial z}\right)=-g \frac{\partial \rho}{\partial t} \\
& \frac{\partial}{\partial z}\left(\frac{\partial P}{\partial t}\right)=-g \frac{\partial \rho}{\partial t}
\end{aligned}
$$

the actual variations of density in successive one kilometer layers in the vertical may be approximated with sufficient accuracy by computing the change in the difference of pressure between the top and the bottom of each layer. Mean values of these weight changes may be obtained with sufficient accuracy directly from the data used in preparing the mean pressure curves. This has been done and the resulting $\Delta(\delta p)$ curves are presented in Fig. 19. Only the winter values of the $\Delta P_{0}>0>\Delta T_{m o}$ and $\Delta P_{0}>0<\Delta T_{m o}$. groups were used. It should be noted that no values were computed at San Juan because the data did not extend to sufficient heights to warrant interpretation. In place of San Juan the subgroups $\Delta P_{8}>0$ and $\Delta P_{8}<0$ of $\Delta P_{0}>0>\Delta T_{m o}$ for Omaha have been included and are presented in the lower right-hand section of Fig. 19.

For the case of $\Delta P_{0}>0>\Delta T_{m o}$ at Fairbanks, Bismarck, El Paso, and St. Louis there are large positive density changes in the lower and middle troposphere and moderately large negative changes in the upper troposphere and in the stratosphere. The height at which there is no change in the density is the level of maximum interdiurnal pressure variability. This is to be expected since the slope of the pressure variation curve is zero at this point and since

$$
\frac{\partial}{\partial z}\left(\frac{\partial P}{\partial t}\right)=0
$$

from

$$
\frac{\partial}{\partial z}\left(\frac{\partial P}{\partial t}\right)=-g \frac{\partial \rho}{\partial t}
$$




$$
\frac{\partial \rho}{\partial t}=0
$$

It is interesting to note that the level of minimum interdiurnal density variation and maximum interdiurnal pressure variation is also approximately the height at which the meridional gradient of density is a minimum. The height at which the meridional density gradient is a minimum over North America has been determined from the winter mean meridional cross section of the North American quadrant prepared by. Willett [19]. The ratio of the $P / T$ (pressure in millibars divided by temperature in degrees Centigrade) was computed at each kilometer level from one to sixteen kilometers for Swan Island, Nashville, Bismarck, Ketchikan and Fairbanks. These stations are located at intervals of approximately ten degrees of latitude beginning with Fairbanks at about $65^{\circ} \mathrm{N}$ and terminating with Swan Island at about $15^{\circ} \mathrm{N}$. By taking the difference of the $P / T$ ratio at each pair of adjacent stations for a given level and then averaging these differences it is possible to obtain an average meridional variation of $P / T$ per ten degrees of latitude. This quantity has been calculated for each level and the variations are presented in Table VI. It is evident that the meridional gradient of density is a minimum at about eight kilometers. A similar conclusion was reached by Sen [22] who computed the vertical distribution of density in the summer season from the mean sea level pressure distribution and an assumed lapse rate of temperature.

\section{TABLE VI}

Average Meridional Variation of $P / T$ per'Ten Degrees of Latitude at Various Levels ( $P$ is Pressure, $T$ is Temperature)

\begin{tabular}{cccc}
\hline \hline$Z(\mathrm{~km})$ & $P / T$ per $10^{\circ}$ Lat. & $Z(\mathrm{~km})$ & $P / T$ per 10 $0^{\circ}$ Lat. \\
\hline 1 & .095 & 9 & .009 \\
2 & .045 & 10 & .017 \\
3 & .036 & 11 & .022 \\
4 & .023 & 12 & .028 \\
5 & .019 & 13 & .031 \\
6 & .016 & 14 & .031 \\
7 & .010 & 15 & .029 \\
8 & .007 & 16 & .035 \\
\hline
\end{tabular}

The density variation curves at Omaha, S. Ste. Marie, Portland, Washington and Miami do not show such a clear distinction between the contributions of the layers below and above this isopycnic level. Reference to the supplementary curves for Omaha indicates that these stations are probably characterized by more complex variations and that a subdivision of the data on the basis of the sign of the pressure change at eight kilometers is necessary. When this subdivision is made it is apparent that when $\Delta P_{8}<0$ the density variations conform to the simple picture given above; however, when $\Delta P_{8}>0$ the density variations are positive in the lower troposphere and above the isopycnic level and negative in the upper troposphere beneath this level.

Considerably different density variations are encountered when $\Delta P_{0}>0<\Delta T_{m o}$. The dominant changes lie above the isopycnic level and the pressure at the surface rises as a result of the density increase aloft and in spite of the decrease of density below the isopycnic level. In the case of $\Delta P_{0}>0>\Delta T_{m o}$ the pressure at the surface increases as a result of the increase in density below the isopycnic level and notwithstanding the density decrease above this level. 

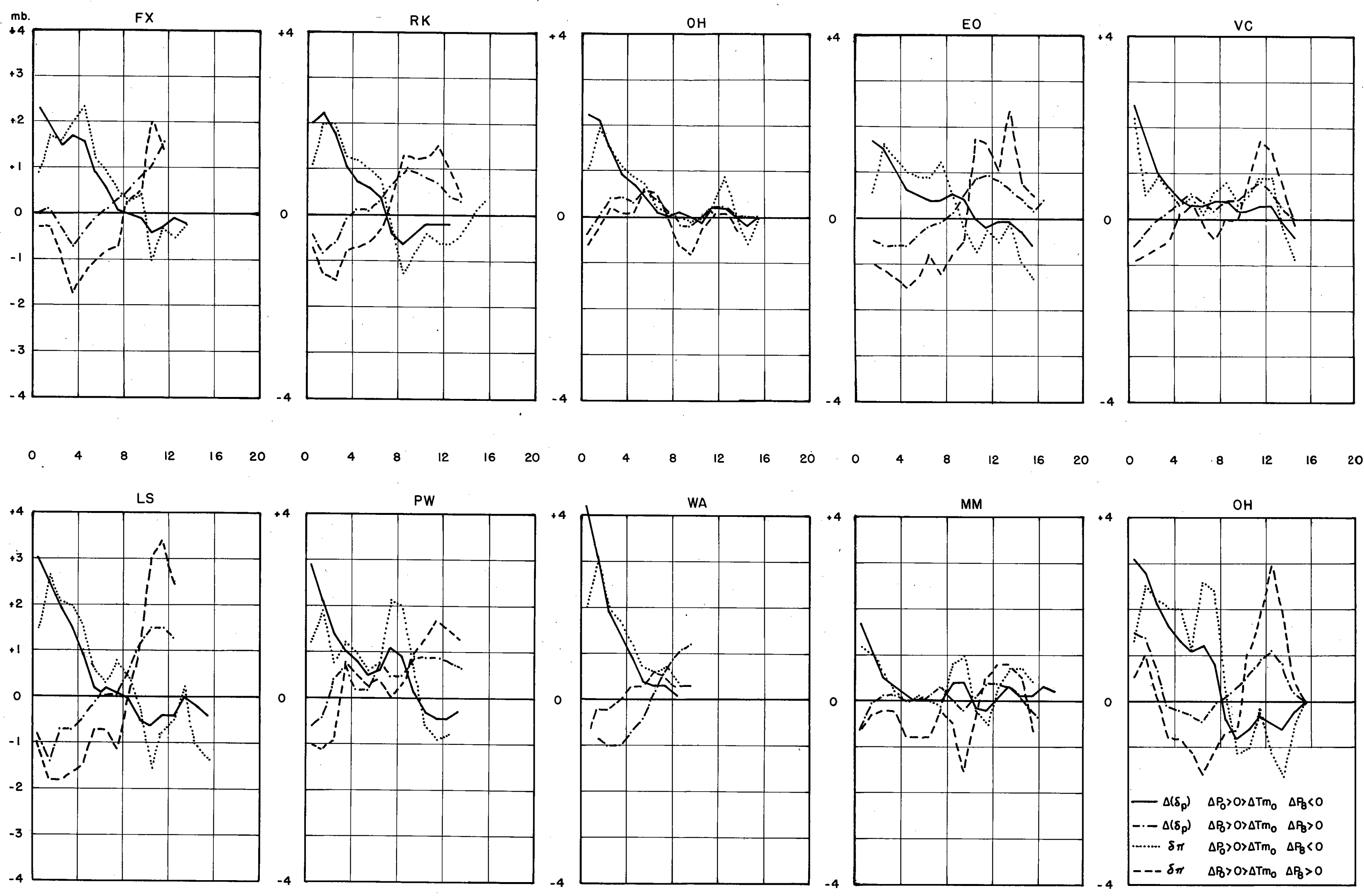

MEAN WEIGHT VARIATION AND ADVECTIVE CHANGES - WINTER
$\Delta\left(\delta_{p}\right) \quad \Delta P_{0}>0>\Delta T m_{0}$
$\delta_{\pi}^{2} \Delta P_{0}>0>\Delta T m_{0}$
$\Delta\left(\delta_{p}\right) \quad \Delta p_{0}>0<\Delta T m_{0} \quad-\cdot \cdot-$
$\delta^{2} \pi P_{0}>0<\Delta T m_{0} \quad----$ 


\section{Advective Change of Mass}

The method employed above fails to distingush between the contribution to the density variation which takes place at a given level as a result of processes at that level and the contribution to the density variation which results from compression or expansion produced by density changes at some other level. This locally produced contribution can be approximated by the application of Rossby's advective formula referred to in Chapter I. The results obtained by applying this method to the mean interdiurnal pressure variations are presented by the $\delta^{2} \pi$ curves in Fig. 19.

In general the essential features of the $\delta^{2} \pi$ curves are the same as those of the $\Delta(\delta P)$ curves. In the case of $\Delta P_{0}>0>\Delta T_{m o}$ the density increase below the isopycnic level and the decrease in the layer above the isopycnic level are magnified and now assume more nearly the true proportions of the actual density variations at those levels. The difference between the two types of curves is particularly noticeable in the case of $\Delta P_{0}>0<\Delta T_{m o}$ where the depletion of mass in the lower levels is now very appreciable. This means, for example in the case of Fairbanks, that in about one-half of the cases of pressure rise at the surface (see Table IV) the controlling factor was an increase in the density of the air above eight kilometers. This increase of density aloft was large enough to offset the decrease below eight kilometers and still provide a net accumulation of mass for a column of unit cross section over the station.

The significance of this distribution of density variations is brought out in. Table VII in which are tabulated the surface pressure changes and the cumulative contributions to those pressure changes by the layers from the surface up to four, eight, ten, twelve and fourteen kilometers for the $\Delta P_{0}>0>T_{m o}$ and the $\Delta P_{0}>0<\Delta T_{m o}$ groups. In Table VIII the data refer to the actual density variations while in Table VII are tabulated the data computed from the Rossby advective changes. From this latter table it should be noted that for the group $\Delta P_{0}>0<\Delta T_{\text {mo, }}$, the cumulative effect up to twelve kilometers is negative for every station except Portland. This means that the particular density variations which controlled the surface pressure change were located well up in the atmosphere. This is significant because these curves are averages of a type of pressure distribution which comprises one-fourth to one-half of the total cases of rising pressure at the stations with which we are concerned.

Similar conclusions could be drawn from an analysis of the groups characterized by falling pressure at the surface. 


\section{TABLE VII}

Surface Pressure Changes and the Cumulative Contributions to those Pressure Changes by the Layers from the Surface up to Four, Eight, Ten, Twelve and Fourteen Kilometers. (Rossby advective changes)

\begin{tabular}{|c|c|c|c|c|c|c|c|}
\hline & & $\Delta P_{0}$ & $\begin{array}{l}4 \mathrm{~km} \\
\Sigma \delta^{2} \pi \\
0\end{array}$ & $\begin{array}{l}8 \mathrm{~km} \\
\Sigma \delta^{2} \pi \\
0\end{array}$ & $\begin{array}{l}10 \mathrm{~km} \\
\Sigma \delta^{2} \pi \\
0\end{array}$ & $\begin{array}{l}12 \mathrm{~km} \\
\Sigma \delta^{2} \pi \\
0\end{array}$ & $\begin{array}{l}14 \mathrm{~km} \\
\Sigma \delta^{2} \pi \\
0\end{array}$ \\
\hline $\mathrm{FX}$ & $\begin{array}{l}\Delta P_{0}>0>\Delta T_{m 0} \\
\Delta P_{0}>0<\Delta T_{m 0}\end{array}$ & $\begin{array}{l}+8.7 \\
+4.9\end{array}$ & $\begin{array}{l}+6.2 \\
-3.2\end{array}$ & $\begin{array}{r}+11.1 \\
-7.0\end{array}$ & $\begin{array}{r}+11.8 \\
-5.8\end{array}$ & $\begin{array}{r}+10.5 \\
-2.4\end{array}$ & $\begin{array}{l}\cdots \\
\cdots\end{array}$ \\
\hline RK & $\begin{array}{l}\Delta P_{0}>0>\Delta T_{m_{0}} \\
\Delta P_{0}>0<\Delta T_{m 0}\end{array}$ & $\begin{array}{l}+6.8 \\
+4.2\end{array}$ & $\begin{array}{l}+6.4 \\
-4.2\end{array}$ & $\begin{array}{l}+9.1 \\
-5.4\end{array}$ & $\begin{array}{l}+7.0 \\
-2.9\end{array}$ & $\begin{array}{l}+6.0 \\
-0.1\end{array}$ & $\begin{array}{l}+5.0 \\
+1.3\end{array}$ \\
\hline $\mathrm{OH}$ & $\begin{array}{l}\Delta P_{0}>0>\Delta T_{m 0} \\
\Delta P_{0}>0<\Delta T_{m 0}\end{array}$ & $\begin{array}{l}+8.3 \\
+2.4\end{array}$ & $\begin{array}{l}+5.3 \\
-0.5\end{array}$ & $\begin{array}{l}+7.2 \\
+0.7\end{array}$ & $\begin{array}{l}+7.1 \\
-0.7\end{array}$ & $\begin{array}{l}+7.3 \\
-1.0\end{array}$ & $\begin{array}{l}+8.2 \\
-0.6\end{array}$ \\
\hline EO & $\begin{array}{l}\Delta P_{0}>0>\Delta T_{m 0} \\
\Delta P_{0}>0<\Delta T_{m 0}\end{array}$ & $\begin{array}{l}+4.5 \\
+2.7\end{array}$ & $\begin{array}{l}+3.5 \\
-3.4\end{array}$ & $\begin{array}{l}+7.5 \\
-8.2\end{array}$ & $\begin{array}{l}+7.8 \\
-9.5\end{array}$ & $\begin{array}{l}+6.8 \\
-6.2\end{array}$ & $\begin{array}{l}+6.2 \\
-2.9\end{array}$ \\
\hline VC & $\begin{array}{l}\Delta P_{0}>0>\Delta T_{m_{0}} \\
\Delta P_{0}>0<\Delta T_{m_{0}}\end{array}$ & $\begin{array}{l}+8.3 \\
+5.1\end{array}$ & $\begin{array}{l}+4.2 \\
-2.8\end{array}$ & $\begin{array}{l}+5.7 \\
-2.9\end{array}$ & $\begin{array}{l}+6.8 \\
-2.9\end{array}$ & $\begin{array}{l}+8.2 \\
-0.3\end{array}$ & $\begin{array}{l}+8.9 \\
+1.9\end{array}$ \\
\hline LS & $\begin{array}{l}\Delta P_{0}>0>\Delta T_{m_{0}} \\
\Delta P_{0}>0<\Delta T_{m_{0}}\end{array}$ & $\begin{array}{l}+7.8 \\
+3.6\end{array}$ & $\begin{array}{l}+8.2 \\
-6.3\end{array}$ & $\begin{array}{l}+11.5 \\
-10.3\end{array}$ & $\begin{array}{r}+11.6 \\
-9.0\end{array}$ & $\begin{array}{l}+9.3 \\
-2.6\end{array}$ & $\begin{array}{l}+9.0 \\
\cdots\end{array}$ \\
\hline PW & $\begin{array}{l}\Delta P_{0}>0>\Delta T_{m 0} \\
\Delta P_{0}>0<\Delta T_{m 0}\end{array}$ & $\begin{array}{r}+10.1 \\
+6.6\end{array}$ & $\begin{array}{l}+5.1 \\
-2.2\end{array}$ & $\begin{array}{l}+9.6 \\
-1.0\end{array}$ & $\begin{array}{r}+12.2 \\
+0.3\end{array}$ & $\begin{array}{r}+10.7 \\
+3.3\end{array}$ & $\begin{array}{l}\cdots \\
\cdots\end{array}$ \\
\hline WA & $\begin{array}{l}\Delta P_{0}>0>\Delta T_{m_{0}} \\
\Delta P_{0}>0<\Delta T_{m_{0}}\end{array}$ & $\begin{array}{r}+11.7 \\
+6.6\end{array}$ & $\begin{array}{l}+8.7 \\
-3.4\end{array}$ & $\begin{array}{r}+11.9 \\
-3.8\end{array}$ & $\begin{array}{l}\cdots \\
-4.6\end{array}$ & $\cdots$ & $\begin{array}{l}\cdots \\
\cdots\end{array}$ \\
\hline $\mathrm{MM}$ & $\begin{array}{l}\Delta P_{0}>0>\Delta T_{m_{0}} \\
\Delta P_{0}>0<\Delta T_{m_{0}}\end{array}$ & $\begin{array}{l}+4.2 \\
+2.4\end{array}$ & $\begin{array}{l}+3.0 \\
-1.3\end{array}$ & $\begin{array}{l}+3.0 \\
-2.7\end{array}$ & $\begin{array}{l}+4.8 \\
-4.7\end{array}$ & $\begin{array}{l}+4.1 \\
-4.5\end{array}$ & $\begin{array}{l}+5.1 \\
-2.9\end{array}$ \\
\hline
\end{tabular}




\section{TABLE VIII}

Surface Pressure Changes and the Cumulative Contributions to those Pressure Changes by the Layers from the Surface up to Four, Eight, Ten, Twelve and Fourteen Kilometers. (Actual density changes)

\begin{tabular}{|c|c|c|c|c|c|c|c|}
\hline & & $\Delta P_{0}$ & $\begin{array}{c}4 \mathrm{~km} \\
\Sigma \Delta(\delta p) \\
0\end{array}$ & $\begin{array}{c}8 \mathrm{~km} \\
\Sigma \Delta(\delta p) \\
0\end{array}$ & $\begin{array}{c}10 \mathrm{~km} \\
\Sigma \Delta(\delta p) \\
0\end{array}$ & $\begin{array}{c}12 \mathrm{~km} \\
\Sigma \Delta(\delta p) \\
0\end{array}$ & $\begin{array}{c}14 \mathrm{~km} \\
\Sigma \Delta(\delta p) \\
\mathbf{0}\end{array}$ \\
\hline $\mathrm{FX}$ & $\begin{array}{l}\Delta P_{0}>0>\Delta T_{m 0} \\
\Delta P_{0}>0<\Delta T_{m 0}\end{array}$ & $\begin{array}{l}+8.7 \\
+4.9\end{array}$ & $\begin{array}{l}+7.4 \\
-0.9\end{array}$ & $\begin{array}{r}+10.2 \\
-1.0\end{array}$ & $\begin{array}{r}+10.1 \\
+0.3\end{array}$ & $\begin{array}{l}+9.4 \\
+2.7\end{array}$ & $\cdots$ \\
\hline $\mathrm{RK}$ & $\begin{array}{l}\Delta P_{0}>0>\Delta T_{m 0} \\
\Delta P_{0}>0<\Delta T_{m_{0}}\end{array}$ & $\begin{array}{l}+6.8 \\
+4.2\end{array}$ & $\begin{array}{l}+7.1 \\
-1.9\end{array}$ & $\begin{array}{l}+8.4 \\
-0.7\end{array}$ & $\begin{array}{l}+7.4 \\
+1.2\end{array}$ & $\begin{array}{l}+7.0 \\
+2.7\end{array}$ & $\begin{array}{l}+6.8 \\
+3.4\end{array}$ \\
\hline $\mathrm{OH}$ & $\begin{array}{l}\Delta P_{0}>0>\Delta T_{m_{0}} \\
\Delta P_{0}>0<\Delta T_{m_{0}}\end{array}$ & $\begin{array}{l}+8.3 \\
+2.4\end{array}$ & $\begin{array}{l}+6.7 \\
+0.4\end{array}$ & $\begin{array}{l}+7.9 \\
+1.7\end{array}$ & $\begin{array}{l}+8.0 \\
+1.3\end{array}$ & $\begin{array}{l}+8.1 \\
+1.4\end{array}$ & $\begin{array}{l}+8.3 \\
+1.5\end{array}$ \\
\hline EO & $\begin{array}{l}\Delta P_{0}>0>\Delta T_{m 0} \\
\Delta P_{0}>0<\Delta T_{m 0}\end{array}$ & $\begin{array}{l}+4.5 \\
+2.7\end{array}$ & $\begin{array}{l}+4.2 \\
-1.7\end{array}$ & $\begin{array}{l}+6.1 \\
-3.0\end{array}$ & $\begin{array}{l}+7.0 \\
-2.4\end{array}$ & $\begin{array}{l}+6.8 \\
-0.6\end{array}$ & $\begin{array}{l}+6.6 \\
+0.8\end{array}$ \\
\hline VC & $\begin{array}{l}\Delta P_{0}>0>\Delta T_{m 0} \\
\Delta P_{0}>0<\Delta T_{m_{0}}\end{array}$ & $\begin{array}{l}+8.3 \\
+5.1\end{array}$ & $\begin{array}{l}+6.0 \\
-0.7\end{array}$ & $\begin{array}{l}+7.4 \\
+0.9\end{array}$ & $\begin{array}{l}+8.0 \\
+1.7\end{array}$ & $\begin{array}{l}+8.3 \\
+3.1\end{array}$ & $\begin{array}{l}+8.5 \\
+3.9\end{array}$ \\
\hline LS & $\begin{array}{l}\Delta P_{0}>0>\Delta T_{m 0} \\
\Delta P_{0}>0<\Delta T_{m 0}\end{array}$ & $\begin{array}{l}+7.8 \\
+3.6\end{array}$ & $\begin{array}{l}+8.9 \\
-3.6\end{array}$ & $\begin{array}{r}+10.1 \\
-3.5\end{array}$ & $\begin{array}{l}+9.6 \\
-1.7\end{array}$ & $\begin{array}{l}+8.6 \\
+1.3\end{array}$ & $\begin{array}{l}\cdots \\
\cdots\end{array}$ \\
\hline $\mathrm{PW}$ & $\begin{array}{l}\Delta P_{0}>0>\Delta T_{m 0} \\
\Delta P_{0}>0<\Delta T_{m 0}\end{array}$ & $\begin{array}{r}+10.1 \\
+6.6\end{array}$ & $\begin{array}{l}+7.3 \\
+0.2\end{array}$ & $\begin{array}{r}+10.3 \\
+1.9\end{array}$ & $\begin{array}{c}+11.3 \\
+3.3\end{array}$ & $\begin{array}{r}+10.6 \\
+5.1\end{array}$ & $\begin{array}{l}+9.9 \\
+6.6\end{array}$ \\
\hline WA & $\begin{array}{l}\Delta P_{0}>0>\Delta T_{m_{0}} \\
\Delta P_{0}>0<\Delta T_{m_{0}}\end{array}$ & $\begin{array}{r}+11.7 \\
+6.6\end{array}$ & $\begin{array}{r}+10.6 \\
-1.0\end{array}$ & $\begin{array}{r}+12.5 \\
+0.7\end{array}$ & $\begin{array}{l}\cdots \\
\cdots\end{array}$ & $\begin{array}{l}\cdots \\
\cdots\end{array}$ & $\cdots$ \\
\hline $\mathrm{MM}$ & $\begin{array}{l}\Delta P_{0}>0>\Delta T_{m_{0}} \\
\Delta P_{0}>0<\Delta T_{m_{0}}\end{array}$ & $\begin{array}{l}+4.2 \\
+2.4\end{array}$ & $\begin{array}{l}+3.5 \\
-0.4\end{array}$ & $\begin{array}{r}+3.6 \\
0\end{array}$ & $\begin{array}{l}+4.4 \\
-0.2\end{array}$ & $\begin{array}{l}+4.1 \\
+0.3\end{array}$ & $\begin{array}{l}+4.5 \\
+1.0\end{array}$ \\
\hline
\end{tabular}




\section{CHAPTER V \\ INTERPRETATIONS AND CONCLUSIONS}

\section{The Interdiurnal Pressure Variations}

The significant characteristics of the interdiurnal pressure variation curves can be conveniently summarized by preparing idealized profiles, based on the general description of these curves given in Chapter II. The minor irregularities which characterized the actual profiles will be omitted, because, for the most part, they have no evident significance and usually result from the fact that the number of observations decreases with increasing elevation. Attention will be confined to the groups characterized by rising surface pressure, since the corresponding curves for cases of falling surface pressure can always be inferred by analogy.

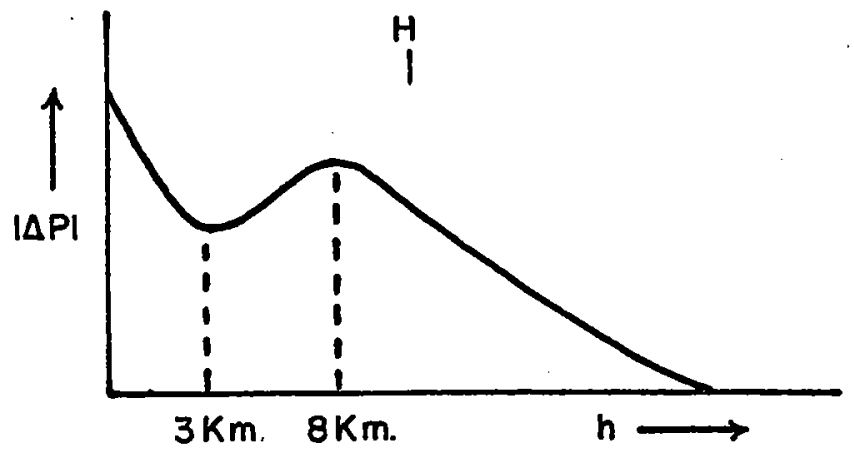

Fig. 20. Idealized $|\Delta P|$ profile.

The typical $|\Delta P|$ curve for all data at a representative station in temperate latitudes would appear to be similar to that shown in Fig. 20.

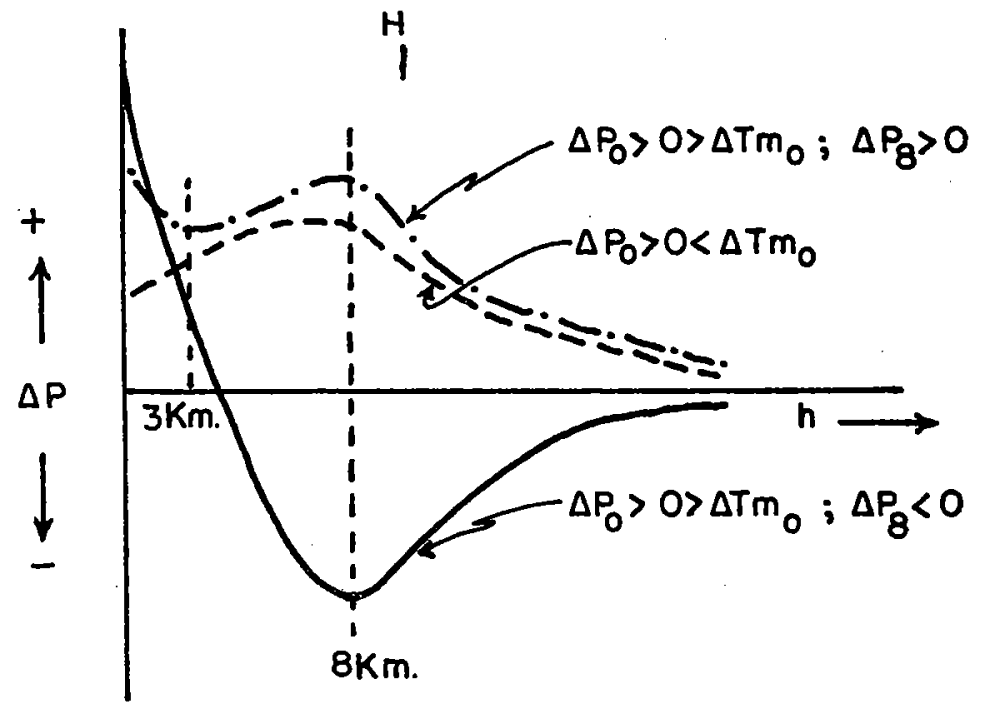

Fig. 21. Idealized $\Delta P$ profiles. 
The corresponding $\Delta P$ curves can be represented by the three profiles in Fig. 21 . An explanation for the shape of these pressure variation profiles can be offered either on the basis of variations of the temperature or of the density. Since density variations are very simply related to the pressure variations they will be considered. The density variation curves have been idealized after Fig. 19 and are presented in Fig. 22.

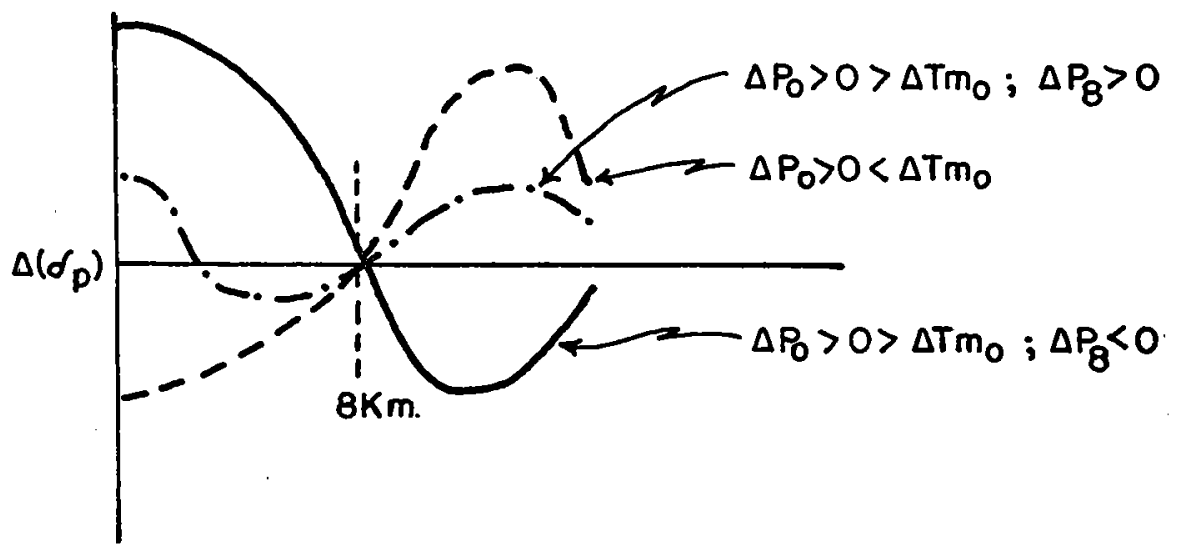

Fig. 22. Idealized density variation curves.

The surface pressure variation is thus seen to be produced by a total mass variation - in a column of unit horizontal cross section - which represents the difference between either (1) an increase of mass below and a decrease of mass above the isopycnic level, or (2) a decrease of mass below and an increase of mass above the isopycnic level. This second possibility may be complicated by increasing density in the surface layers. The density variations below the isopycnic level control the surface pressure change for the cases where $\Delta P_{0}>0>\Delta T_{m o} ; \Delta P_{8}<0$. For the groups $\Delta P_{0}>0<\Delta T_{m o}$, the density variation above eight kilometers is dominant in determining the pressure variation at the surface. There may be some uncertainty in the case of $\Delta P_{0}>0>\Delta T_{m a}$; $\Delta P_{8}>0$, although the data for Omaha (Fig. 19) would suggest that here also the density variations above eight kilometers exert relatively greater influence than the net density variation below this level. These density changes may be produced through the combined effects of horizontal advection and vertical motion or as the results of either one of these factors operating in the absence of the other.

The phase relationship between the density variations above and those below the isopycnic level account for the profiles of the $|\Delta P|$ and the $\Delta P$ curves. This can be illustrated by considering: (1) the effects of a density variation above eight kilometers with no changes below that level except those which result directly from the diminution of mass aloft, and (2) the effects of a density variation below eight kilometers with no change above that level except that which results from the variation in the lower layers.

When the density change above eight kilometers is negative, the pressure at that level must fall. Assuming no change below eight kilometers except that which is produced by the decreasing density aloft, there will be a surface pressure change of the same magnitude as the individual pressure change in the vicinity of eight kilometers. The local pressure changes at successively higher elevations above the surface will show decreasing magnitudes until at eight kilometers the local change would be, according to the Rossby advective formula, just one half as large as the pressure variation at the surface. The resulting pressure variation profile would have the form of curve A in Fig. 23. 


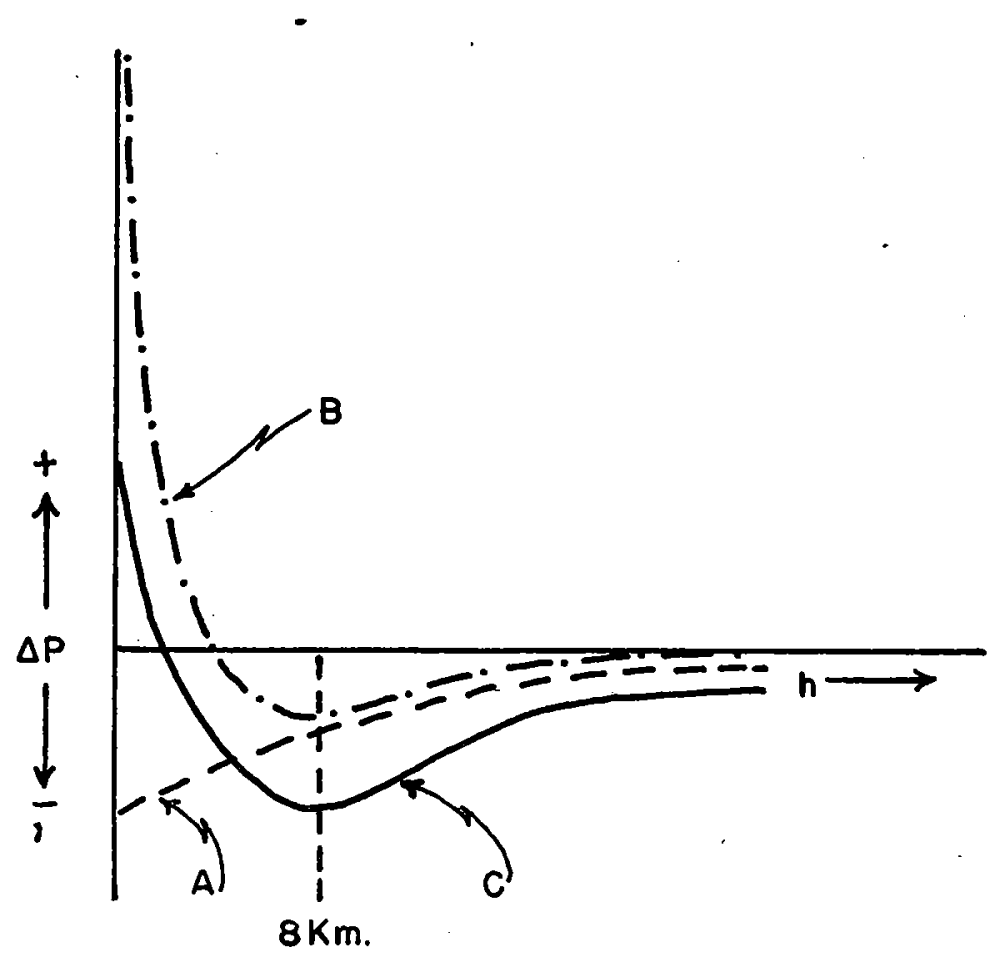

Fig. 23. Idealized pressure variation curves for specified density variations (see text).

If, instead of a decrease in density aloft, there had been an increase in density below eight kilometers by a process which effectively replaced the air column below that level with one which was denser and shorter than the original, the pressure variation profile would resemble curve $B$ in Fig. 23. In this case there would be a negative local variation of pressure at eight kilometers, since the process now visualized requires that the air above eight kilometers descends a distance equal to the difference between the heights of the original air column helow eight kilometers and the shorter and denser column which replaced it.

If these two processes take place simultaneously with the largest density variation in the lower layer, the resulting profile will be represented by curve $\mathrm{C}$ in Fig. 23. Curve $\mathrm{C}$ is obtained by adding curve $A$ to curve $B$. It is similar to the actual $\Delta P$ curve for $\Delta P_{0}>0>\Delta T_{m o} ; \Delta P_{8}<0$ at Omaha as shown in Fig. 17. It is obvious that a similar discussion for the $\Delta P_{0}>0>\Delta T_{m o} ; \Delta P_{8}>0$ and the $\Delta P_{0}>0<\Delta T_{m o}$ groups would lead to idealized pressure variation profiles (Fig. 21) which would approximate the actual curves (e.g. Fig. 17). The $|\Delta P|$ curve in Fig. 20 can be obtained directly by combining the three curves of Fig. 21 , since the absolute and algebraic variations are nearly the same when the data are divided into those three groups.

From the foregoing discussion it is apparent that the isopycnic level is a rather critical height separating two sets of similar processes which act in opposite senses and tend to compensate each other. For example, in the case of the mean pressure variation at Omaha represented by the $\Delta P_{0}>0>\Delta T_{m 0} ; \Delta P_{8}<0$ curve of Fig. 17, if there had been no change below eight kilometers and the pressure variations aloft had taken place as represented, the surface pressure would have fallen nine millibars instead of rising about nine millibars. Conversely, if the only changes had been below eight kilometers with no compensating changes aloft, the surface pressure would have risen about eighteen millibars instead of nine millibars. It appears that the processes affecting 
density changes aloft deserve as much attention as those influencing the density variations in the lower levels - even for the case of $\Delta P_{0}>0>\Delta T_{m o} ; \Delta P_{8}<0$ where the largest variations take place below the isopycnic level.

In the idealized models of the density variations presented above there is one inconsistency with actual conditions, and that arises from the fact that the simple processes described there do not satisfy the condition that density remains constant with time at about eight kilometers. When both processes were combined there was still a decrease of density at eight kilometers. This suggests that there should be ascending motion relative to the isobaric surfaces - a process which would tend to stabilize the density at its original value. This aspect of the problem will be discussed at greater length in a later paragraph.

\section{The Interdiurnal Temperature Variations}

The most interesting characteristic of the $|\Delta T|$ curves is the existence of a triple maxima as shown in Fig. 24. The primary maximum at the surface is clearly the result of horizontal advection in the surface layers where there are frequently larger horizontal temperature gradients than are found at higher elevations. The minimum at the height of the tropopause can also be explained on the basis of horizontal advection. The explanation can be facilitated by reference to Fig. $\mathbf{2 5}$. The temperature height curve labeled $\mathrm{A}$ represents the vertical distribution of temperature for a given station at the beginning of a twenty-four hour period and the curve $B$ represents the conditions there at the end of the period. If horizontal advection is assumed to be responsible for the temperature changes, it is apparent that there will be no interdiurnal temperature variation at the point of intersection of the two curves. This point will lie somewhere between the heights of the tropopause at the beginning and at the end of the period. Over a large number of cases the height of this point will show considerable variation so that there will be a small temperature change at all points in the vicinity of the mean position of the tropopause. Vertical motion may also account for some of the observed temperature variation at this elevation. However, the effect of horizontal advection will be to establish a minimum in the absolute temperature variation profile at about the mean height of the tropopause.

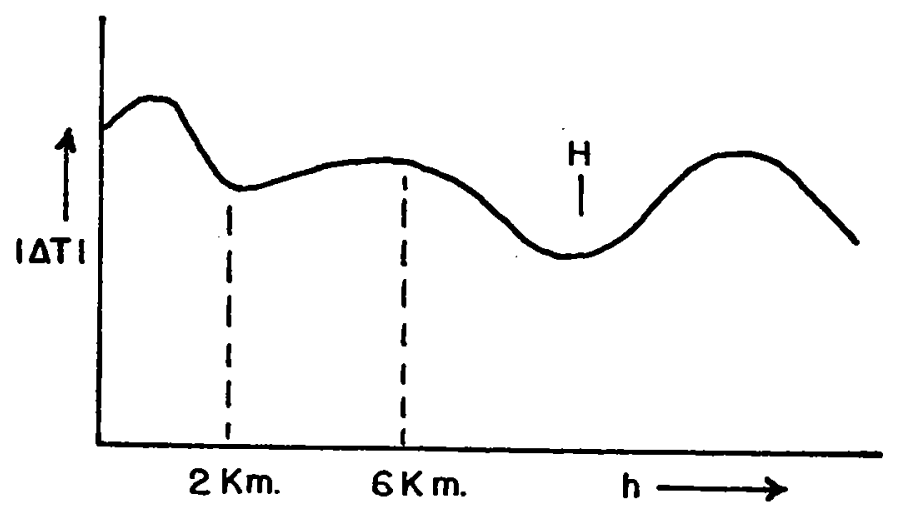

Fig. 24. Idealized $|\Delta T|$ profile.

In Fig. 24, the idealized $|\Delta T|$ curve shows slightly higher values above the tropopause than below it." The evidence for this in the original $|\Delta T|$ curves in Fig. 2 is not at all conclusive, although it is suggested by the data at several stations. In those cases where the largest variations do occur in the stratosphere, it is very likely that an explanation can be offered which would be based on the greater effect of vertical motion on temperature changes above the tropopause where the 


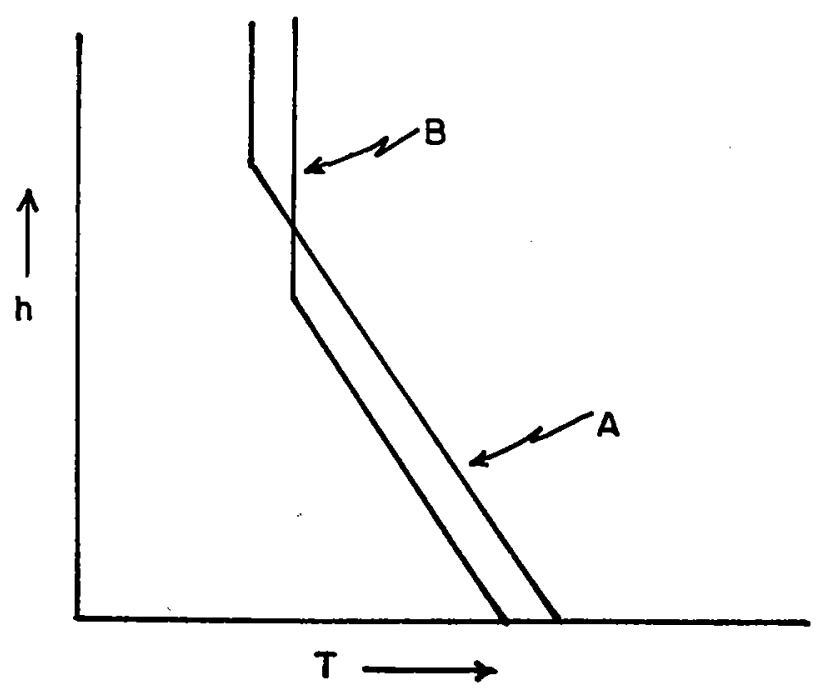

Fig. 25. Idealized temperature height curves.

stability is greater than below the tropopause where the stability is much less. It becomes increasingly evident in trying to explain the characteristics of the $|\Delta T|$ curves at upper levels that both horizontal advection and vertical motion have to be considered.

The minimum in the $|\Delta T|$ curves at a height of about two kilometers may also be largely the result of vertical motion. Examination of the $\Delta T$ curves for rising pressure at the surface reveals. that, in many cases, the characteristically large negative temperature variations at the surface decrease in magnitude with great rapidity in the first two or three kilometers and then at a more moderate rate immediately above. There seems to be an interruption in the rate at which the interdiurnal temperature variations decrease with elevation and this interruption takes the form of decreased temperature falls at two kilometers in the case of rising prèssure. There is a similar condition for $\Delta P_{0}<0$, except that here the rate at which the positive temperature variations decrease with elevation is accelerated between one and two kilometers. In the case of rising surface pressure, descending motion would produce such a condition and for falling pressure ascending motion offers a convenient explanation. These possibilities are in accord with the impressions gained from a study of synoptic maps and are also consistent with certain aspects of the mean lapse rates. For example, consider the mean lapse rates for Bismarck and E1 Paso during February 1941, 1942, 1943 which have been plotted in Fig. 26. The lapse rate at Bismarck is far more stable below three kilometers than that at El Paso. This would imply that for the same vertical velocity in the vicinity of one or two kilometers there would be a greater temperature change at Bismarck than at E1 Paso. A comparison of the $|\Delta T|$ curves in Fig. 2 for these two stations reveals that there is a definite minimum in the lower troposphere at Bismarck and that it is conspicuously absent at El Paso. Although other factors must certainly enter into the picture, these results are at least consistent with the interpretation that the lower tropospheric minimum in the $|\Delta T|$ curves can be attributed to the effects of vertical motion.

\section{Some Implications of the Constancy of Density at Eight Kilometers*}

A particularly significant feature of the $|\Delta P|$ curves is the existence of an upper leve1 maximum at a level which is located one or two kilometers below the mean height of the tropo-

*The Irish Meteorological Service has distributed some advance issues of papers by M. Doporto in which he deals extensively with the constancy of density at $8 \mathrm{~km}$. 


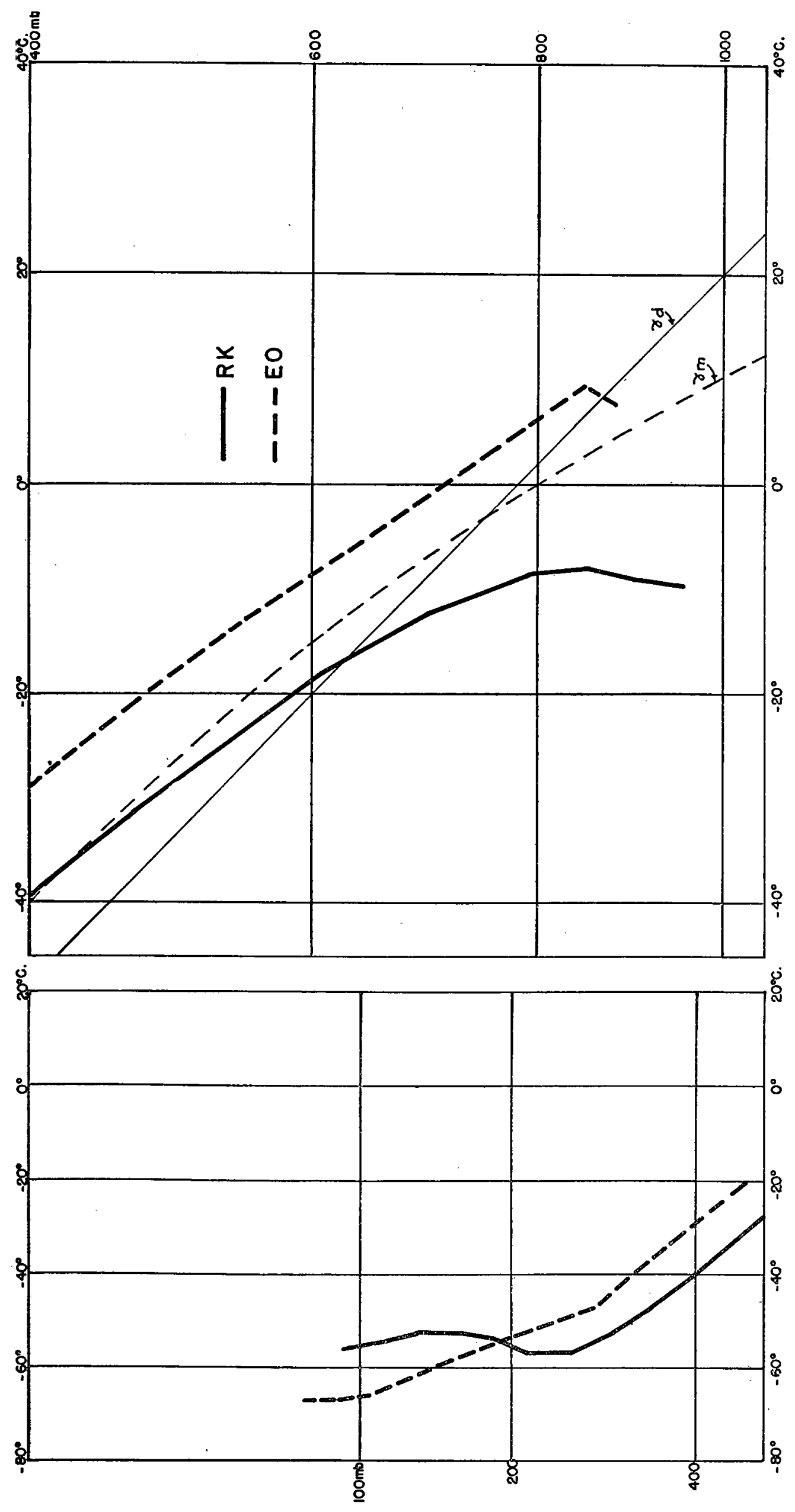


pause. (The standard deviation of the mean height of the tropopause ranges between one and two kilometers over North America.) This coincides with the level of minimum density variation and it is interesting to note that at about this same level, the horizontal gradient of density is negligibly small. Certain conclusions can be drawn regarding the type of vertical motion to be expected as a result of this combination of circumstances.

If conditions are idealized to the extent that at eight kilometers there is absolutely no variation in density, the horizontal gradient of density is exactly zero, and there is an upper level maximum in the interdiurnal variability of pressure, a relatively simple picture of conditions there ensues. The isotherms and the isobars at that level are coincident and therefore the horizontal advection of the temperature field is zero. Since there are large pressure changes at this level there must be associated temperature changes if the density is to be maintained constant. These temperature changes may be the result of vertical motion or of horizontal deviations from the gradient wind. The deviations from the gradient wind in a field of changing pressure distribution are very difficult to evaluate and since they seem to be rather intimately associated with vertical motion, the assumption, will be made here that the local temperature variations, necessary to maintain isopycnic conditions, result from vertical motion relative to the isobars.

The processes which take place at eight kilometers can readily be illustrated by an example. Assuming an interdiurnal pressure variation consistent with the values at that level in Fig. 1, let the pressure vary from $360 \mathrm{mb}$ to $365 \mathrm{mb}$ over a twenty-four-hour period. This change may be effected by adding mass above nine kilometers and keeping the air unchanged below eight kilometers (except for the effects of compression), or it may be accomplished by effectively removing the column of air below seven kilometers and replacing it with a lighter, taller column and maintaining the column above that level unchanged (except for the bodily lifting to accommodate the new underlying layer of air). Actually these two methods of effecting a pressure change at eight kilometers go on simultaneously, but they will be considered separately for the moment.

Consider the first of the two processes suggested above. The individual pressure change at eight kilometers corresponding to a $5 \mathrm{mb}$ local variation is approximately $10 \mathrm{mb}$ according to the Rossby advective formula given on page 10. The substantial layer of air which was originally under a $355 \mathrm{mb}$ pressure at some height above eight kilometers is now placed under a $365 \mathrm{mb}$ pressure and carried down to eight kilometers. The temperature change at eight kilometers resulting from this adiabatic process would be

$$
\begin{gathered}
\Delta T_{1}=0.288 T / p d p-\frac{\delta T}{\delta z} \delta z \\
=0.288 T / p d p+0.0287 T / p \frac{\delta T}{\delta z} \delta p
\end{gathered}
$$

where $\Delta T_{1}=$ local temperature change at $8 \mathrm{~km}$ resulting from the increase of mass above that level

$T=$ temperature

$p=$ pressure

$d p=$ individual pressure change on the air parcels during the adiabatic compression

$\frac{\delta T}{\delta z}=$ lapse rate of temperature

$\delta z=$ height difference between eight kilometers and the original position of the air parcels which move down to $8 \mathrm{~km}$

$\delta p=$ pressure difference over the height interval $\delta z$

The temperature change which is necessary to maintain a constant density at eight kilometers can be obtained by differentiating the equation of state logarithmically, which gives 


$$
\frac{\partial T_{2}}{\partial t}=T / p \frac{\partial p}{\partial t}=\Delta T_{2}
$$

where $\frac{\partial T_{2}}{\partial t}=$ local temperature change at $8 \mathrm{~km}$ necessary to keep the density constant

$$
\begin{aligned}
T & =\text { temperature } \\
p & =\text { pressure } \\
\frac{\partial p}{\partial t} & =\text { local pressure variation at } 8 \mathrm{~km}
\end{aligned}
$$

The difference between these two expressions for temperature change is the amount by which the temperature must vary locally as a result of vertical movement relative to the isobars - a type of motion whch implies two accelerational fields at different levels, one producing convergence below the level of the vertical motion and another producing divergence above this level. The temperature change resulting from this type of vertical motion may be expressed as

$$
\Delta T_{3}=-V_{2}\left(\frac{\delta T}{\delta z}+10\right)
$$

where $V_{\mathrm{s}}=$ vertical velocity in $\mathrm{km} / 24 \mathrm{hrs}$. at $8 \mathrm{~km}$

$$
\frac{\delta T}{\delta z_{3}}=\text { lapse rate of temperature in }{ }^{\circ} \mathrm{C} / \mathrm{km}
$$

$\Delta T_{3}=$ local temperature change at $8 \mathrm{~km}$ as a result of the vertical motion relative to the isobars

Assuming a lapse rate of $7^{\circ} \mathrm{C} / \mathrm{km}$ and letting the pressure be $360 \mathrm{mb}$ and the temperature $-33^{\circ} \mathrm{C}$ $(d p=10 \mathrm{mb} ; \partial p=\delta p=5 \mathrm{mb})$, it is possible to solve for the vertical velocity by combining the preceding three equations

$$
\begin{aligned}
\Delta T_{3} & =\Delta T_{2}-\Delta T_{1} \\
-V_{z}\left(\frac{\delta T}{\delta z}+10\right) & =T / p\left(\partial p-0.288 \mathrm{~d} p-0.0287 \frac{\delta T}{\delta z} \delta p\right) \\
V_{z} & =-0.65 \mathrm{~km} / 24 \mathrm{hrs}
\end{aligned}
$$

Now considering the process in which the primary changes lie below eight kilometers. In this case the local temperature change at eight kilometers resulting from bodily lifting of the air column above seven kilometers will be

$$
\Delta T_{1}=\frac{\delta T}{\delta z} \delta z=-0.0287 T / p \frac{\delta T}{\delta z} \delta p
$$

and the equation giving the vertical velocity will be

$$
-V_{z}\left(\frac{\delta T}{\delta z}+10\right)=T / p\left(\partial p+0.0287 \frac{\delta T}{\delta z} \delta p\right)
$$

and using the same numerical values as before

$$
V_{\mathrm{z}}=-0.88 \mathrm{~km} / 14 \mathrm{hrs}
$$

The density variation curves (Fig. 19) suggest that the actual processes in the atmosphere are a combination of the two which formed the basis for these computations, so it seems plausible to conclude that pressure rises at eight kilometers are accompanied by descending velocities and that the approximate magnitude of this motion is about 0.7 to $0.8 \mathrm{~km} / 24 \mathrm{hrs}$ for each five millibars of pressure change. A similar example for the case of falling pressure at that level would lead to the conclusion that the vertical velocity is then positive and of about the same magnitude. 
It would seem from the foregoing remarks that the pressure at eight kilometers should be negatively correlated with the height of the tropopause. No correlations coefficients have been worked out between these two variables; however, it has already been remarked that the correlation between the pressure at constant levels and the height of the tropopause increases with increasing elevation and correlation coefficients are available relating the pressure at nine kilometers to the height of the tropopause. These correlations between $P_{9}$ and $H$ are definitely positive - impressively so, however, only in the case of S. Ste. Marie. The correlations between $P_{5}$ and $H$ are also generally positive so that it seems correct to conclude that the pressure at eight kilometers is positively correlated with the height of the tropopause. What seems to be an inconsistency between the physical picture and the statistical check can be explained by the fact that the tropopause is not a level surface, but is frequently sharply inclined to the horizontal and advection in the horizontal direction may easily cause local variations in its height which are greater than those obtained as the result of vertical motion. Some idea of the probable magnitude of these variations can be obtained by considering a tropopause having a slope of 1:250 (this figure is an estimated average, based on some contour maps of the tropopause over Europe presented by J. Bjerknes and Palmen [23]). A horizontal wind component of approximately ten miles per hour along the gradient of the tropopause contours would produce a twenty-four hour local variation of about twice the magnitude of that which computations suggest takes place when the pressure changes five millibars at eight kilometers.

It frequently happens that the pressure at eight kilometers is falling when the circulation favors movement of a lower tropopause over a station and rising when horizontal advection of a higher tropopause is indicated. This suggests that the vertical motion pictured above acts as a "brake" on the local variation of the height of a tropopause at a given station. Some such mechanism is necessary in the typical case of a sinusoidal pattern of pressure at eight kilometers in which the speed of the wind is appreciably greater than the velocity at which the pressure wave is being propagated. In such a system there would be a tendency for the lower tropopause in the rear of the trough to be carried through the trough and on into the next wedge. However, as soon as a substantial line in the tropopause is carried past the trough line it enters a field of falling pressure and ascending motion. This field of positive vertical velocities may actually raise the tropopause or it may simply retard its rate of fall above a given station. Similar arguments apply in front of the wedge line. The correlation coefficients between $P_{9}$ and $H$ would suggest that more often than not the role of the vertical motion is merely to retard the advective effects rather than to completely overbalance them. It is only by virtue of such a field of vertical velocities that the contours of the tropopause are maintained in a fairly constant orientation relative to the isobar pattern in the usual moving pressure wave in the upper troposphere. It is noticeable that the highest correlations between $P_{9}$ and $H$ are encountered in middle latitudes where this type of pressure wave is more commonly observed than at lower latitudes where they are less frequent.

\section{The Significance of the Vertical Distribution of Density Variations FOR THE SGN $\Delta P_{0}=\operatorname{SGN} \Delta T_{m o}$ AND THE $\operatorname{SGN} \Delta P_{0} \neq \operatorname{SGN} \Delta T_{m o}$ GROUPS}

It is logical to expect that there should be a statistical relationship between rising surface pressure and falling temperatures in the lowest layers of the atmosphere. This is a natural consequence of the normal meridional gradient of temperature, the west to east movement of migratory cyclones and anticyclones, and the sense of the circulation around these pressure systems. The same reasoning would lead to the conclusion that cases where $\operatorname{sgn} \Delta P_{0}=\operatorname{sgn} \Delta T_{m o}$ represent, at least to some extent, certain types of cyclogenesis and anticyclogenesis. A wave cyclone in the late occlusion stage and still deepening or undergoing regeneration might very well show 
falling pressure at the surface and falling temperature in the lower troposphere in the western quadrant, particularly if the system were a slowly moving one. Similarly, an anticyclone which is undergoing so-called dynamic anticyclogenesis might very well show rising temperature and rising pressure in the surface layers of the western quadrant.

In view of these considerations, it is especially interesting that the data for the $\operatorname{sgn} \Delta P_{0}=\operatorname{sgn} \Delta T_{m o}$ group show that it is the density variations taking place at levels above eight kilometers which seem to be exerting the greatest influence on the surface pressure variations. It is not possible to determine from the data studied here whether the physical processes producing the large density variations in the stratosphere have their origin at those high levels or down in the lower troposphere. However, it should not be inferred that the primary accelerational field is located in the upper atmosphere simply because the largest density variations are taking place there. It is possible for an accelerational field in the lower atmosphere to produce density changes in the stratosphere which are larger than those observed in the immediate vicinity of the accelerational field itself. The significance of these density variations aloft is that they are associated with pressure changes at the surface and often in a sense opposite to that of the density variations in the lower troposphere.

The vertical distribution of density variations for the $\operatorname{sgn} \Delta P_{0} \neq \operatorname{sgn} \Delta T_{m o}$ groups substantiates the Bjerknes theory of coupling between the lower troposphere and the substratosphere for nascent wave cyclones [3]. The primary variations occur at low levels and the magnitudes of the variations diminish with increasing elevation. The surface pressure and temperature variations are also consistent with the typical conditions associated with an incipient wave cyclone.

\section{Summary of Results}

The principal results of this investigation may be summarized by laying down certain characteristic conditions in the free atmosphere which seem to be associated with pressure changes at the surface and which must be satisfied, in the mean, by any proposed mechanism for pressure changes.

(1) The interdiurnal variations of pressure show a primary maximum at the surface and a secondary maximum in the vicinity of eight kilometers, with a tropospheric minimum at about three kilometers. These variations are greater in winter than in summer and show more variability with height in winter than in summer. At low latitudes the variations are small in the surface layers and somewhat greater aloft. There is a slight difference in the rate at which the interdiurnal variations change with height between stations subject solely to continental influences and those exposed alternately to continental and maritime regimes. The variations along the vertical for the cases of rising surface pressure have symmetrical counterparts in the variations associated with falling surface pressure.

(2) The interdiurnal variations of temperature show three maxima: one at the surface, one just above the tropopause, and one in the middle troposphere. There are minima at two or three kilometers and at about the mean height of the tropopause. The temperature variations are less in summer than in winter and the distribution of maxima and minima along the vertical are less noticeable in summer than in winter, although there is a tendency for them to shift with the seasonal changes in the mean height of the tropopause. The variations are smaller at low latitudes than at temperate latitudes, but at low latitudes there is a tendency for larger variations in the upper troposphere and the stratosphere than in the lower troposphere.

(3) Any proposed mechanism for pressure changes must be adaptable to a subdivision of cases of rising and of falling pressure into groups based on the relation between the sign of the surface pressure change and the sign of the change in the mean temperature of the surface layers. For cases of $\operatorname{sgn} \Delta P_{0} \neq \operatorname{sgn} \Delta T_{m o}$, the mass variations which dominate the surface pressure change occur 
below a height of about eight kilometers and are sufficiently strong to more than compensate for mass variations of the opposite sense above eight kilometers. In the case of $\operatorname{sgn} \Delta P_{0}=\operatorname{sgn} \Delta T_{m o}$, the reverse is true, with the sign of the surface pressure variation consistent with the effect of the mass variations above eight kilometers and in contradiction to the mass variations below eight kilometers. This last case is not as frequent as the first; however, the ratio of the number of cases of $\operatorname{sgn} \Delta P_{0} \not \operatorname{sgn} \Delta T_{m o}$ to the number of cases of $\operatorname{sgn} \Delta P_{0}=\operatorname{sgn} \Delta T_{m o}$ varies considerably with geographical position.

(4) The density is nearly constant with respect to space and time at a height of about eight kilometers. This critical elevation is the location of the upper tropospheric maximum of interdiurnal pressure variation and is the line of demarcation above which the mass variations are of a sense opposite to those taking place below that level. The height of this isopycnic level is about one or two kilometers below the mean height of the tropopause in temperate latitudes.

(5) A pronounced increase in atmospheric stability is noted in the surface layers when $\Delta P_{0}>0>\Delta T_{m o}$ and a sharp decrease in the stability occurs at about the mean height of the tropopause when $\Delta P_{0}>0<\Delta T_{m o}$. Stability changes at these levels are of the opposite sense for cases of $\Delta P_{0}<0<\Delta T_{m o}$ and $\Delta P_{0}<0>\Delta T_{m o}$ respectively. Considerable variation in the stability changes at intermediate levels is encountered between different geographical locations.

(6) The field of vertical motion is closely associated with pressure variations. Rising surface pressure is generally accompanied by descending motion in the surface layers and falling pressure by ascending motion. At eight kilometers ascending motion is associated with falling pressure and descending motion with rising pressure. In the majority of cases, vertical motion produces temperature changes in the surface layers and at eight kilometers which are opposite to those concurrently being produced by horizontal advection.

(7) The correlations between the height of the tropopause and the pressures at constant levels show improvement with increasing elevation and these correlations are better in temperate latitudes than in low latitudes. The mean temperature between the surface and nine kilometers correlates well with the pressure at nine kilometers and poorly with the surface pressure. The correlation between this mean temperature and the height of the tropopause is moderately good.

\section{Suggestions for Future Research}

On the basis of the results of this study, the following recommendations are made with respect to future research:

(1) A worthwhile investigation would be an analysis of the upper air data which have been screened on the basis of the type of development which is occurring on the synoptic weather charts, e.g. classification of certain types of cyclogenesis, anticyclogenesis, and simple translation of pressure systems and a statistical study of the associated interdiurnal pressure and temperature variations in the free atmosphere.

(2) Subdivision of the data for similar statistical studies on the basis of the pressure changes at eight kilometers instead of on the relations between the sign of the surface pressure change and the change in the mean temperature of the lowest kilometer layer.

(3) Investigation of the physical nature of the accelerational fields in the atmosphere which might be responsible for the type of vertical motion which the present analysis indicates is associated with changing pressure at eight kilometers.

(4) More intensive investigation - on the basis of selected upper air data - of the physical background of the mass variations above twelve kilometers which frequently exert a controlling influence on surface pressure variations. 
VOL. IX, NO. 4. INTERDIURNAL PRESSURE AND TEMPERATURE VARIATIONS

\section{ACKNOWLEDGMENT}

The author wishes to thank Professors B. Haurwitz and H. C. Willett for their helpful suggestions and patient guidance during the course of this study. Grateful appreciation is expressed to Professor J. M. Austin for his advice and counsel and to Professor H. G. Houghton, Head of the Department of Meteorology, who made available clerical assistance to carry out part of the tedious computations. Mr. Lloyd Stevens, as Acting Chief, Statistics Division of the United States Weather Bureau, was very coöperative in providing copies of original upper air data. Miss Dorothy Green facilitated organization of the data by her skillful and efficient preparation of the many diagrams. 


\section{REFERENCES}

1. Stüve, F.: "Thermozyklogenese," Beiträge zur Physik der freien Atmosphäre, 13: 23, 1926.

2. Defant, A.: "Primäre und sekundäre - freie und erzwungene Druckwellen in der Atmosphäre," Sitz.-Ber. Ak. D. Wiss., Wien, Math. - Nat. K1., Abt. IIa, 135: 357, 1926.

3. Bjerknes, V., Bjerknes, J., Solberg, H., Bergeron, T.: "Physikalishe Hydrodynamik," Julius Springer, Berlin, 1933.

4. Wulf, O. and OBLoy, S.: "The Utilization of the Entire Course of Radiosonde Flights in Weather Diagnosis," U. of Chicago, Inst. of Meteor., Misc. Rep. No. 10, 1944.

5. BJerknes, J. and Holmboe, J.: "On the Theory of Cyclones," Journ. of Meteor., 1 and 2: 1, 1944.

6. Petterssen, S.: "Contribution to the Theory of Pressure Variation," Quat. Journ. Royal Meteor. Soc., 71: 56, 1945.

7. WeXler, H.: "Analysis of a Warm Front Type Occlusion," Mon. Wea. Rev., 63: 213, 1935.

8. Namias, J.: "Subsidence Within the Atmosphere," Harvard Meteor. Studies No. 2, 1934.

9. Willet , H. C.: "Discussion and Illustration of Problems Suggested by the Analysis of Atmospheric Cross Sections," M. I. T. Papers in Phys. Oceanography and Meteor., Vol. IV, No. 2, 1935.

10. Emmons, G.: "Atmospheric Structure over the Southern U. S., Dec. 30-31, 1937, Determined with the Aid of Sounding Balloon Observations," M. I. T. Meteor. Course Prof. Notes No. 9, 1935.

11. Wexler, H.: "The Cooling of the Atmosphere and the Structure of Pc Air," Mon. Wea. Rev., 64: $105,1936$.

12. Dines, W. H.: "Correlation and Regression Tables for the Upper Air," Beiträge zur Physik der freien Atmosphäre," 5: 213, 1913.

13. Schedler, A.: "Ueber den Einfluss der Lufttemperature in verschiedenen Höhen auf Luftdruckschwankungen am Boden," Beiträge zur Physik der freien Atmosphäre," 7: 88, 1917.

14. HaURwitz, B.: "Beziehungen zwischen Luftdruck- und Temperaturänderungen," Veröff. Geophys. Ins. Leipzig, 2 ser. 3:267, 1927.

15. Haurwitz, B. and Turnbuld, W.: "Relations between Interdiurnal Pressure and Temperature Variations in Troposphere and Stratosphere over North America," Can. Meteor. Mem. Vol. I, No. 3, 1938.

16. Haurwitz, B. and Turnbuld, W.: "Die Vertikale Verteilung der Interdiurnen Luftdruckund Temperaturschwankungen in Troposphäre und Stratosphäre über Europa und NordAmerika," Met. Z. 55: 147, 1938.

17. Haurwitz, B. and Haurwitz, E.: "Pressure and Temperature in the Free Atmosphere over Boston," Harvard Meteor. Studies No. 3, 1939.

18. Penner, C. M.: "The Effects of Tropospheric and Stratospheric Advection on Pressure and Temperature Variations," Can. Journ. of Research, XIX: 1 Sec. A, 1941.

19. Willetr, H.: "Descriptive Meteorology," p. 64, Academic Press, Inc., New York, 1944.

20. Rossby, C. G.: "Studies in the Dynamics of the Stratosphere," Beiträge zur Physik der freien Atmosphäre, 14: 240, 1926.

21. ERTEL and SJAN-ZSI Li: "Der Advektionsmechanismus der Atmosphärischen Druckschwankungen," Zeit. für Physik, 94: 661, 1935.

22. SEN, S. N.: "On the Distribution of Density over the Globe," Quat. Journ. Royal Meteor. Soc. 50:29, 1924.

23. BJerknes, J. and Palmen, E.: "Investigation of Selected European Cyclones by Means of Serial Ascents," Geof. Pub., Vol. XII, No. 2, Oslo, 1937. 


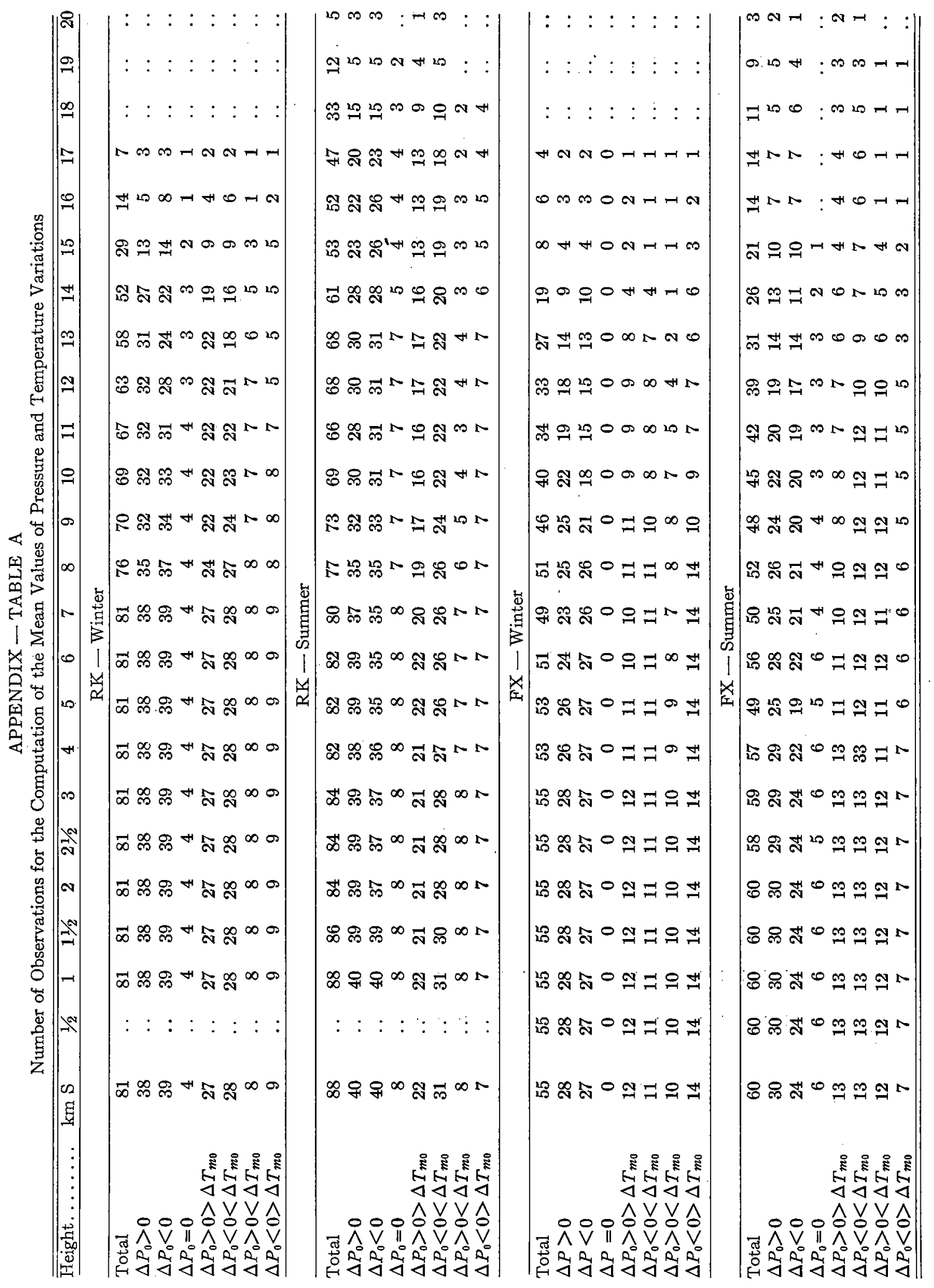




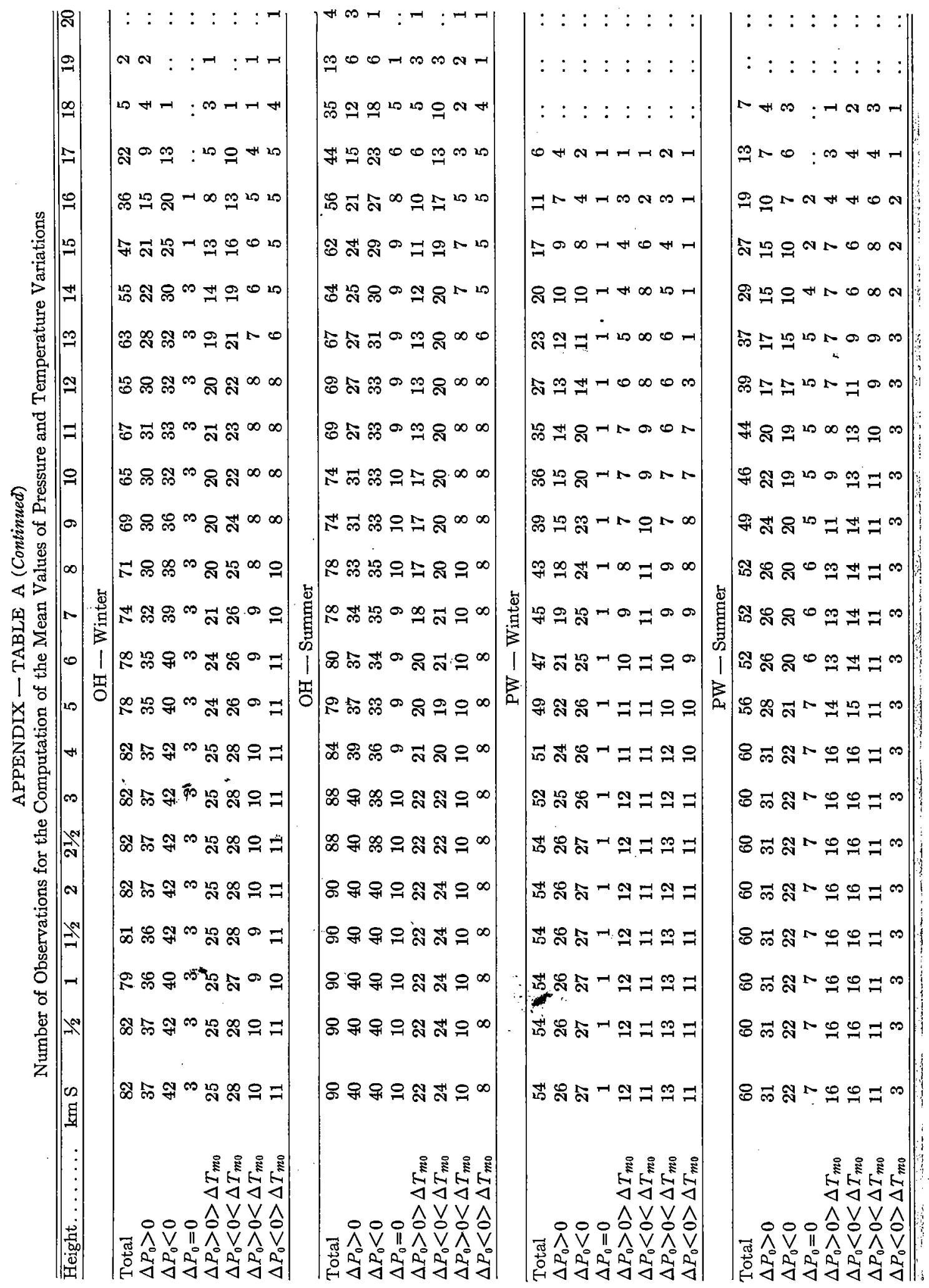




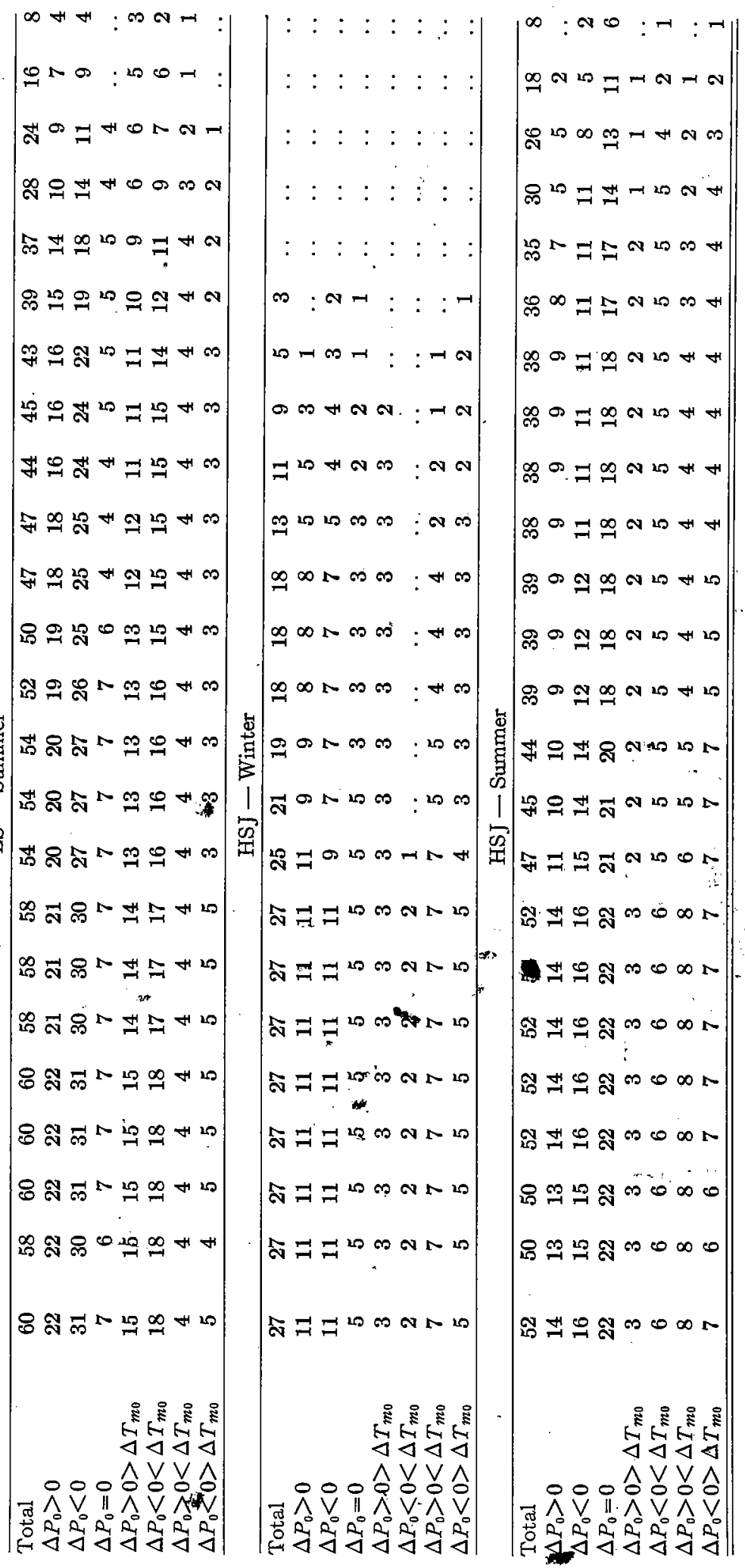




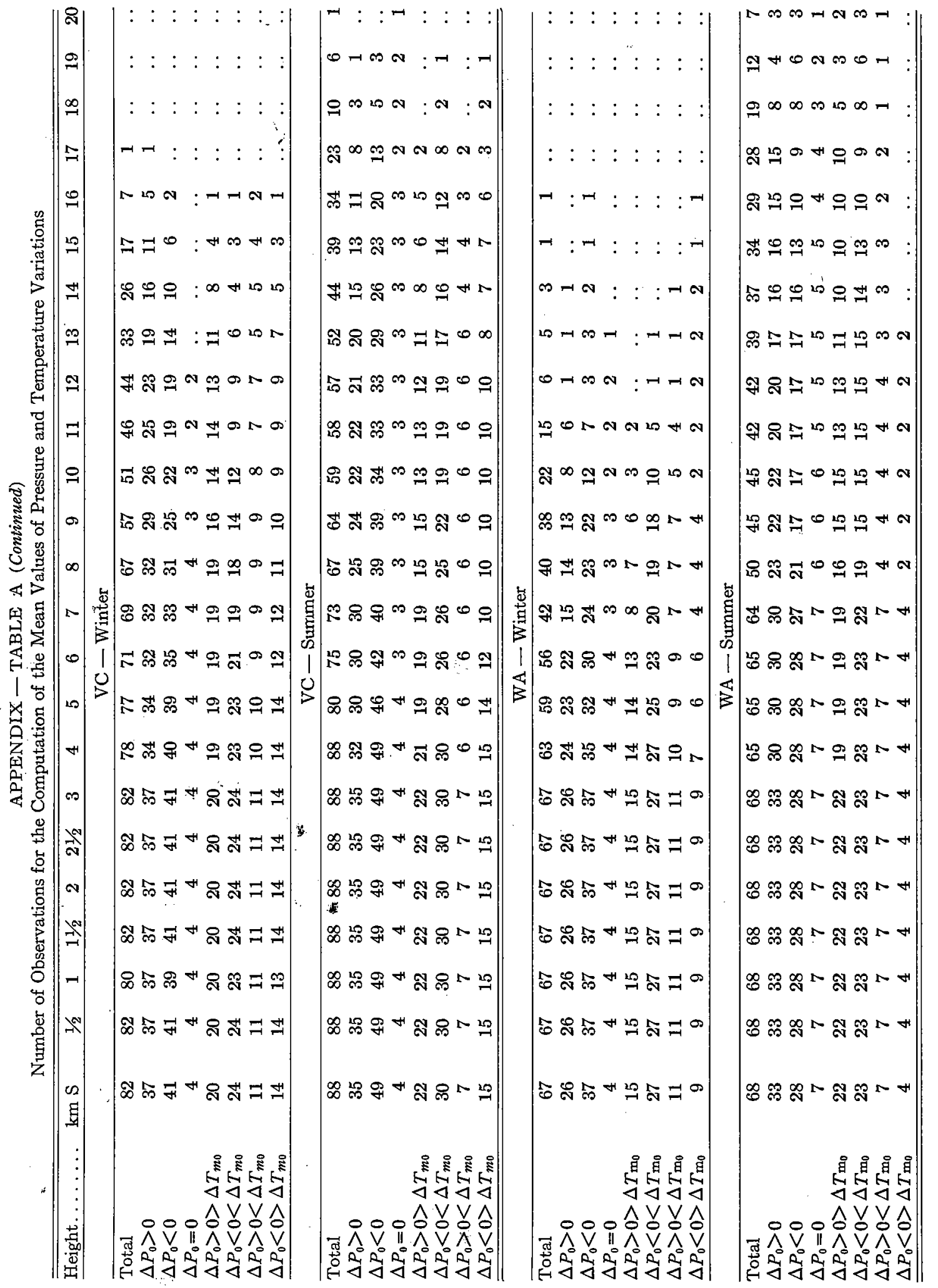




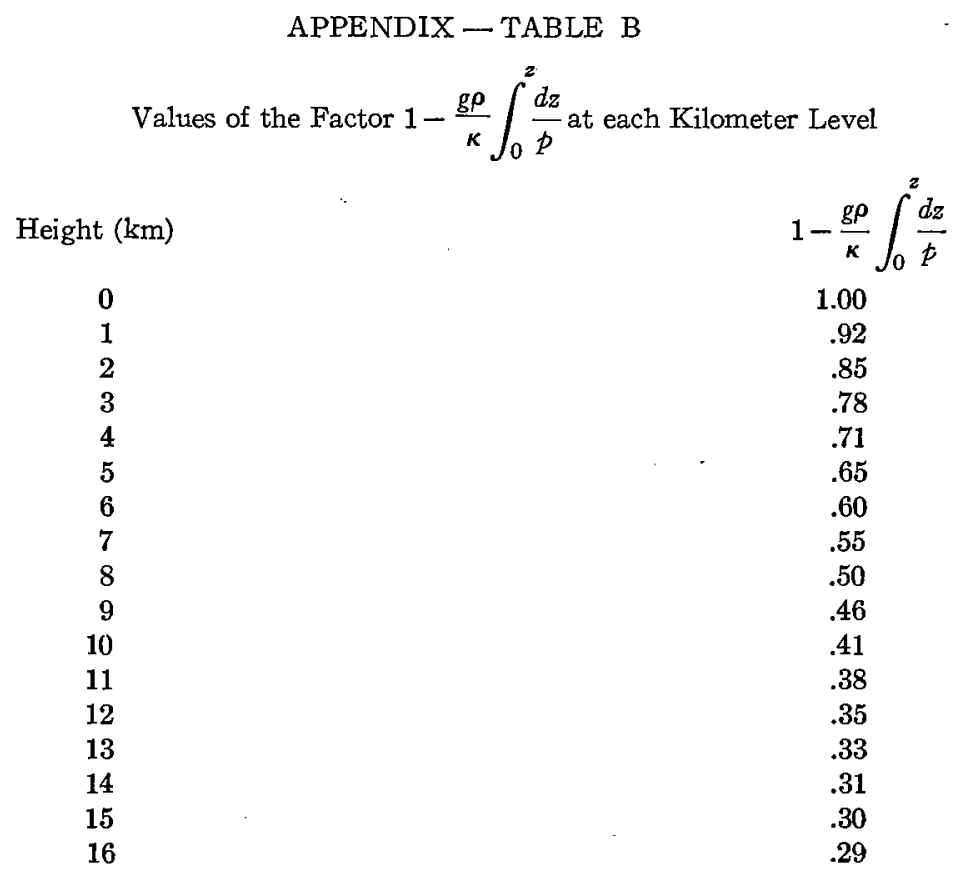

